\title{
WestVirginiaUniversity
}

THE RESEARCH REPOSITORY @ WVU

Graduate Theses, Dissertations, and Problem Reports

2009

\section{Parametric study of a single PDC cutter with a numerical model}

Ozge Sunal

West Virginia University

Follow this and additional works at: https://researchrepository.wvu.edu/etd

\section{Recommended Citation}

Sunal, Ozge, "Parametric study of a single PDC cutter with a numerical model" (2009). Graduate Theses, Dissertations, and Problem Reports. 2022.

https://researchrepository.wvu.edu/etd/2022

This Thesis is protected by copyright and/or related rights. It has been brought to you by the The Research Repository @ WVU with permission from the rights-holder(s). You are free to use this Thesis in any way that is permitted by the copyright and related rights legislation that applies to your use. For other uses you must obtain permission from the rights-holder(s) directly, unless additional rights are indicated by a Creative Commons license in the record and/ or on the work itself. This Thesis has been accepted for inclusion in WVU Graduate Theses, Dissertations, and Problem Reports collection by an authorized administrator of The Research Repository @ WVU. For more information, please contact researchrepository@mail.wvu.edu. 
Parametric Study of A Single PDC Cutter with A Numerical Model

Ozge Sunal

Thesis submitted to the

College of Engineering and Mineral Resources

at West Virginia University

in partial fulfillment of the requirements

for the degree of

Master of Science

in

Petroleum and Natural Gas Engineering

H. Ilkin Bilgesu, Ph.D., Chair

Samuel Ameri, M.Sc.

Khashayar Aminian, Ph.D.

Keith Heasley, Ph.D.

Department of Petroleum and Natural Gas Engineering

Morgantown, West Virginia

2009

Keywords: Drilling, PDC, cutter, modeling 


\section{ABSTRACT}

\section{PARAMETRIC STUDY OF A SINGLE PDC CUTTER WITH A NUMERICAL MODEL}

\section{Ozge Sunal}

Single cutter models constitute a cornerstone to understand the cutting process while drilling. There are various experimental and numerical studies on simulating cutting behavior of a single cutter in order to optimize drilling performance. In this study, the numerical model developed to analyze single PDC cutter performance was verified with the experimental data. Numerous runs with different model properties and rock post failure properties were conducted for the purpose of creating a model that works accurately in different conditions. The data used in this study for model verification was obtained from an experimental study reported in the literature. The study focuses on a single cutter-rock model to understand how axial and rotational loads change under different cutting conditions. The model is composed of a single cutter interacting with the rock specimen and was developed using $F L A C^{3 D}$, an explicit finite difference program. Back analysis was performed with the reported laboratory experiments and various formation parameters in the model were varied to match the experimental results. 


\section{DEDICATION}

This thesis is dedicated to my mom, Halide and my dad, Nuri for their unconditional love and spiritual help and for making me who I am today, my brother, Kamil whose help and support were always with me and his dear wife, Esra, and my lovely nephew, Nuri Alp, my source of motivation. 


\section{ACKNOWLEDGEMENTS}

I would like to thank my advisor, Dr. Ilkin Bilgesu for his contributions to this thesis and for the financial support he provided. I would like to express my gratefulness to Dr. Keith Heasley for his guidance throughout my study. I also would like to thank to my committee members Sam Ameri and Kashy Aminian for their help and suggestions.

Special thanks to Sam Ameri for his support, encouragement and kindness.

Most importantly, I would like to express my thankfulness to my family for their constant support and love and to my friends for their help and support.

Financial support from the U.S. Department of Energy is greatly acknowledged. 


\section{TABLE OF CONTENTS}

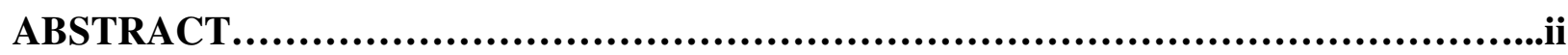

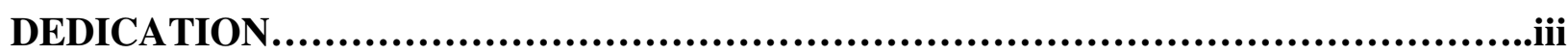

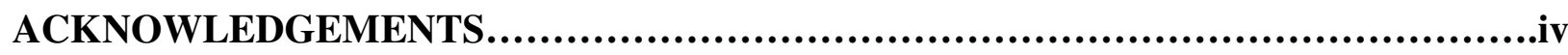

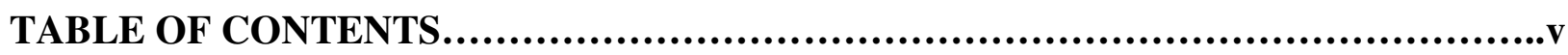

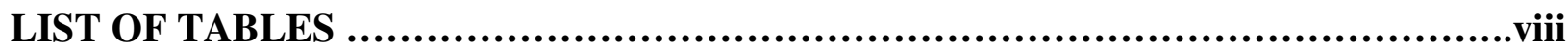

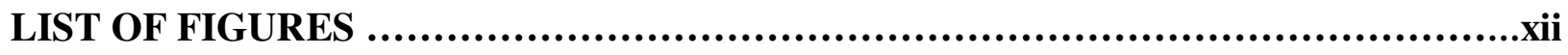

SYMBOLS AND ABBREVIATIONS...........................................................

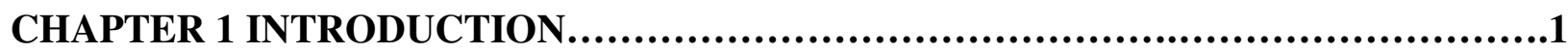

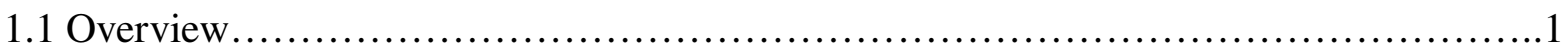

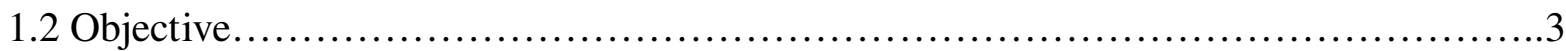

CHAPTER 2 LITERATURE REVIEW ....................................................4

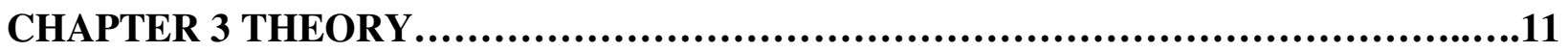

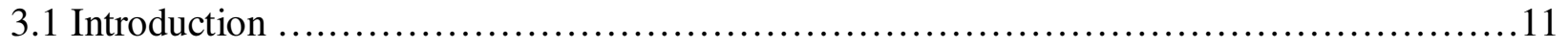

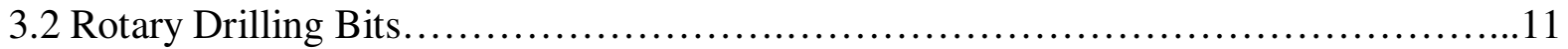

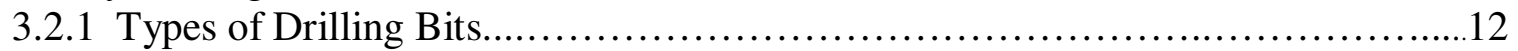

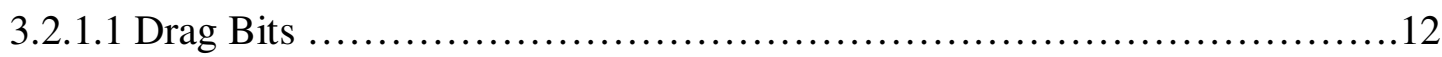

3.2.1.2 Rolling Cutter Bits..................................................... 13

3.2.2 Cutting Mechanisms of Drilling Bits.............................................14

3.3.2.1 Cutting Mechanisms of Drag Bits......................................... 15

3.3.2.2 Cutting Mechanisms of Rolling Cutter Bits................................15

3.3 Factors Affecting Rate of Penetration............................................. 16

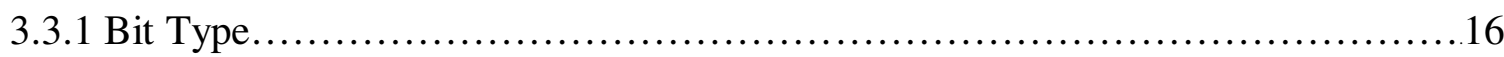

3.3.2 Formation Characteristics................................................. 17

3.3.3 Bit Weight and Rotary Speed..............................................17

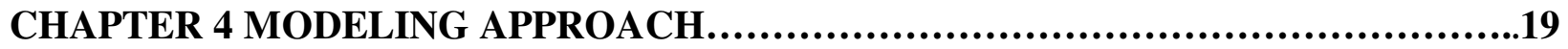

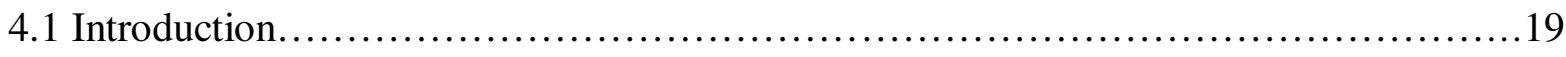

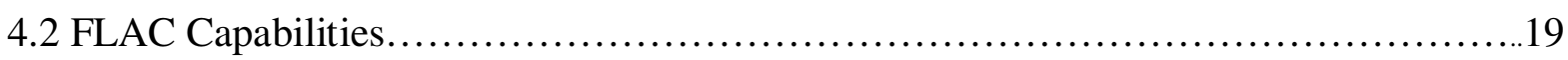

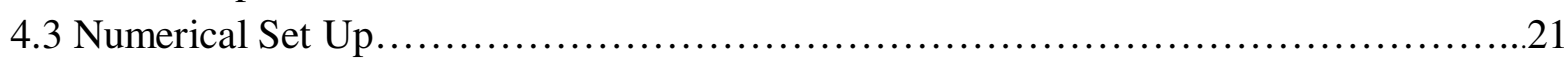

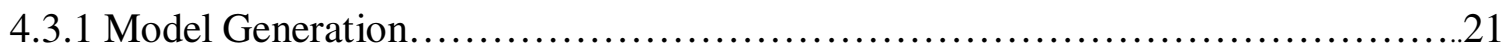

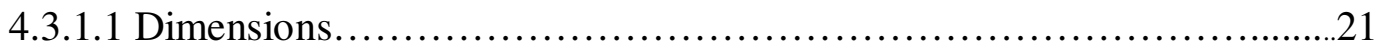


4.3.1.2 Mesh Density................................................22

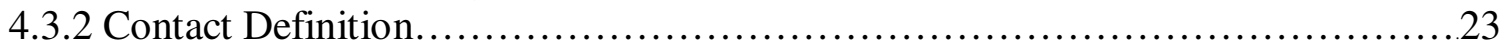

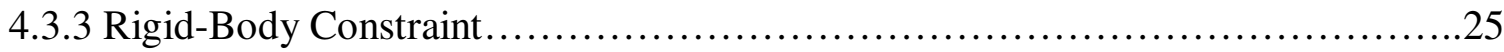

4.3.4 Boundary Conditions....................................................... 25

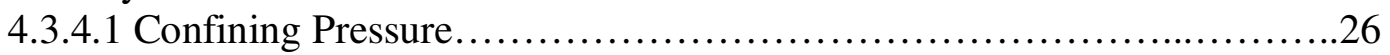

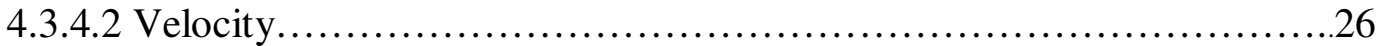

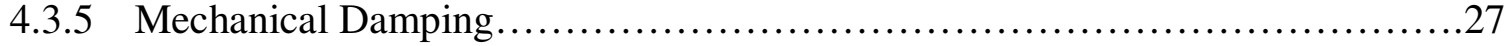

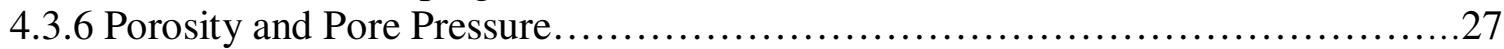

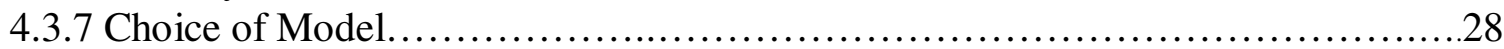

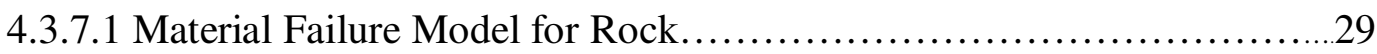

4.3.7.1.1 Mohr-Coulomb Theory.................................. 30

4.3.7.2 Shear Hardening/Softening ......................................... 33

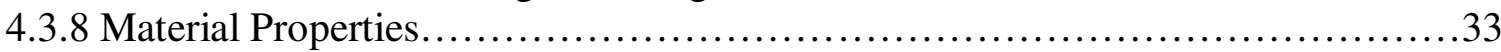

4.3.8.1 Direct Shear Test Results...........................................34

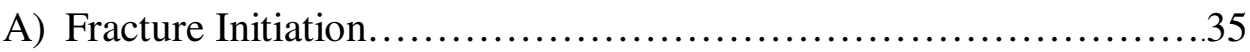

B) Peak Failure Stress (at failure) ............................... 36

C) Residual Stress (during failure) .................................. 37

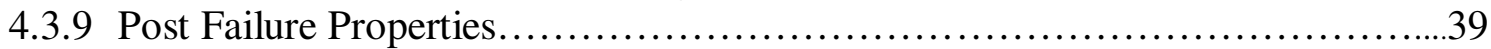

4.3.10Step and Analysis Procedure ............................................. 40

4.3.11 Element Removal......................................................41

4.3.12 Tangent Force Calculation............................................... 41

CHAPTER 5 SENSIVITY RUNS \& RESULTS AND DISCUSSIONS........................43

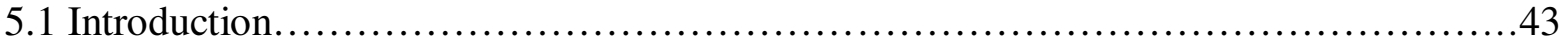

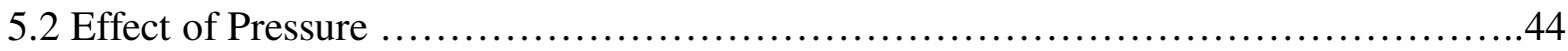

5.2.1 Runs Conducted at 2.07 MPa Confining Pressure...........................45

5.2.1.1 Effect of Friction Angle..........................................47

5.2.1.2 Effect of Plastic Shear Strain at Failure Point............................50

5.2.1.3 Effect of Cohesion................................................51

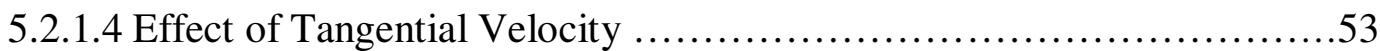

5.2.1.5 Effect of Plastic Shear Strain and Post Failure Properties Relationship...54

5.2.1.6 Effect of Tensile Strength.........................................57

5.2.1.7 Effect of Dilation Angle.............................................58

5.2.1.8 Effect of Plastic Tensile Strain at Failure Point..........................60

5.2.1.9 Effect of Residual Dilation Angle..................................61

5.2.1.10 Effect of Residual Friction Angle...................................64

5.2.1.11 Effect of Residual Cohesion.......................................66

5.2.1.12 Additional Runs Conducted with 2.07 MPa Confining Pressure.........69

5.2.2 Runs Conducted at $6.89 \mathrm{MPa}$ Confining Pressure...............................71

5.2.3 Runs Conducted at 20.7 MPa Confining Pressure.............................72

5.2.4 Runs with the Same Set of Properties for Different Confining Pressures............75

CHAPTER 6 CONCLUSIONS AND RECOMMENDATIONS.............................79 


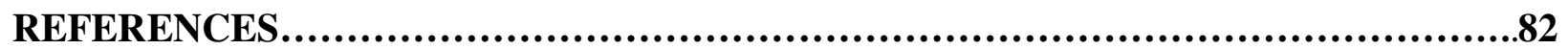

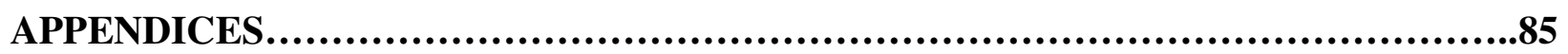

APPENDIX A................................................................................86

APPENDIX B...................................................................88 


\section{LIST OF TABLES}

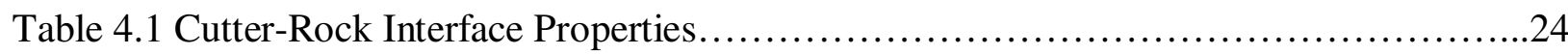

Table 4.2 Material Properties of PDC cutter..................................................

Table 4.3 Ranges of material properties for shale used in the model...........................34

Table 4.4 Shear and normal stress measurements with Catoosa shale under different fluids ${ }^{(2)} \ldots 35$

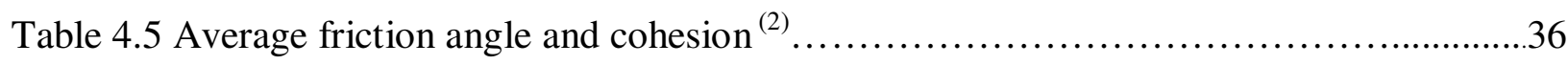

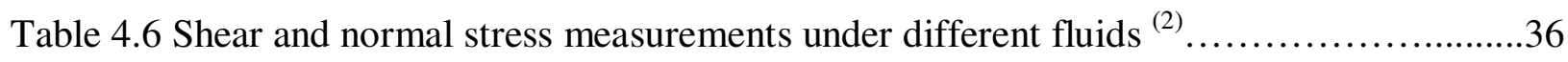

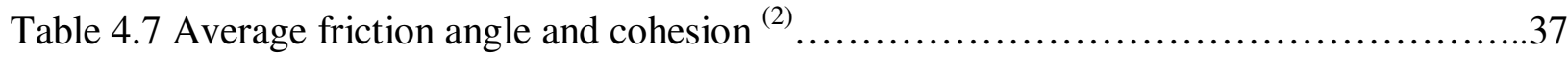

Table 4.8 Shear and normal stress measurements under different fluids ${ }^{(2)} \ldots \ldots \ldots \ldots \ldots \ldots \ldots . . . \ldots 38$

Table 4.9 Average friction angle and cohesion ${ }^{(2)}$.......................................... 38

Table 5.1 Average axial and tangential forces measured in laboratory tests conducted with

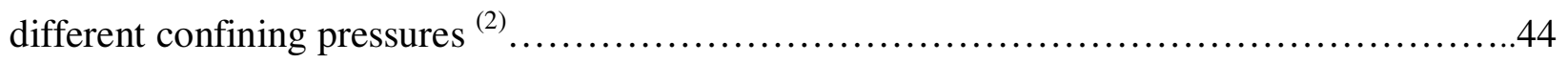

Table 5.2 Material properties used for the initial run ........................................46

Table 5.3 Axial and tangential force results for initial run................................47

Table 5.4 Dilation angle and cohesion as a function of plastic shear strain (Runs 1, 2 \&

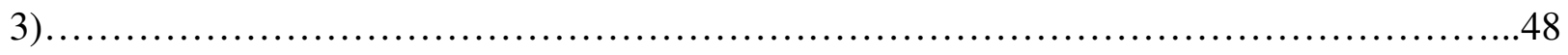

Table 5.5 Friction angle as a function of plastic shear strain (Runs 1, $2 \& 3$ ) ..................48

Table 5.6 Tensile strength as a function of plastic tensile strain (Runs 1, $2 \& 3$ )................48

Table 5.7 Effect of friction angle on axial and tangential forces on the cutter for Catoosa

Shale

Table 5.8, Cohesion, dilation and friction angles as a function of plastic shear strain (Run

4). 
Table 5.9 Effect of plastic shear strain at failure point on axial and tangential forces on the cutter for Catoosa Shale........................................................................

Table 5.10 Variation in cohesion as a function of plastic shear strain (Runs 4,5 \& 6)..........52

Table 5.11 Effect of cohesion on axial and tangential forces on the cutter for Catoosa Shale.....53

Table 5.12 Effect of tangential velocity on axial and tangential forces on the cutter for Catoosa

Shale .54

Table 5.13 Variation in friction angle, dilation angle and cohesion as a function of plastic shear

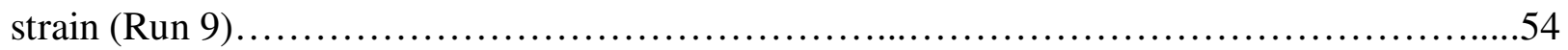

Table 5.14 Tensile strength as a function of plastic tensile strain (Run 9) ....................55

Table 5.15 Effect of linear decrease in properties on axial and tangential forces on the cutter for Catoosa Shale .55

Table 5.16 Friction angle, dilation angle and cohesion as a function of plastic shear strain (Run 10) .56

Table 5.17 Effect of plastic shear strain at failure point on axial and tangential forces on the

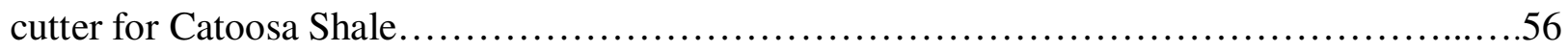

Table 5.18 Effect of cohesion on axial and tangential forces on the cutter for Catoosa Shale.....57 Table 5.19 Effect of tensile strength on axial and tangential forces on the cutter for Catoosa Shale. .58

Table 5.20 Effect of dilation angle on axial and tangential forces on the cutter for Catoosa Shale. .58

Table 5.21 Effect of cohesion on axial and tangential forces on the cutter for Catoosa Shale.....59

Table 5.22 Dilation angle as a function of plastic shear strain (Runs 15 and 16) .59 
Table 5.23 Effect of dilation angle on axial and tangential forces on the cutter for Catoosa Shale. .60

Table 5.24 Effect of tensile strain at failure point on axial and tangential forces on the cutter for Catoosa Shale. . .61

Table 5.25 Friction angle relationships as a function of plastic shear strain (Runs 17 \& 18).....61

Table 5.26 Effect of friction angle on axial and tangential forces on the cutter for Catoosa Shale. .61

Table 5.27 Dilation angle relationship as a function of plastic shear strain (Runs 18 \& 19). .62

Table 5.28 Effect of residual dilation angle on axial and tangential forces on the cutter for Catoosa Shale. .63

Table 5.29 Dilation angle as a function of plastic shear strain (Runs 20, 21, 22 \& 23).... .63

Table 5.30 Effect of dilation angle on axial and tangential forces on the cutter for Catoosa Shale.

Table 5.31 Friction angle relationship as a function of plastic shear strain (Runs 21, 24, 25)....65

Table 5.32 Effect of residual friction angle on axial and tangential forces on the cutter for

Catoosa Shale. .66

Table 5.33 Residual cohesion relationship as a function of plastic shear strain (Runs $21 \& 26$ )...

Table 5.34 Effect of residual cohesion on axial and tangential forces on the cutter for Catoosa

Shale. .67

Table 5.35 Tensile strength as a function of plastic tensile strain (Run 27)... .67 
Table 5.36 Effect of tensile strain at failure point on axial and tangential forces on the cutter for

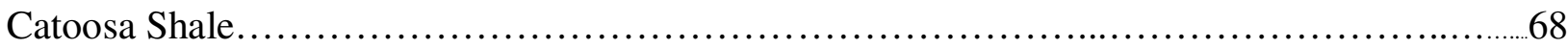

Table 5.37 Effect of property changes on axial and tangential forces .......................68

Table 5.38 Material properties and the results for additional runs conducted with $2.07 \mathrm{MPa}$

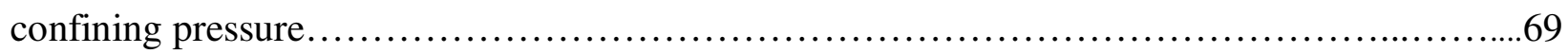

Table 5.39 Runs conducted with 1000 psi confining pressure............................71

Table 5.40 Runs conducted with 3000 psi confining pressure.............................73

Table 5.41 Runs conducted with 300 psi, 1000 psi and 3000 psi confining pressures..............77

Table 5.42 Comparison of model results with experimental results at the end of one

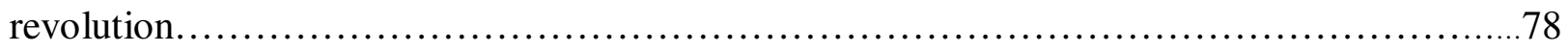

Table A.1 Comparison of test parameters used in the experiments and the model...............86

Table A.2 PDC cutter properties used in the experiments and the model......................86

Table A.3 Core properties used in the experiments and the model..........................87 


\section{LIST OF FIGURES}

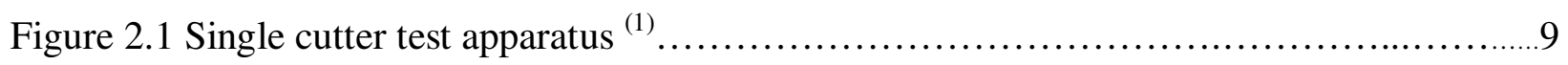

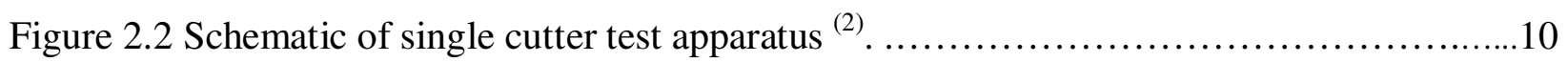

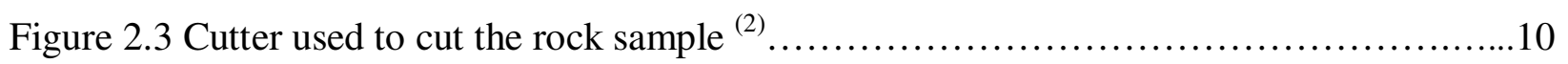

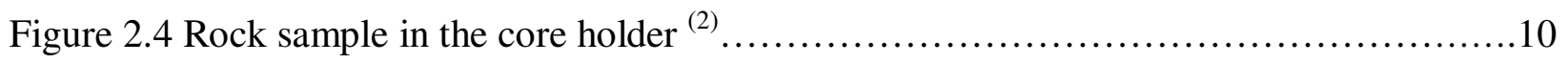

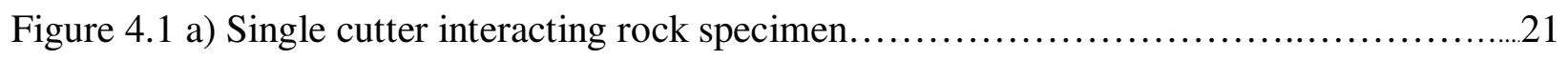

Figure 4.1 b) Single cutter interacting rock specimen, side view........................... 21

Figure 4.2 Horizontal stress distribution across the formation and the cutter...................23

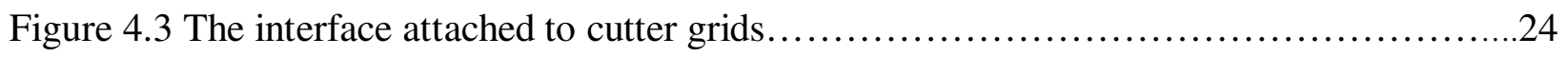

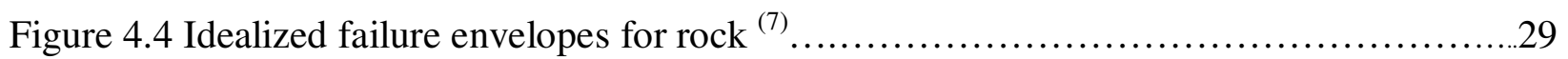

Figure 4.5 Mohr-Coulomb failures. Intermediate principle stress (a) equal to minor principle

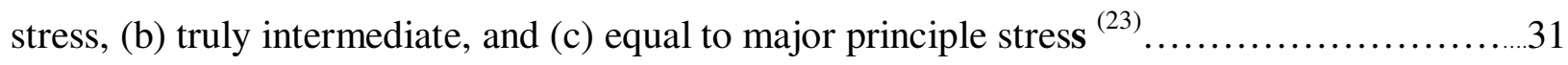

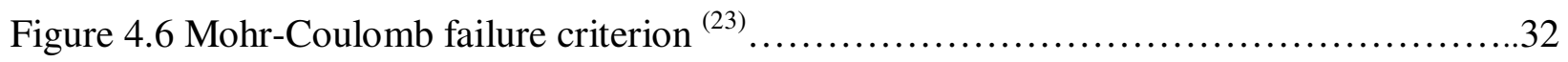

Figure 4.7 Shear stress versus normal stress plot for Catoosa shale with oil (fracture initiation) (2) .35

Figure 4.8 Shear stress versus normal stress plot for Catoosa shale (at failure) ${ }^{(2)} \ldots \ldots \ldots \ldots . . .37$

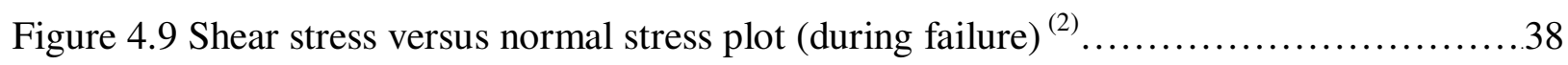

Figure 4.10 Example of different softening behavior of the rock (drop in cohesion)............39

Figure 4.11 Example of softening behaviors of the rock (drop in cohesion) for different plastic

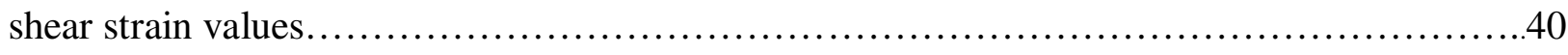

Figure 4.12 Horizontal $x$-force on the cutter and core tangential force......................42 
Figure 5.1 Catoosa Shale with a depth of cut of $1.905 \mathrm{~mm}(0.075$ in) after one full

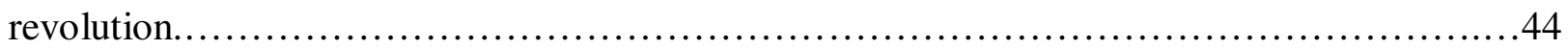

Figure 5.2 Sketch of a cutter-rock interaction under down-hole conditions ${ }^{(25)} \ldots \ldots \ldots \ldots \ldots \ldots . . . .46$

Figure 5.3 Variation of friction angle as a function of shear strain (Runs 1, 2 \& 3)............49

Figure 5.4 Variation in cohesion as a function of shear strain (Runs $4,5 \& 6)$................52

Figure 5.5 Variation in dilation angle as a function of shear strain (Runs $18 \& 19)$.............62

Figure 5.6 Variation in friction angle as a function of shear strain (Runs 21, 24 and25).........65

Figure 5.7 Comparison of axial and tangential forces from experimental results and model

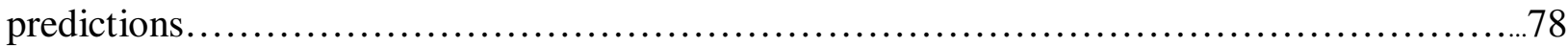

Figure B.1 Axial force versus time step for the model run conducted under 300 psi confining

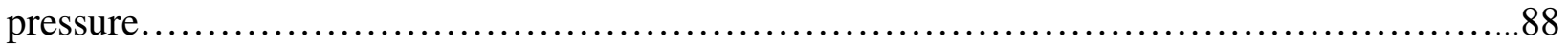
Figure B.2 Tangential force versus time step for the model run conducted under 300 psi

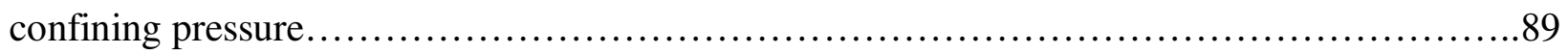
Figure B.3 Axial force versus time step for the model run conducted under 1000 psi confining

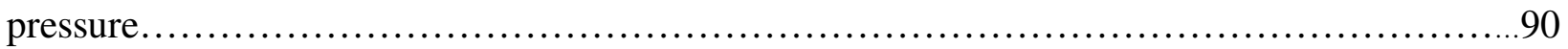
Figure B.4 Tangential force versus time step for the model run conducted under 1000 psi

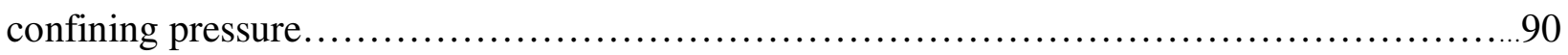

Figure B.5 Axial force versus time step for the model run conducted under 3000 psi confining pressure . .91

Figure B.6 Tangential force versus time step for the model run conducted under 3000 psi confining pressure .91 


\section{SYMBOLS AND ABBREVIATIONS}

$\sigma_{t}: \quad$ Tensile strength, $\mathrm{Pa}$

$\sigma_{c}: \quad$ Compressive strength, $\mathrm{Pa}$

$\tau_{0}: \quad$ Shear strength, $\mathrm{Pa}$

$\sigma: \quad$ Normal (principal) stress

$\tau: \quad$ Shear stress

$\theta_{\max }: \operatorname{Arctan}($ slope of maximum strength failure envelope)

$\theta_{r}: \quad$ Arctan (slope of residual strength failure envelope)

$\phi$ : The slope of the Mohr envelope

$c: \quad$ Intercept of the failure envelope with the $\tau$ axis

$k n: \quad$ Normal stiffness of PDC-rock interface, $\mathrm{Pa}$

$k s: \quad$ Shear stiffness of PDC-rock interface, $\mathrm{Pa}$

$K$ : $\quad$ Bulk modulus of rock, $\mathrm{Pa}$

$G: \quad$ Shear modulus of rock, $\mathrm{Pa}$

$\psi: \quad$ Interface friction angle, degrees

$F_{y}: \quad$ Axial force component, N

$F_{x}: \quad$ Tangential force component, $\mathrm{N}$

$\theta: \quad$ Cutter back rake angle, degrees

$p_{m}: \quad$ Mud pressure (bottom-hole), $\mathrm{Pa}$

$p_{o}: \quad$ Virgin pore pressure, $\mathrm{Pa}$

$p_{b}$ : $\quad$ Pore pressure in the failed zone, $\mathrm{Pa}$ 
$v: \quad$ Linear velocity of cutter, $\mathrm{m} / \mathrm{s}$

$d: \quad$ Depth of cut, $\mathrm{m}$

$F_{N:} \quad$ Average axial load, $\mathrm{N}$

$F_{T:} \quad$ Average tangential load, N

PDC: Polycrystalline diamond compact

Rpm: Revolution per minute

MPa: Mega Pascal

GPa: Giga Pascal

m: $\quad$ Meter 


\section{CHAPTER 1}

\section{INTRODUCTION}

\subsection{Overview}

Polycrystalline diamond compact (PDC) bit drilling optimization has been of great interest for drilling engineers. It has been studied by many researchers since its primitive origins in the early 1970s due to the need to reduce drilling cost by overcoming the challenges of PDC bit applications. Rate of penetration (ROP) is a major issue while a well is being drilled. ROP usually decreases with depth. Low ROP (for example, 3 to 5 feet per hour) is mainly a result of the high compressive strength of the formations due to overburden loads encountered at greater depths. Fixed cutter bits with PDC cutters are preferable in various environments since the difficulty in recognizing the failure of tricone bit's bearings especially at greater depths lead to lost cones, more frequent trips, higher costs and lower overall rates of penetration. Additionally, PDC bits typically drill several times faster than roller cone bits, particularly in softer formations. However, PDC bits have their own set of problems in hard formations, such as bit whirl which PDC bit produces a non-cylindrical hole due to unbalanced condition and stick slip which its rotation stops momentarily and slips free at high speed. PDC bits also have some shortcomings when drilling under extreme environments, such as pressures exceeding $20000 \mathrm{psi}$ and temperatures greater than $250^{\circ} \mathrm{F}$.

Design and optimization of PDC bits require an understanding of the cutting process. Single cutter studies are very helpful to understand the cutting process of PDC bits under simulated downhole conditions and provide input for PDC bit development and mathematical models ${ }^{(1)}$. 
The objective of this study is to verify the effectiveness of a single cutter finite difference numerical model which predicts the effects of formation characteristics and drilling parameters on the rate of penetration (ROP) of the drilling operation including: formation properties, pore pressures, confining pressure, cutting angle and drilling parameters such as weight on bit and rotary speed. This study focuses on the verification process of the model based on the experimental single cutter results. Axial and tangential forces were matched for various runs under different conditions. Thrust and speed of revolution are the two key factors for the rate of penetration of a drill bit in a given medium.

The model has been developed by a group of researchers at West Virginia University in which the author of this thesis is also a part. A three-dimensional explicit finite-difference program, $F L A C^{3 D}$ has been used for this study. The basis for this program is the well-established numerical formulation used by two-dimensional program, FLAC. FLAC ${ }^{3 D}$ extends the analysis capability of FLAC into three dimensions. The explicit, Lagrangian calculation scheme and the mixed-discretization zoning technique used in $F L A C^{3 D}$ ensure that plastic collapse and flow are modeled very accurately. 


\subsection{Objective}

The goal of this study has been to test, fine tune and verify a finite-difference model of a single rotary cutter, and to calibrate it with published laboratory data for different confining pressures. A cutter-rock numerical model was developed at West Virginia University to investigate the influence of: pressure, formation and mud properties, bit design and drilling parameters on the cutting process and drilling rate of penetration (ROP). In this study, the model was calibrated with laboratory experiments ${ }^{(2)}$ for a single PDC cutter conducted under different confining pressure conditions. The axial and tangential cutting forces measured on the cutter for a given depth of cut in the experiments are compared to the cutting forces calculated in the model and the results of the experiments and the model were matched. Numerous runs were conducted to understand how cutting forces change based on various formation parameters and to obtain the closest match to the experimental results. Ultimately, a fair agreement was observed between experimentally observed cutter forces, and those predicted by a finite difference model. 


\section{CHAPTER 2}

\section{LITERATURE REVIEW}

There are various studies regarding cutting behavior of PDC bits. Single cutter and full scale laboratory tests with multiple cutters are the two most widely used techniques. Numerical modeling methods have also been applied to investigate cutter forces and cutting character during drilling.

Single cutter testing rather than full-scale bit testing provides a better way of predicting PDC bit performance since full scale testing concerns all the cutters on a bit, each of which is subjected to different cutting and cleaning conditions making the interpretation of the net result difficult. Great majority of single cutter experiments were conducted during $1980 \mathrm{~s}^{(1,5)}$. Through the end of the decade, full scale tests have gained great importance.

Researchers have focused on better understanding of cutter/formation interaction, cutter performance, bit dynamics and bottomhole dynamics. These studies are helpful to understand how this interaction affects bit performance so new designs for a PDC bit can be developed. One of the earliest research studies were conducted by Sandia National Laboratories in the late 1970s and early 1980s that played a leading role in the PDC drill bit development for rock drilling ${ }^{(3)}$.

Swenson et al. ${ }^{(4)}$ described a constitutive model for rock in which fracturing occurs due to both tensile and shear stresses. Their model was incorporated into the finite element code (HONDO) and the analytical results were compared with both material model verification tests and single cutter tests ${ }^{(5)}$.

Zeuch and Finger ${ }^{(6)}$ conducted both experimental and numerical studies on rock breakage mechanisms with a PDC cutter. They focused on the stress field in the rock around the cutter, 
chip generation and damage patterns in the rock. They used sharp and worn PDC cutters in their experiments conducted at atmospheric pressure where there is no confining pressure effect. They concluded that there is a notable similarity in chip generation among very different kinds of rocks and for different cutter geometries. In addition, they observed that the theory of chip generation in which fractures are nucleated in the rock in advance of the cutter tip is consistent with the experimental evidence.

One of the greatest challenges for any PDC bit application is "hard rock" drilling in which bit performance is limited due to impact damage, heat damage and the abrasive wear of PDC cutters. Unknown mechanisms of hard rock drilling under high pressure/high temperature environment generally encountered in deep drilling are the major reasons of slow rate of penetration. Since drillers can spend as much as $80 \%$ of their budget drilling hard rock footage that represents only $20 \%$ of a well's total footage, bit selection becomes critical since poor bit choices can be costly. Clayton et. al. ${ }^{(7)}$ proposed a new highly abrasion-resistant PDC cutter which expanded PDC bit application to hard rock drilling. They developed a new model considering cutter wear, in other words, diamond failure as a result of mechanical loading and/or thermal degradation.

Some researchers used full scale bits instead of single cutter while studying rock failure mechanisms in the process of bit penetration. One of the earliest studies was conducted by Wang and Lehnhoff in $1976{ }^{(8)}$. They developed a general mathematical rock failure model using the finite element techniques. The model simulates the bit penetration process from the bit-rock interaction to chip formation. It gives quantitative information on stress, displacement and material failure due to penetration of the bit. The analytical results obtained from their model are very consistent with the experimental observations made by other scientists. 
Huang and Iversen ${ }^{(9)}$ used laboratory and field tests to show that polycrystalline diamond compact with side rake angle can provide a better mechanical cleaning action and therefore improve the bit performance in soft and plastic formations such as salt and shale.

Cherkovnik ${ }^{(10)}$ proposed that the type of chip generated can be controlled by the orientation of the cutter face which basically depends on side rake, back rake and depth of cut. He stated that the efficiency of drilling with a PDC bit is related to the angle between the cutter and the surface of the formation being drilled.

Cheatham and Daniels ${ }^{(11)}$ examined causes of difficulty in drilling shales which represents a major part of the footage drilled for oil and gas wells. They investigated some of the factors influencing shale drilling using single and double cutter experiments. They used STRATAPAX drill blanks which is composed of a man-made diamond layer bonded to a cemented tungsten carbide substrate and two types of shales; namely Mancos and Pierre shales. They analyzed the effects of rake angle and pressure on cutting performance using translational motion in their experiments. They determined that plasticity occurs in shales under elevated mud pressures. They also determined that tool shape has no appreciable effect on force per unit area, and zero or small negative rake provides the most efficient tool.

Glowka and Stone ${ }^{(12,13)}$ performed both analytical and numerical studies on PDC cutter response under simulated downhole conditions where thermal and mechanical loading take place. They stated that PDC cutter wear rate strongly depends on the frictional temperature that develops at the cutter-rock interface and even a minor wear in the cutter geometry can have a significant effect on cutter and bit performances. Glowka ${ }^{(14)}$ further studied cutter/rock interaction experimentally and developed a mathematical model based on laboratory results to determine the penetrating and drag forces acting on a cutter located on the bit face. The model 
was generalized and used to develop algorithms for a computer code which predicts wear and performance of PDC bits ${ }^{(15)}$. He used three rock types, Berea sandstone, Tennessee marble, and Sierra white granite since they cover a wide range in rock properties, such as strength, composition and ductility. Their experience showed that PDC cutters do not cause much rock breakage outside the projected area of the cutter profile.

A recent study was conducted on modeling rock failure using $F L A C^{3 D}$. Han et.al ${ }^{(16)}$ developed a FLAC $^{3 \mathrm{D}}$ model to improve the fundamental understanding of the physical mechanisms of percussion drilling with a hammer bit. They proposed three different failure mechanisms to explain rock damage and failure during bit-rock interactions under compressive bit load and rock failure due to excessive tensile and shear forces. Rock is more likely to experience tensile failure than compressive failure during percussion drilling because of its low tensile strength. However, if the mud pressure is high enough during bit retreat, rock rarely becomes tensional. Thus, they concluded that the efficiency of percussion drilling decreases with mud pressure or deep borehole. Their model can describe when, where and how rock fails and calculates rates of penetration and shows the history with dynamic time simulated. Kaitkay ${ }^{(17)}$ modeled rock cutting with and without an external hydrostatic pressure using the distinct element method. He also conducted experiments on a Carthage marble specimen using a PDC bit under atmospheric and external hydrostatic pressure. The model was developed with $\mathrm{PFC}^{2 \mathrm{D}}$ (Particle Flow Code) to simulate the rock cutting experiments. He observed that cutting forces as well as chip length increase dramatically with the application of external pressure. In addition, external pressure was found to transform the cutting mechanism from brittle to ductile-brittle mode. 
Zijsling ${ }^{(1)}$ conducted single cutter experiments to study the cutting process of PDCs in rock under simulated downhole conditions. The tests were carried out with soft Pierre shale (samples) from an outcrop in Colorado, and medium-hard Mancos shale from an outcrop in Utah using a cutting angle of $-20^{\circ}$ at various simulated wellbore pressure levels. The cutting forces were measured during the tests. The results indicate that the cutting process in shales responds differently to downhole pressures unlike permeable formations. Cutting forces in Mancos shale were controlled by total bottomhole pressure while in Pierre shale both the total bottomhole pressure and the pore pressure control the cutting forces due to the different dilatancy characteristic of shales. He tried different cutter designs and concluded that cutter design is very effective in cleaning the bit mechanically and preventing or minimizing the balling-up of cuttings.

Smith ${ }^{(2)}$ investigated slow drilling problem in shales by conducting single cutter experiments on Catoosa shale and Pierre shale to reveal the different possible causes of the problem. Shales are fine grained sedimentary rocks which are composed of clay minerals. Great majority of drilling operations' problems are related to shales due to their vulnerability to swelling, shrinking, hydration, strength reduction and failure. The strategy of his study was to define the indications of the actual problem in the field and to compare them with the indications that resulted from different causes in controlled laboratory tests. He used Catoosa shale as the primary medium for the direct shear and single cutter tests. Catoosa shale is a type of marine formation of Pennsylvanian age ${ }^{(18)}$. The data obtained in the experiments with Catoosa shale was used to accomplish the objectives of this research.

In the experiments, he measured the normal and tangential forces acting on the cutter to reach a given depth of cut. Total depth of cut and cutter width were set before the test started and 
depth of cut per revolution, total axial cutter travel, confining pressure, rotary speed, and load limits were controlled during the test. The measured normal and tangential forces were used to calculate the 'specific energy' which is the consumed energy during the cutting process.

The tests allowed evaluation of the effects of rock mineralogy, rock strength, wellbore pressure, drilling fluid, cutter back rake angle, cutter surface, chip breakers and cutter standoff on the cutter forces and cutting character on slow drilling. He concluded that global bit balling is the major cause of the problem. Tests were conducted with a single cutter apparatus which is a powerful research tool for providing input for PDC bit development (Figures 2.1 and 2.2).

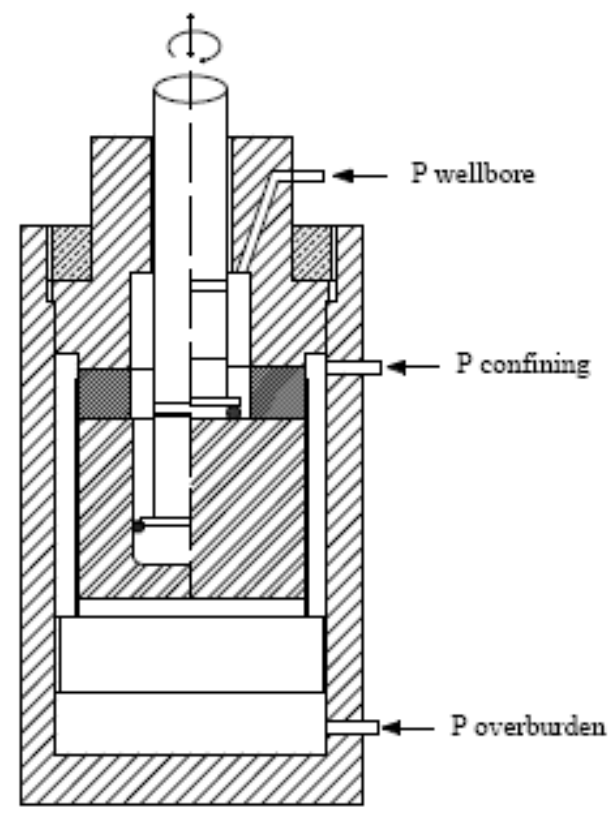

Figure 2.1 Single cutter test apparatus ${ }^{(1)}$. 


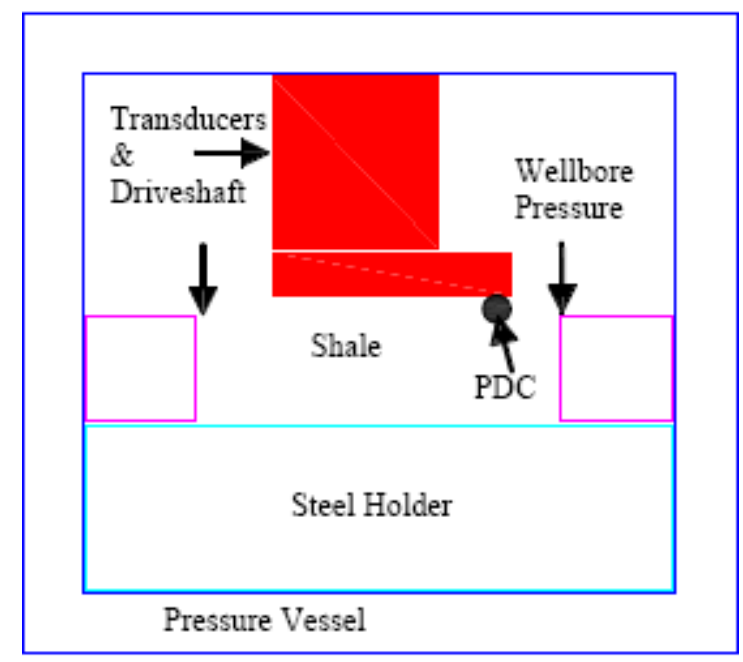

Figure 2.2 Schematic of single cutter test apparatus ${ }^{(2)}$.

Smith ${ }^{(2)}$ used four different confining pressures in his tests with Catoosa shale; 300, 1000, 3000 and 6000 psi with a cutting depth of 0.075 inch at $273 \mathrm{rpm}$. The cutters for the tests were trimmed to a width of 70 percent of their original diameter, which is around 0.37 inch. The cutter used in the test apparatus is shown in Figure 2.3. The core sample has a diameter of 3.5 inch and it is mounted in a core holder (Figure 2.4). Other test parameters are given in Appendix A together with the model properties.

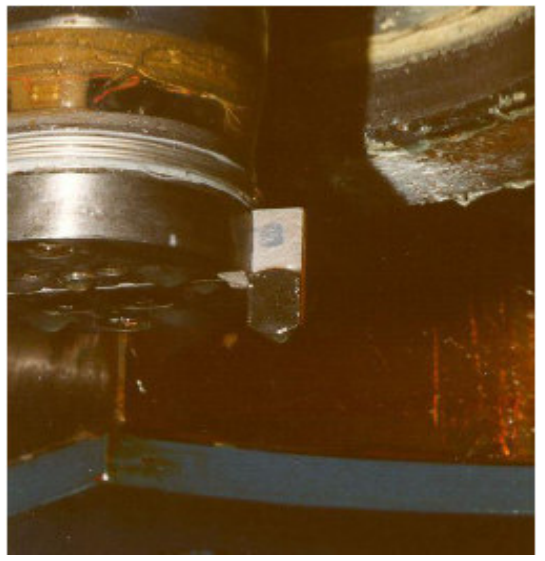

Figure 2.3 Cutter used to cut the rock sample ${ }^{(2)}$.

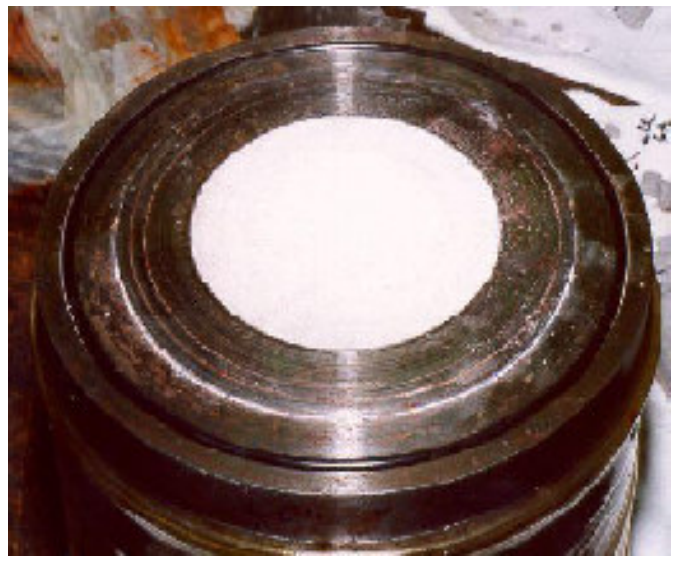

Figure 2.4 Rock sample in the core holder $^{(2)}$. 


\section{CHAPTER 3}

\section{THEORY}

\subsection{Introduction}

The process of drilling a hole in the ground is achieved by drilling bits. Selection of the bit and the bit operating conditions that suit the existing drilling conditions best is one of the most important duties of a drilling engineer. Rotary drilling operations require the use of rotary drilling bits. A specific type of bit is required for different situations encountered during drilling. In this chapter, only basic rotary drilling bit types will be discussed.

\subsection{Rotary Drilling Bits}

The drill bit is located at the bottom end of the drill string, and is responsible for actually making contact with the subsurface layers, and drilling through them. The drill bit breaks up and dislodges rock, sediment, and anything else that may be encountered while drilling. There are dozens of different drill bit types, each designed for different subsurface drilling conditions. Different rock layers experienced during drilling may require the use of different drill bits to achieve maximum drilling efficiency. It can be a long process to change bits since the whole drill string must be removed; but using the correct drill bit saves a great deal of time during drilling. Drill bits are chosen given the underground formations expected to be encountered, the type of drilling used, whether or not directional drilling is needed, the expected temperatures, and whether or not cores (for logging purposes) are required. There are two main types of drill bits, each suited for particular conditions ${ }^{(19)}$. 


\subsubsection{Types of Drilling Bits}

Rotary drilling bits are classified in categories according to their design. Drag bits and rolling cutter bits are the two main types. Drag bits are composed of fixed cutter blades that are made from either steel or diamond or polycrystalline diamond. Rolling cutter bits comprise a body member and inwardly facing rolling cones on which cutting inserts are arranged in circumferential rows ${ }^{(20)}$.

Drag bits are the best for very strong surfaces and non-brittle formations that have a plastic mode of failure while rolling cutter bits are used in a large variety of formations ranging from soft to hard.

\subsubsection{Drag Bits}

All drag bits have fixed cutter blades on the body of the bit and the cutters rotate with the drill string as a unit. This type of bit includes bits with steel cutters, diamond bits and polycrystalline diamond (PDC) bits.

Drag bits with steel cutters, also called fishtail bits were the early type of rotary bits, dating back to drilling before 1900 and mostly used until 1950's. They are occasionally used today for soft, shallow drilling prior to setting surface casing. An advantage of drag bits over rolling cutter bits is that they do not have any rolling parts, which require strong, clean bearing surfaces.

Diamond bits are preferred to other bit types while drilling non-brittle formations that show a high tendency to deform plastically under the bottomhole stress conditions ${ }^{(19)}$. Diamond bits do not have cones; nor do they have teeth. Many diamonds are set in a tungsten carbide matrix on the face or crown of the bit ${ }^{(19)}$. The size, shape, quality and quantity of diamonds are 
of critical importance regarding the performance in different type of formations. Since diamonds are so hard, diamond bits are sometimes used to efficiently drill rock formations that are quite hard. They are also used to drill softer formations, such as shales and chalks effectively. The matrix diamond bit cuts rock by grinding.

A new family of drag bits called polycrystalline diamond compact bits was introduced to the industry in the mid-1970. Polycrystalline diamond drill blanks composed of a layer of synthetic diamond bounded to a cemented tungsten carbide stud or blade at high pressure and high temperature are sintered as bit cutter elements ${ }^{(19)}$. The design of the crown and the bit shape are unique features of PDC bits.

PDC bits now hold the record for single-run footage in a well. PDC bits typically drill several times faster than roller cone bits, particularly in softer formations, and PDC bit life has increased dramatically over the past 20 years. This type of bit is designed to cut the rock by shearing.

\subsubsection{Rolling Cutter Bits}

Rolling cutter bits are also known as roller cone bits. It is composed of a body member on which there are inwardly facing rolling cutter cones that are rotatably mounted on the body. Each rolling cutter cone has circumferential rows around its peripheral surface and plenty of cutting inserts on the rows at least one of which intermeshes with a row on an adjacent cone ${ }^{(20)}$. Roller cone bits may have two, three or four cones. The most common bit type used in rotary drilling operations is the three-cone rolling cutter bit ${ }^{(19)}$ due to its ability to accommodate various formation characteristics with a large variety of tooth design and bearing types. 
The cones rotate about their axis as the bit rotates with the drill string. Rolling cutter bit has two types of cutter; tungsten carbide insert cutters and milled tooth cutters. The tungsten carbide insert bits are manufactured by sintering tungsten carbide cylinders into the machined holes in the cone. The milled tooth cutters are manufactured by milling teeth out of steel rolling cones. Long steel teeth which are widely spaced are used to drill soft formations while relatively shorter teeth are needed to drill harder rocks to avoid tooth breakage. The life of the milled tooth bits is limited compared to bits with the cutting elements made of sintered tungsten carbide inserts.

Dual cone and three-cone rolling bits were invented and patented by Howard R. Hughes, Sr., who allowed rotary drilling for oil in previously inaccessible places ${ }^{(21)}$. Milled tooth cutter bit was the first type of rolling cutter bit used in the industry. Then, tungsten carbide inserts were introduced in the early 1950's and defined as a revolution in rolling cutter drill bits since they significantly improved drill bit life ${ }^{(20)}$. However, this type of bit requires a careful layout of cutting elements since carbide inserts are relatively smaller than milled teeth.

\subsubsection{Cutting Mechanisms of Drilling Bits}

The basic mechanisms of rock removal need to be understood well by the drilling engineer for a proper bit operation. These mechanisms are classified as a) wedging, b) scraping and grinding, c) erosion by fluid jet action, d) percussion or crushing, and e) torsion or twisting ${ }^{(19)}$. All of these mechanisms are interrelated to each other to certain extent. In general, during the drilling process, more than one cutting mechanism is present. However, for each type of bit, there is one dominant mechanism of rock removal. In this section, the drag bits and the rolling cutter bits, the two basic rotary drilling bit types, will be discussed. 


\subsubsection{Cutting Mechanisms of Drag Bits}

The primary cutting mechanisms of drag bits is wedging. This mechanism causes drag bits dull so quickly and drill slowly. The tooth is subjected to a vertical force from drill collar weight applied to the bit, and to a horizontal force from the torque applied to turn the bit. The resultant of the vertical and horizontal forces on the tooth establishes the plane of thrust of the tooth or wedge.

The bottom cutting angle is a very important factor for the cutting efficiency during drilling. The wedge is prevented from dragging the hole bottom due to the angle existing between the cutter and the rock, however, the bit jumps and vibrations occur as a result of the bottom cutting angle and that leads to fast wearing of the bit. It is suggested that for optimum bit performance, small bottom cutting angles should be used since the wedging mechanism can be improved by a slight rake angle.

The primary cutting mechanism of diamond drag bits is grinding. The design of diamond bits leads to a small penetration of the bit into the formation ${ }^{(19)}$.

\subsubsection{Cutting Mechanisms of Rolling Cutter Bits}

Some types of rolling cutter bits apply all of the basic mechanisms of rock removal. These bit types are designed for soft formations and have a great cone offset angle. The other types of rolling cutter bits that are designed to drill hard and brittle formation apply percussion or crushing as predominant cutting mechanisms. Percussion drilling is of great economic interest while drilling hard rocks which cause low penetration rate and high drilling cost. There are various experimental tests conducted with a single tooth interacting with a rock sample to understand the failure mechanism below the bit tooth ${ }^{(19)}$. 


\subsection{Factors Affecting Rate of Penetration}

Rate of penetration or penetration rate refers to the speed at which the drill bit can break the rock under it and thus deepen the wellbore. This speed is usually reported in units of feet per hour or meters per hour.

The most important parameters that affect penetration rate are:

a) Bit type, b) formation characteristics, c) drilling fluid properties, d) bit operating conditions (weight on bit and rotary speed), e) bit tooth wear, and f) bit hydraulics ${ }^{(19)}$.

Numerous studies have been conducted to understand the effect of these parameters on drilling rate. In this study; effect of formation characteristic, confining (fluid) pressure and bit operating conditions on penetration rate for PDC cutters have been considered and the related data were used in the model verification process.

\subsubsection{Bit Type}

Selected bit type has a great effect on the rate of penetration. The penetration rates for different types of bits may greatly vary for a specific condition as well as for a selected bit in different bit designs and/or drilling environments. For example, initial penetration rate is often the highest for rolling cutter bits when the bit has long teeth and a large cone offset angle. However, that type of design of rolling cutter bit is only appropriate for soft formations due to a rapid tooth wear and therefore a decrease in penetration rate in hard formations ${ }^{(19)}$.

Bit penetration depends on the number of blades and the bottom cutting angle for drag bits. The diamond and PDC bits are designed to achieve a certain rate of penetration per revolution depending on the selection of the size and number of diamonds or PDC blanks. The 
depth of cut (also penetration rate) is limited by the length of the cutters projecting from the face of the bit ${ }^{(19)}$.

\subsubsection{Formation Characteristics}

The most significant formation properties that influence the penetration rate are the elastic limit and ultimate strength of the rock. The strength of the formation can be characterized by the shear strength predicted by the Mohr failure criteria ${ }^{(19)}$. To determine the shear strength, uniaxial test needs to be conducted. The angle of internal friction is essential to decide the shear strength and it can vary greatly, less than 10 for some very soft rocks and more than 50 for hard rocks.

An important rock property is the permeability that affects the rate of penetration. Permeability lets the drilling fluid filtrate move into the rock ahead of the bit which results in a pressure equalization. Also, the nature of the fluids existing in the rock pore spaces affects this mechanism due to different filtrate volumes required to equalize the pressure in a rock with gas than in a rock with liquid ${ }^{(19)}$.

Penetration rate is also affected by the mineral composition of the rock since hard abrasive rocks may cause rapid dulling of the bit teeth and rocks containing sticky clay minerals may cause bit balling ${ }^{(19)}$.

\subsubsection{Bit Weight and Rotary Speed}

Weight on bit and the rotational speed of the drill string are the two major operating factors affecting rate of penetration and bit life. The drilling engineer is expected to select the most appropriate bit weight and rotary speed which minimize the cost per foot considering the 
effects of selected bit operating conditions, the possible hole problems, the fluid circulating rates and the equipment limitations.

The optimum bit weight/ rotary speed to achieve minimum drilling costs can be calculated with the published methods that use the mathematical models to define the effect of bit weight and rotary speed on penetration rate and bit wear ${ }^{(19)}$. 


\section{CHAPTER 4}

\section{MODELING APPROACH}

\subsection{Introduction}

This study presents a parametric model developed based on the geometry of the PDC single cutter using $F L A C^{3 D}$, a commercial finite difference software. This chapter presents the numerical modeling methodology for this study and the properties of the model. The parameters, such as dimensions of cutter and core, depth of cut, confining pressure, material properties (cohesion, tensile strength, and friction and dilation angles) were assigned as variables in the model algorithm and can be changed easily to study the cutting forces obtained for numerous different cases. The values of parameters were obtained from the published data and experimental work ${ }^{(2)}$.

\subsection{FLAC Capabilities}

$F L A C^{3 D}$ is a three-dimensional explicit finite-difference program for engineering mechanics computation produced by Itasca Consulting Group ${ }^{(22)}$. The program simulates the behavior of three-dimensional structures built of soil, rock or other materials that undergo plastic flow when their yield limits are reached. Materials are represented by three dimensional polyhedral elements whose size and shape can be adjusted depending on the shape of the object to be modeled. The behavior of each element is determined by a prescribed linear or non-linear stress/strain law in response to applied forces or boundary restraints. The material can flow and fail. The grid can deform and move with the yielding material in large-strain mode. FLAC ${ }^{3 D}$ models plastic collapse, failure and flow accurately using explicit, Lagrangian, calculation scheme and the mixed-discretization zoning technique. Large three-dimensional calculations can 
be made without needing excessive memory since no matrices are formed. The shortcomings of the explicit formulation such as small time steps and the question of required damping are overcome by automatic inertia scaling and automatic damping that does not have effect in the mode of failure ${ }^{(22)}$. $F L A C^{3 D}$ is an efficient tool to solve three-dimensional problems in geotechnical engineering.

$F L A C^{3 D}$, like finite-element solutions, translates a set of differential equations into matrix equations that relate the forces and displacements at the element nodes. The difference of $F L A C^{3 D}$ and finite element methods is that in $F L A C^{3 D}$ the equations are derived by the finitedifference method which leads a number of fundamental variations from the finite-element method. Those differences for $F L A C^{3 D}$ can be listed as:

- "Mixed discretization" technique is used for accurate modeling of plastic flow.

- Physically unstable processes can be modeled without numerical distress.

- Nonlinearity in stress/strain laws can be followed in almost the same computer time as linear laws.

- Various constitutive models and user-defined failure criteria can be handled. $F L A C^{3 D}$ has some additional features ${ }^{(22)}$ :

- Deformable porous element grid and a viscous fluid flowing within the pore space can be fully coupled.

- Thermal analysis option simulates transient heat flux of thermally induced stresses. The thermal model can be coupled to the mechanical stress and pore pressure calculations.

- A powerful built-in programming language (FISH) is embedded within $F L A C^{3 D}$ that enables the user to define new variables and functions. 


\subsection{Numerical Set Up}

\subsubsection{Model Generation}

The model developed to simulate the cutting behavior of a single PDC cutter is composed of a rock specimen and a PDC cutter on top of it as shown in Figures 4.1a and 4.1b.

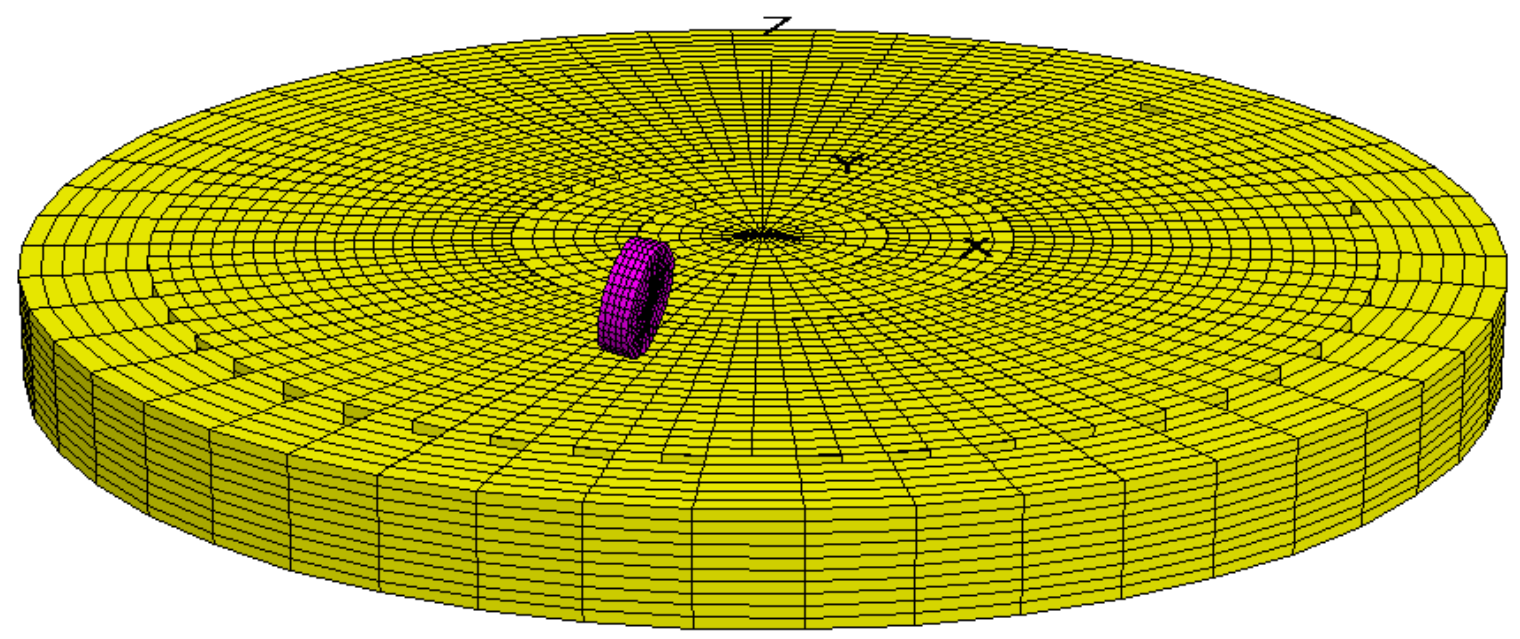

Figure 4.1 a) Single cutter interacting rock specimen.

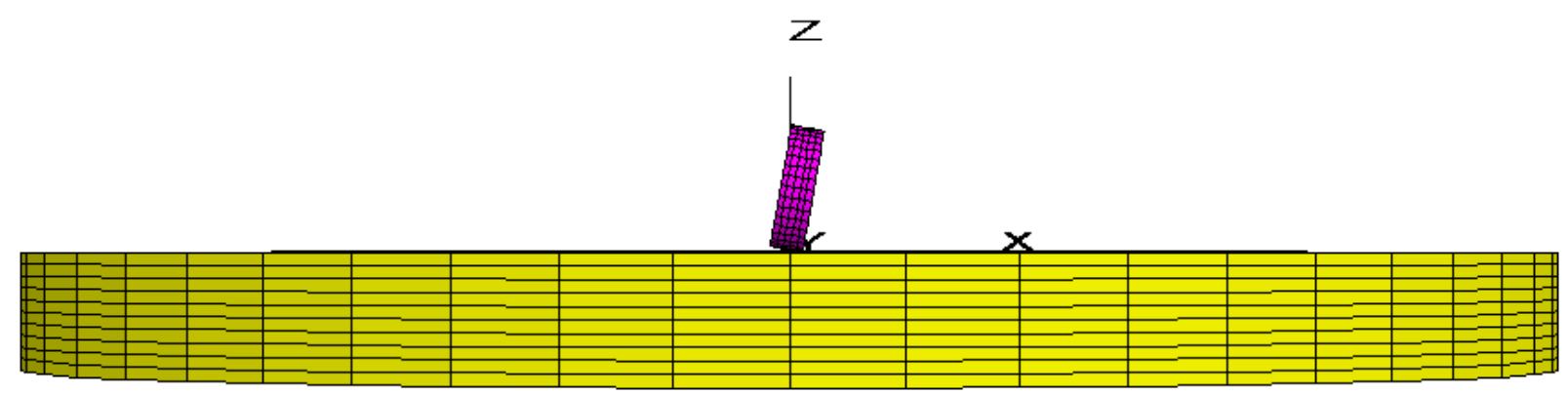

Figure 4.1 b) Single cutter interacting rock specimen, side view.

\subsubsection{Dimensions}

The model consists of a cutter with a diameter of $9 \mathrm{~mm}$ and a thickness of $7.5 \mathrm{~mm}$ and a shale core with a diameter of $12.5 \mathrm{~cm}$. The core length was taken as five times the maximum 
depth of cut $(9.525 \mathrm{~mm})$ used in the runs. The rock sample in the model was slightly larger in diameter and smaller in length compared to the core sample used in experiments. A shorter core was used to reduce the number of elements and decrease the calculation time considerably. The model runs were conducted for one revolution, where only $1.905 \mathrm{~mm}$ depth of cut was achieved. Therefore, the core length of $9.525 \mathrm{~mm}$ was used in the model to save run time since only $1 / 5$ of the core in length was cut in the model. The same cutter offset was used in the model as in the experiments, and the difference in diameter does not affect the results as long as the cutter was placed at the same radial distance as in the laboratory tests.

\subsubsection{Mesh Density}

The core sample was represented with a cylinder whose mesh size is varied (Figure 4.1). The cutter is located above the middle part of the core; therefore smaller mesh size was assigned to that part where cutting process takes place. The use of varying mesh density allows the model run more efficiently with a proper representation of cutting-rock interaction. With a reduced number of elements in different parts of the model, the stress distribution in the rock was checked to verify that discontinuity does not exist across the material. Figure 4.2 below shows the horizontal stress distribution across the material. As seen in Figure 4.2, there is no discontinuity in stress on the boundaries of different mesh sizes. Higher stress is observed along the cut area and the cutter tip where the cutting process takes place. 


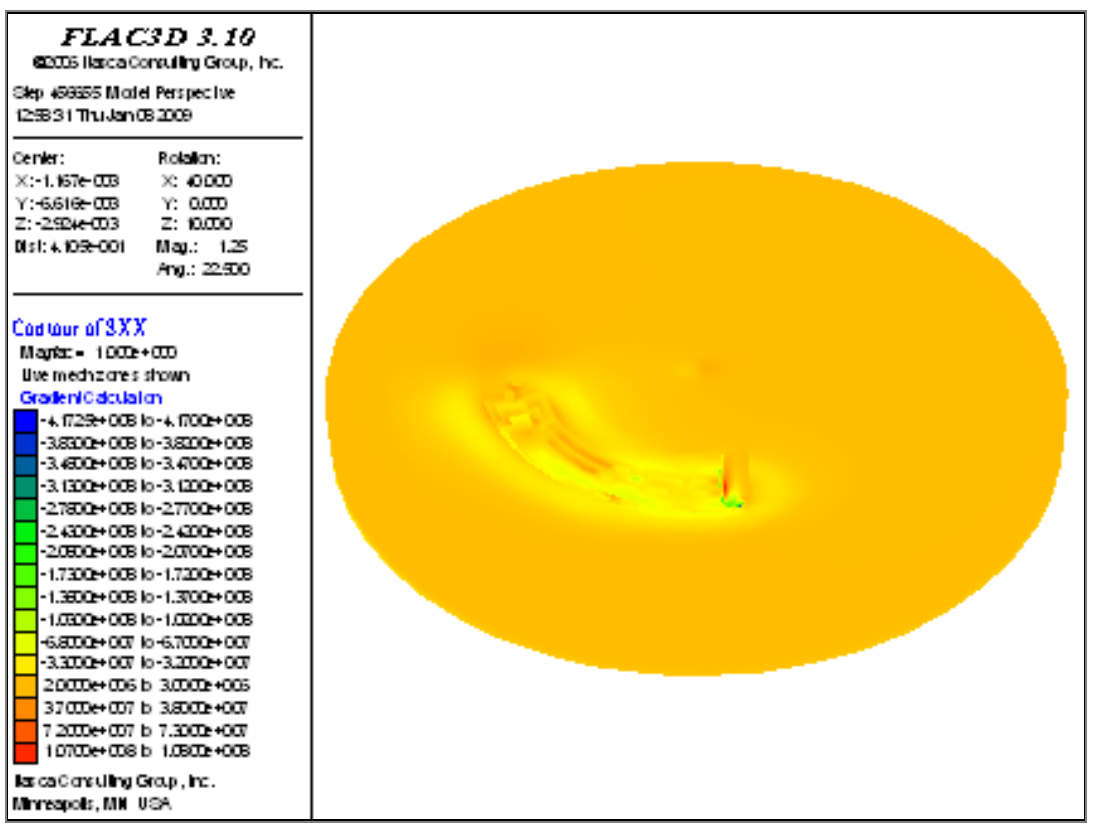

Figure 4.2 Horizontal stress distribution across the formation and the cutter.

\subsubsection{Contact Definition}

Since the model is composed of two different bodies, it is necessary to define the contact between the cutter and the rock. FLAC ${ }^{3 D}$ provides interfaces that are characterized by Coulomb sliding and/or tensile and shear bonding. The model has a continuously changing contact interface between the cutter and the rock as the bit penetrates and fails the rock matrix. Therefore, the interface was created on the cutter surface in this model and is shown in blue color in Figure 4.3 below. Interface properties used in this study are tabulated in Table 4.1. 


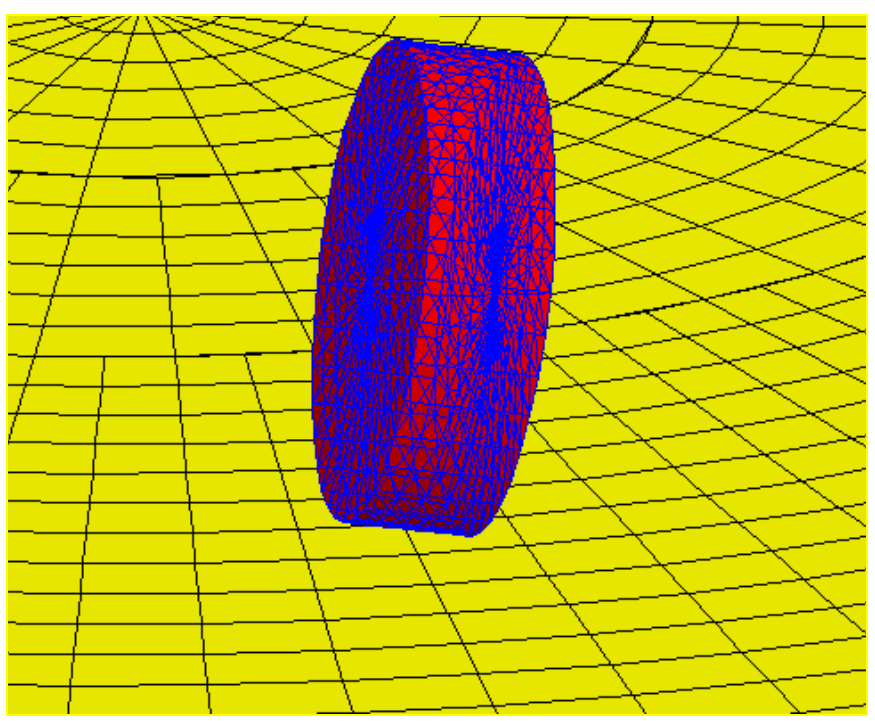

Figure 4.3 The interface attached to cutter grids.

Table 4.1 Cutter-Rock Interface Properties.

\begin{tabular}{|c|c|c|c|}
\hline Interface & $\begin{array}{c}\text { Normal Stiffness, kn } \\
(\mathrm{Pa} / \mathrm{m})\end{array}$ & $\begin{array}{c}\text { Shear Stiffness, ks } \\
(\mathrm{Pa} / \mathrm{m})\end{array}$ & $\begin{array}{c}\text { Friction Angle } \\
\text { (degrees) }\end{array}$ \\
\hline PDC-Catoosa Shale & $1 \mathrm{e} 16$ & $1 \mathrm{e} 16$ & $34,36,40$ \\
\hline
\end{tabular}

Interfaces have the properties of friction and dilation angles, cohesion, normal and shear stiffnesses, and tensile and shear bond strength. When a grid surface on the core comes into contact with an interface element, the contact is detected at the interface node, and is characterized by normal and shear stiffnesses. Normal and shear stiffness values were calculated according to the shear and bulk moduli of the two materials, and the lowest stiffness, consistent with small interface deformation, was found to be $1 \times 10^{16} \mathrm{~Pa}$ (Equation 4.1).

A good rule-of-thumb is to use normal stiffness, $k_{n}$ and shear stiffness, $k_{s}$ values that are ten times the equivalent stiffness of the stiffest neighboring zone. When higher stiffnesses were specified, the response and solution convergence were observed to be slow. 


$$
k_{n}=k_{s}=\max \left[\frac{\left(K+\frac{4}{3} G\right)}{\Delta z_{\min }}\right]
$$

where $K$ and $G$ are the bulk and shear moduli, respectively; and $\Delta \mathrm{z}_{\min }$ is the smallest width of an adjoining zone in the normal direction.

\subsubsection{Rigid-Body Constraint}

A rigid body is composed of nodes, elements and/or surfaces and its motion is managed by the motion of the nodes. The relative positions of the nodes remain constant throughout the simulation if the model is in small strain analysis mode where the reference position is the configuration for which stiffness matrices have been formed and do not change. During a largestrain analysis, the reference position is set equal to the current position during each large-strain update which lets the elements deform.

\subsubsection{Boundary Conditions}

The boundaries conditions in a numerical model such as force, stress and/or displacement are defined at the boundary of the numerical grid. In a model, mechanical, fluid-flow and thermal boundary conditions can be applied. In this study, mechanical boundary condition was applied. Mechanical conditions that can be applied at boundaries are of two main types: prescribed displacement or prescribed stress. For this model, axial and rotational displacements were applied to the nodes at the bottom of rock. Also, confining stress was applied to the top surface of the rock in the normal direction to simulate the pressure due to the drilling mud. The core was fixed in the horizontal $\mathrm{x}$ and $\mathrm{y}$ directions along its central vertical axis, the back plane of the cutter was fixed in all directions. The core was moved vertically up towards the cutter until a 
certain penetration was obtained. Then, the core bottom was fixed in the vertical $\mathrm{z}$ direction in the model.

\subsubsection{Confining Pressure}

The confining pressure was applied to the top of the core in the model similar to the

procedure followed in the experiments ${ }^{(2)}$. The model runs were performed with 300,1000 and 3000 psi confining pressures.

\subsubsection{Velocity}

A velocity in the vertical axial direction was applied at grid points located at the bottom of the core, and a tangential velocity was applied at every grid point located on the perimeter of the core at the bottom. Axial velocity was applied as a mechanical boundary conditions to the external boundary of the model grid. An algorithm was developed to assign the correct tangential velocity vector due to the change in $\mathrm{x}$ and $\mathrm{y}$ coordinates of each grid point during the rotation of the core. The angle tangent to the perimeter was calculated at every step as the core rotates and the tangential velocity vector was assigned at every grid point in a direction tangent to the perimeter. To save run time, the tangential velocity vector was updated every 10 steps since the change in the velocity vectors in between 10 steps was negligible. The majority of runs were performed with a velocity of $4 \mathrm{e}-7$ meter/timestep. In $F L A C^{3 D}$, calculation time is represented with timesteps automatically determined by the program, and real time option is present only if a dynamic analysis is performed. In this study, dynamic analysis was not used. Instead, static, mechanical calculations were performed for the uniform slow motion. 


\subsubsection{Mechanical Damping}

The equations of motion need to be damped either automatically by the program or by the user commands to provide static or quasi-static (non-inertial) solutions. In $F L A C^{3 D}$, automatic damping is activated when the velocity component changes sign, i.e. when the velocity goes to zero at any time during the run, oscillations are damped automatically by the program. In situations where there is significant uniform motion (velocity is nonzero), oscillatory motion is dissipated by the user command. FLAC $C^{3 D}$ has various damping algorithms for different static and dynamic analyses. The default damping algorithm for static analysis in $F L A C^{3 D}$ is local nonviscous damping where only accelerating motion is damped. An alternative damping

algorithm is provided in $F L A C^{3 D}$ for situations in which the steady-state solution includes a significant uniform motion like in the case of the model in this study. This damping is called combined damping and is more efficient than local damping used for static analysis at removing kinetic energy for this special case. Combined damping is invoked with the SET mechanical damp combined command.

\subsubsection{Porosity and Pore Pressure}

The rock samples used in the experiments were obtained from outcrops and had zero pore pressures at the beginning of the experiment. Consistent with the actual core samples, no pore pressure was assigned in the model. The outcrop samples in the experiments were porous and saturated. In the model, porosity and saturation values were not assigned since those properties can only be assigned to the zones when a fluid-flow analysis is performed. In this study, fluid flow was not considered due to very low permeability of the shale formation. Also, the runs conducted with the fluid model did not converge to a solution under the given experimental 
conditions. Therefore, changes in pore pressure due to the fluid saturation during the cutting process were neglected in this study. In the laboratory tests, the cutting experiments took very short time (few seconds) at a rotation speed of $273 \mathrm{rpm}$ (revolution per minute). For the duration of the experiment, stress change in the pores was assumed to be negligible and it is not considered in the model.

\subsubsection{Choice of Model}

$F L A C^{3 D}$ has twelve built-in constitutive models each of which is developed to represent a specific type of material behavior. "Null" model represents the parts that are removed or excavated from the model. The elastic, isotropic model is used for homogeneous, isotropic, continuous materials that do not yield. The elastic, orthotropic model represents material that has elastic symmetry in three perpendicular planes. The elastic, transversely isotropic model is preferred when the elastic materials exhibit anisotropy. The Drucker-Prager plasticity model is not generally used to model geologic materials. The Mohr-Coulomb plasticity model is the conventional model. It is used for materials to represent shear failure. Yield stress only depends on the major and minor principal stresses not the intermediate principal stress. The ubiquitousjoint model, an anisotropic plasticity model, is used to represent a material that has strength anisotropy due to plane of weakness. The strain-hardening/softening Mohr-Coulomb model represents nonlinear material softening and hardening behavior. The bilinear strain-softening ubiquitous-joint model allows material softening and hardening behavior based on the variations of ubiquitous-joint model. The double-yield model, which is an extension of the strain-softening model, is used to represent the material that has a considerable irreversible compaction. The modified Cam-clay model is used when the influence of volume change on bulk property and 
resistance to shear are taken into consideration. The Hoek-Brown model is an empirical relation that incorporates a plasticity flow rule that changes as a function of the confining stress level ${ }^{(22)}$.

In this study, rock was modeled with strain-hardening/softening Mohr-Coulomb plasticity in the region where the cutting process took place and the cutter was modeled with a linear elastic model to prevent its failure.

\subsubsection{Material Failure Model for Rock}

The maximum strength of an intact rock can be approximated by a linear Mohr envelope whose shape is determined by its tensile and compressive strengths as well as the slope as shown Figure 4.4. When the Mohr circle corresponding to state of the stress in the rock touches the envelope, failure of the rock occurs. ${ }^{(8)}$.

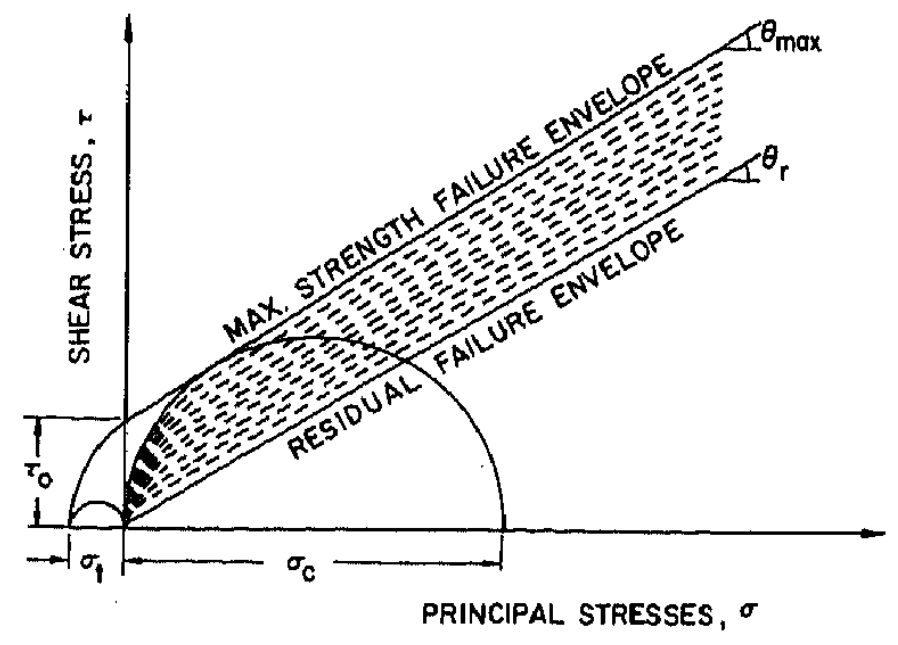

Figure 4.4 Idealized failure envelopes for rock $^{(8)}$.

The terms shown in Figure 4.4 are defined below:

$\mu$ : The slope of the Mohr envelope,

$\sigma_{t}: \quad$ Tensile strength,

$\sigma_{c}$ : Compressive strength, 
$\tau_{0}: \quad$ Shear strength,

$\sigma: \quad$ Principal stress,

$\tau: \quad$ Shear Stress,

$\theta_{\max }:$ Arctan (slope of maximum strength failure envelope),

$\theta_{r}: \quad$ Arctan (slope of residual strength failure envelope).

\subsection{Mohr-Coulomb Theory}

The Mohr-Coulomb model is a conventional model that represents shear failure in soils and rocks. According to Mohr-Coulomb failure criterion, failure of a rock occurs when the resolved shear stress on any plane in the rock attains a critical value. This relation is expressed as:

$$
\tau= \pm(c+\sigma \tan \phi)
$$

where $\tau$ is the shear strength, $\sigma$ is the normal stress, $c$ is the intercept of the failure envelope with the $\tau$ axis, and $\varphi$ is the slope of the failure envelope.

The relation given in Equation 4.2 forms a pair of straight lines in the $\sigma: \tau$ plane (Figure 4.5). The failure occurs if Mohr's circle of effective stress of the rock reaches these lines. In order for sliding to occur on any plane, it is assumed that the shear stress has to overcome a frictional resistance $\sigma \tan \phi$, which is dependent on the effective normal stress $\sigma$ acting on the plane and on a friction angle $\phi$, together with the component $\mathrm{c}$, which is independent of the normal stress.

Figure 4.5 defines Mohr-Coulomb failure in terms of principle stresses ${ }^{(23)}$. The limiting relationship between the major and minor principal effective stresses $\sigma_{I}$ and $\sigma_{\text {III }}$ is given in Equation 4.3. 


$$
\frac{\sigma_{I}+c \cot \phi}{\sigma_{I I I}+c \cot \phi}=\frac{1+\sin \phi}{1-\sin \phi}
$$
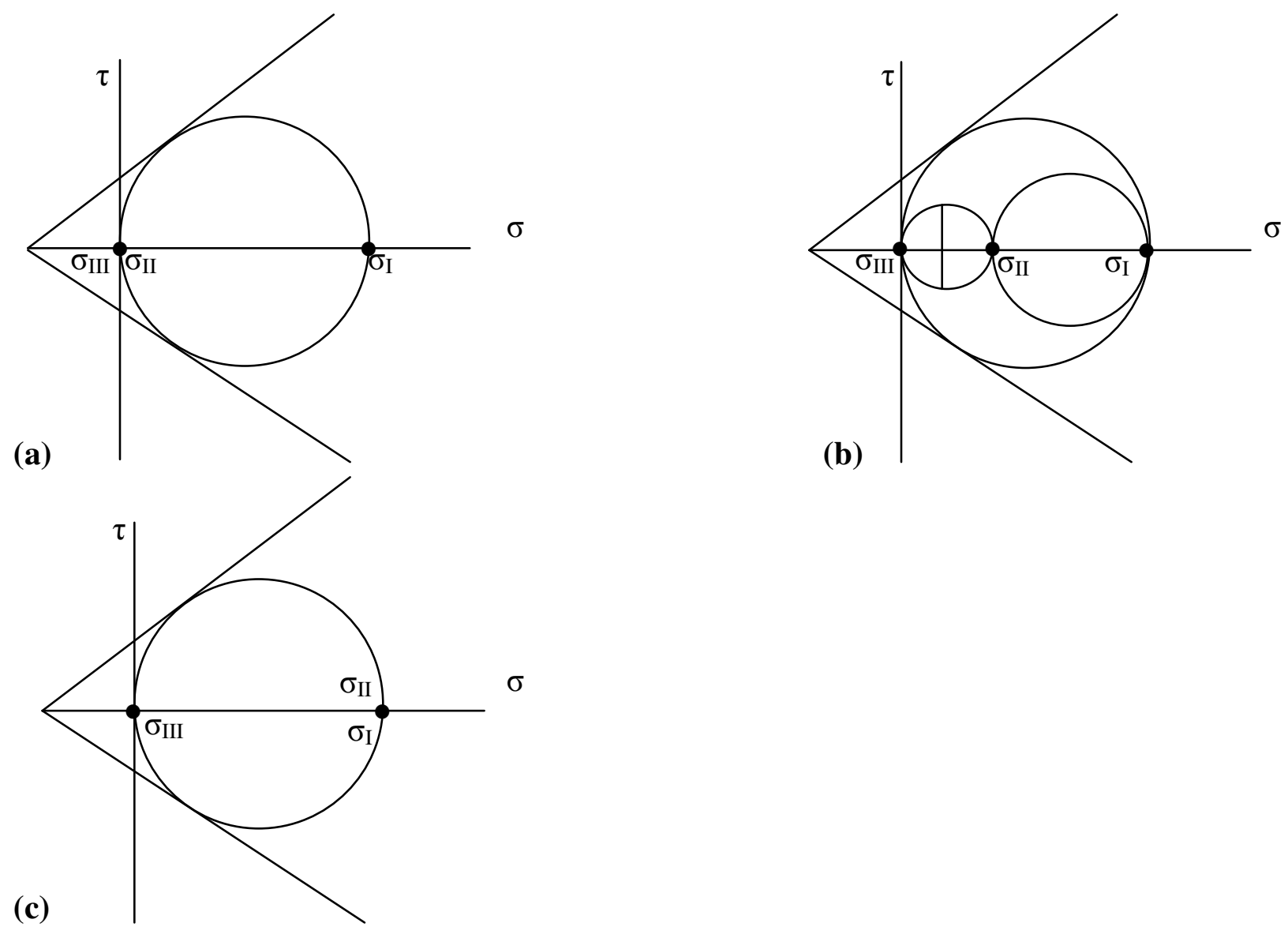

Figure 4.5 Mohr-Coulomb failure. Intermediate principle stress (a) equal to minor principle stress, (b) truly intermediate, and (c) equal to major principle stress ${ }^{(23)}$.

In Figure 4.5a, the stress conditions shown with $\sigma_{\mathrm{II}}=\sigma_{\mathrm{III}}$ correspond to triaxial compression where the cell pressure provides the minor (and equal intermediate) principle stress. If Expression 4.3 is rewritten in terms of triaxial stress variables p: q, where

$$
\begin{aligned}
& p=\frac{\sigma_{I}+2 \sigma_{I I I}}{3} \\
& q=\sigma_{I}-\sigma_{I I I}
\end{aligned}
$$


The relationship becomes:

$$
\frac{q}{p+c \cot \phi}=\frac{6 \sin \phi}{3-\sin \phi}
$$

In Figure 4.5c, the stress conditions shown with $\sigma_{\mathrm{II}}=\sigma_{\mathrm{I}}$ correspond to triaxial extension where the cell pressure provides the major (and equal intermediate) principle stress. The relation for triaxial stress variable $\mathrm{p}$ is given in Equation 4.7

$$
p=\frac{2 \sigma_{I}+\sigma_{I I I}}{3}
$$

and Equation 4.3 can be rewritten as in Equation 4.8:

$$
\frac{q}{p+c \cot \phi}=\frac{-6 \sin \phi}{3+\sin \phi}
$$

The expressions 4.6 and 4.8 can be plotted as in Figure 4.6 and the negative sign has been assigned to values of $\mathrm{q}$ in triaxial extension for the convenience ${ }^{(23)}$.

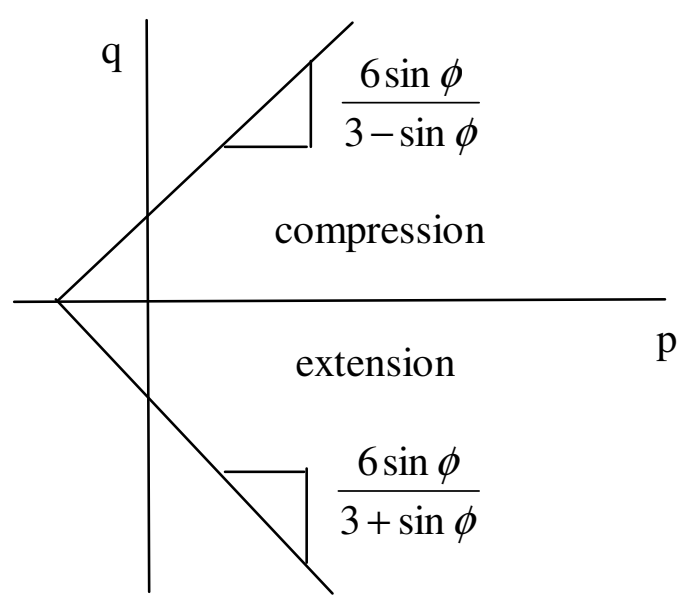

Figure 4.6 Mohr-Coulomb failure criterion ${ }^{(23)}$. 


\subsubsection{Shear Hardening/Softening Mohr Coulomb Model}

In $F L A C^{3 D}$, the strain-softening behavior is controlled by the variation in friction angle, cohesion and dilation angle as a function of plastic shear strain and the variation of tensile strength as a function of plastic tensile strain ${ }^{(22)}$. The strain-softening model assumes both a brittle softening (due to reduction in cohesion) and a gradual softening (due to a reduction in friction angle).

When the plastic yield begins, a gradual process of material hardening or softening is initiated. The deformation becomes more and more inelastic at failure resulting from microcracking in rock and concrete or particle sliding for soil. In addition, degradation of strength and the initiation of shear bands start in the material.

In $F L A C^{3 D}$, shear hardening and softening are simulated by defining Mohr-Coulomb model properties such as cohesion, friction and dilation angles as a function of plastic strain and tensile strength as a function of tensile strain. Hardening and softening parameters are generally back-calculated from laboratory triaxial test results and must be calibrated for each specific analysis ${ }^{(22)}$. It should be noted that knowledge of material properties after failure is very limited.

\subsubsection{Material Properties}

Material properties of the PDC cutter and the formation properties used in this study are given in Tables 4.2 and 4.3, respectively. The properties used in the model were obtained from the literature ${ }^{(2,18,24)}$, and from the default values given in the software ${ }^{(22)}$, also from the direct shear tests conducted with Catoosa shale ${ }^{(2)}$. 
Table 4.2 Material properties of PDC cutter.

\begin{tabular}{|c|c|c|c|}
\hline Material & Density, $\mathrm{kg} / \mathrm{m} 3$ & Bulk Modulus, GPa & Shear Modulus, GPa \\
\hline PDC & 3830 & 345 & 416 \\
\hline
\end{tabular}

Table 4.3 Ranges of material properties for shale used in the model.

\begin{tabular}{|c|c|c|c|c|c|c|c|}
\hline$\underline{\text { Material }}$ & $\begin{array}{c}\text { Density, } \\
\mathrm{kg} / \mathrm{m} 3\end{array}$ & $\begin{array}{c}\text { Bulk } \\
\text { Modulus, } \\
\mathrm{GPa}\end{array}$ & $\begin{array}{c}\text { Shear } \\
\text { Modulus, } \\
\mathrm{GPa}\end{array}$ & $\begin{array}{c}\text { Cohesion, } \\
\mathrm{MPa}\end{array}$ & $\begin{array}{c}\text { Internal } \\
\text { Friction } \\
\text { Angle, } \\
\text { degrees }\end{array}$ & $\begin{array}{c}\text { Dilation } \\
\text { Angle, } \\
\text { degrees }\end{array}$ & $\begin{array}{c}\text { Tensile } \\
\text { Strength, } \\
\mathrm{MPa}\end{array}$ \\
\hline $\begin{array}{c}\text { Catoosa } \\
\text { Shale }\end{array}$ & 2700 & 8.8 & 4.3 & $8-36$ & $14-30$ & $0-15$ & $0-14.4$ \\
\hline
\end{tabular}

\subsubsection{Direct Shear Test Results}

In this study, direct shear tests conducted by Smith ${ }^{(2)}$ were evaluated and the material properties were calculated from the results of the tests. He conducted tests with Catoosa shale with four different fluids; air, water, oil, water based mud. Shear stress and normal stress measurements were given below for three different stages of failure $\{$ A) fracture initiation, B) peak failure, and C) residual failure $\}$. Friction angle and cohesion were calculated from shear stress versus normal stress plot. Intercept of the plot is equal to the cohesion and arc tangent of slope equals to the friction angle value. Average cohesion and friction angle used in the initial model runs were calculated from the peak failure stress plot in Figure 4.9 and tabulated in Table 4.6. 


\section{A) Fracture Initiation:}

The shear stress and normal stress measurements are listed in Table 4.4 for air, water and oil as confining fluids when the initial fracture started in the material ${ }^{(2)}$.

Table 4.4 Shear and normal stress measurements under different fluids ${ }^{(2)}$.

\begin{tabular}{|c|c|c|}
\hline & $\begin{array}{c}\text { Shear Stress, } \\
\text { psi }\end{array}$ & $\begin{array}{c}\text { Normal Stress, } \\
\text { psi }\end{array}$ \\
\hline Air & 1998 & 992 \\
\hline Water & 815 & 1087 \\
\hline \multirow{2}{*}{ Oil } & 806 & 941 \\
\cline { 2 - 3 } & 194 & 96 \\
\hline
\end{tabular}

Based on the available data, friction angle and cohesion were calculated for the experiment conducted with oil as the drilling fluid. Figure 4.7 shows the plot of data used for calculations of friction angle and cohesion (Table 4.5).

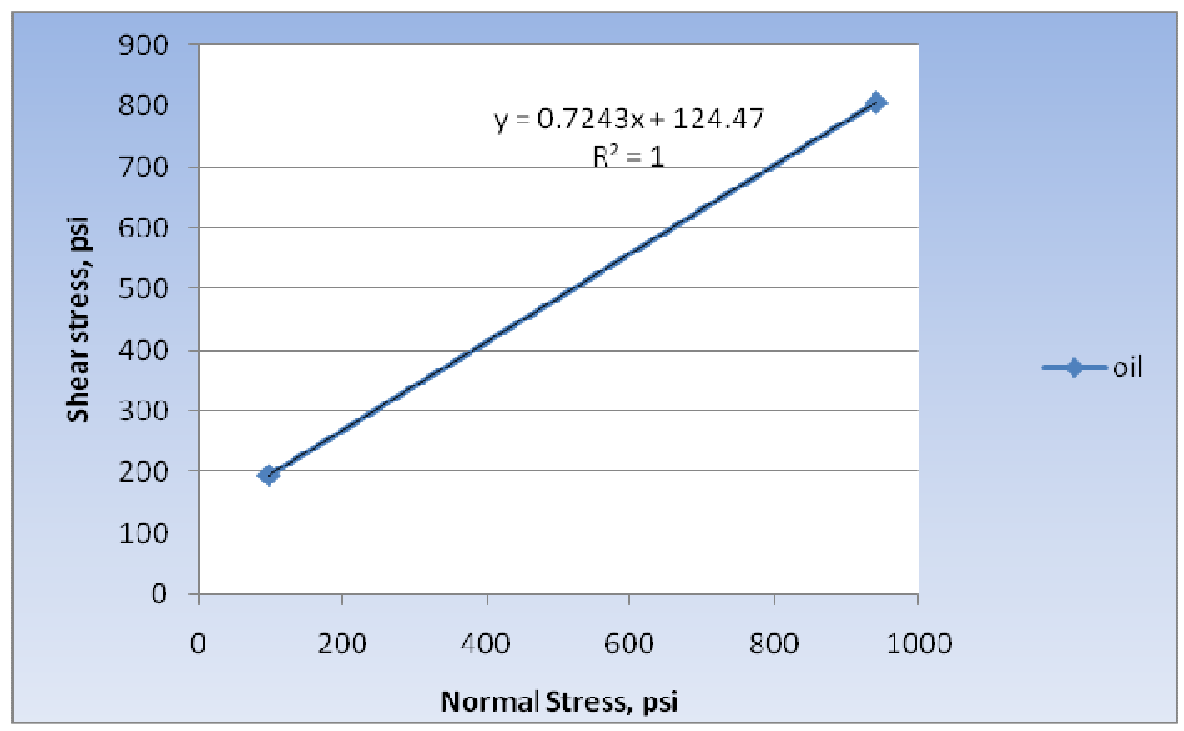

Figure 4.7 Shear stress versus normal stress plot for Catoosa shale with oil (fracture initiation) ${ }^{(2)}$. 
Table 4.5 Average friction angle and cohesion ${ }^{(2)}$.

\begin{tabular}{|c|c|c|c|}
\hline \multirow{2}{*}{ Fluid } & \multirow{2}{*}{$\begin{array}{c}\text { Friction } \\
\text { Angle, } \\
\text { degrees }\end{array}$} & \multicolumn{2}{|c|}{ Cohesion } \\
\hline & & Psi & $\mathrm{MPa}$ \\
\hline Oil & 36 & 124.47 & 0.9 \\
\hline
\end{tabular}

where

$$
\begin{aligned}
& \text { Cohesion }=\text { intercept } \\
& \text { Friction angle }=\operatorname{arc} \tan (\text { slope })
\end{aligned}
$$

\section{B) Peak Failure Stress (at failure):}

The shear stress and normal stress measurements for Catoosa shale with four different confining fluids are listed in Table 4.6 and plotted in Figure 4.8 for peak stress ratios.

Table 4.6 Shear and normal stress measurements under different fluids ${ }^{(2)}$.

\begin{tabular}{|c|c|c|}
\hline Fluid & $\begin{array}{c}\text { Shear Stress, } \\
\text { psi }\end{array}$ & $\begin{array}{c}\text { Normal Stress, } \\
\text { psi }\end{array}$ \\
\hline \multirow{4}{*}{ Air } & 1998 & 992 \\
\cline { 2 - 3 } & 1101 & 853 \\
\cline { 2 - 3 } & 3146 & 8072 \\
\hline \multirow{2}{*}{ Water } & 1658 & 2284 \\
\cline { 2 - 3 } & 1791 & 1530 \\
\hline \multirow{3}{*}{ Oil } & 1514 & 1617 \\
\cline { 2 - 3 } & 1029 & 626 \\
\hline \multirow{2}{*}{$\begin{array}{c}\text { Water } \\
\text { Mased }\end{array}$} & 3113 & 7804 \\
\cline { 2 - 3 } Mud & 1582 & 381 \\
\hline
\end{tabular}




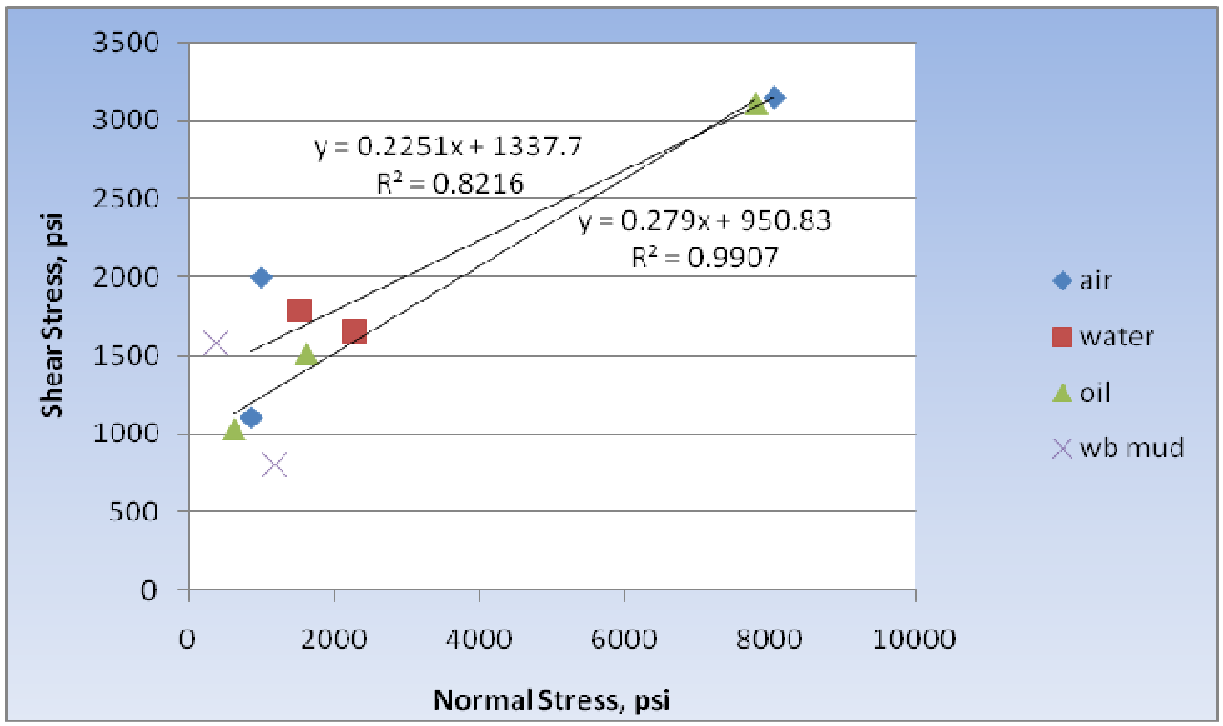

Figure 4.8 Shear stress versus normal stress plot for Catoosa shale (at failure) ${ }^{(2)}$.

The calculated friction angle and cohesion values for the experiments conducted with air and oil drilling fluids along with their average values are listed in Table 4.7

Table 4.7 Average friction angle and cohesion ${ }^{(2)}$.

\begin{tabular}{|c|c|c|c|}
\hline \multirow{2}{*}{ Fluid } & \multirow{2}{*}{$\begin{array}{c}\text { Friction } \\
\text { Angle, } \\
\text { degrees }\end{array}$} & \multicolumn{2}{|c|}{ Cohesion } \\
\hline & & Psi & $\mathrm{MPa}$ \\
\hline Air & 12.7 & 1337.7 & 9.2 \\
\hline Oil & 15.6 & 950.83 & 6.6 \\
\hline Average & 14 & 1144 & 8 \\
\hline
\end{tabular}

\section{C) Residual Stress (during failure):}

The results from the experiments conducted with Catoosa shale using four different confining fluids are listed in Table 4.8 and the shear stress versus normal stress values are plotted in Figure 4.9. The calculated friction angle and cohesion for the tests with air and oil along with their average values are given in Table 4.9. 
Table 4.8 Shear and normal stress measurements under different fluids ${ }^{(2)}$.

\begin{tabular}{|c|c|c|}
\hline \multirow{2}{*}{ Air } & $\begin{array}{c}\text { Shear Stress, } \\
\text { psi }\end{array}$ & $\begin{array}{c}\text { Normal Stress, } \\
\text { psi }\end{array}$ \\
\cline { 2 - 3 } & 275 & 692 \\
\cline { 2 - 3 } & 202 & 369 \\
\hline \multirow{2}{*}{ Water } & 1771 & 7678 \\
\cline { 2 - 3 } & 345 & 638 \\
\hline \multirow{3}{*}{ Oil } & 368 & 660 \\
\cline { 2 - 3 } & 366 & 800 \\
\cline { 2 - 3 } & 351 & 595 \\
\hline \multirow{2}{*}{$\begin{array}{c}\text { Water } \\
\text { Mased }\end{array}$} & 2117 & 7921 \\
\cline { 2 - 3 } Mud & 463 & 665 \\
\hline
\end{tabular}

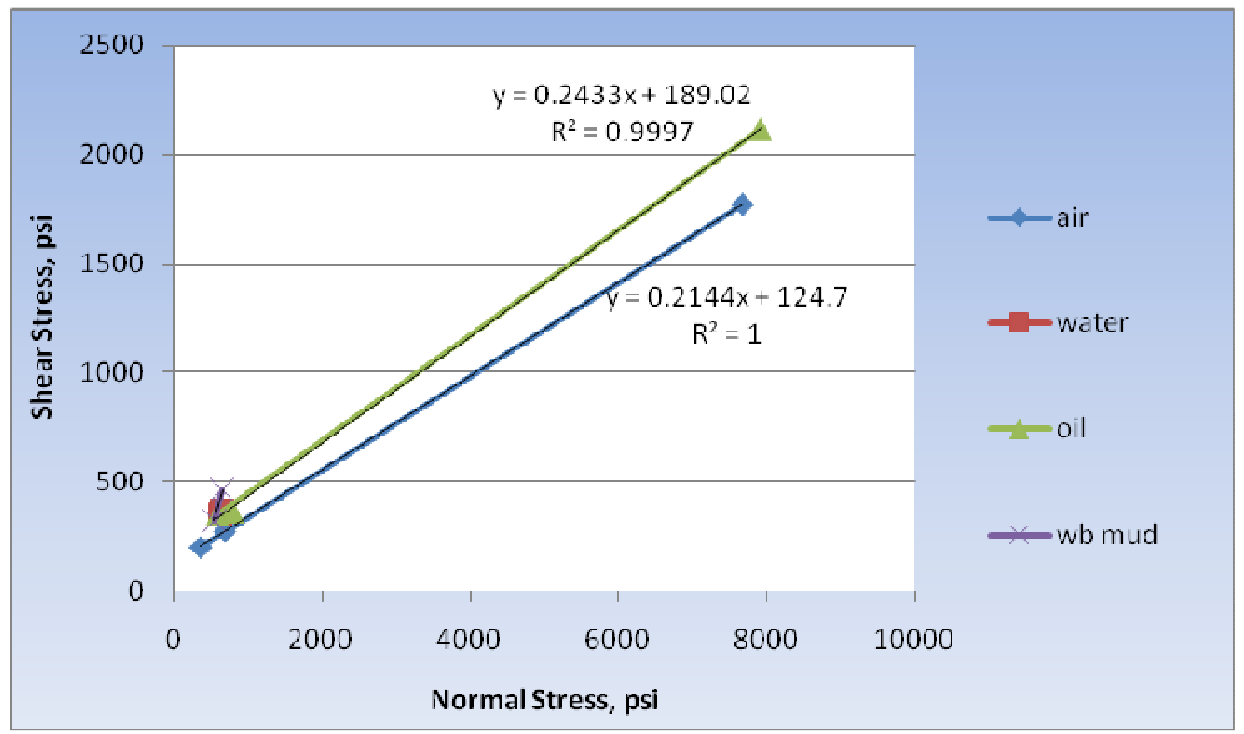

Figure 4.9 Shear stress versus normal stress plot (during failure) ${ }^{(2)}$.

Table 4.9 Average friction angle and cohesion ${ }^{(2)}$.

\begin{tabular}{|c|c|c|c|}
\hline \multirow{2}{*}{ Fluid } & \multirow{2}{*}{$\begin{array}{c}\text { Friction } \\
\text { Angle, } \\
\text { degrees }\end{array}$} & \multicolumn{2}{|c|}{ Cohesion } \\
\cline { 3 - 4 } & Psi & MPa \\
\hline Air & 12.1 & 124.7 & 0.86 \\
\hline Oil & 13.7 & 189.02 & 1.3 \\
\hline Average & 13 & 156.9 & 1.1 \\
\hline
\end{tabular}




\subsubsection{Post Failure Properties}

The behavior of deformation in the rock was simulated with a strain-softening model. The strain-hardening/softening behavior is controlled by the variations in friction angle, cohesion and dilation angle as a function of plastic shear strain as well as the variation of tensile strength as a function of plastic tensile strain in the model. The rock mass behaves as a strain-softening material with a total loss of cohesion and a drop in friction angle. Softening behavior of the rock is illustrated below in Figure 4.10 for the cohesion strength of the rock as a function of plastic shear strain for three different behaviors. A higher amount of drop is observed in the first plot represented by square blocks in blue. When the relationship is approaching to a linear drop represented by triangle blocks in green, a less rapid loss of cohesion is observed in the material.

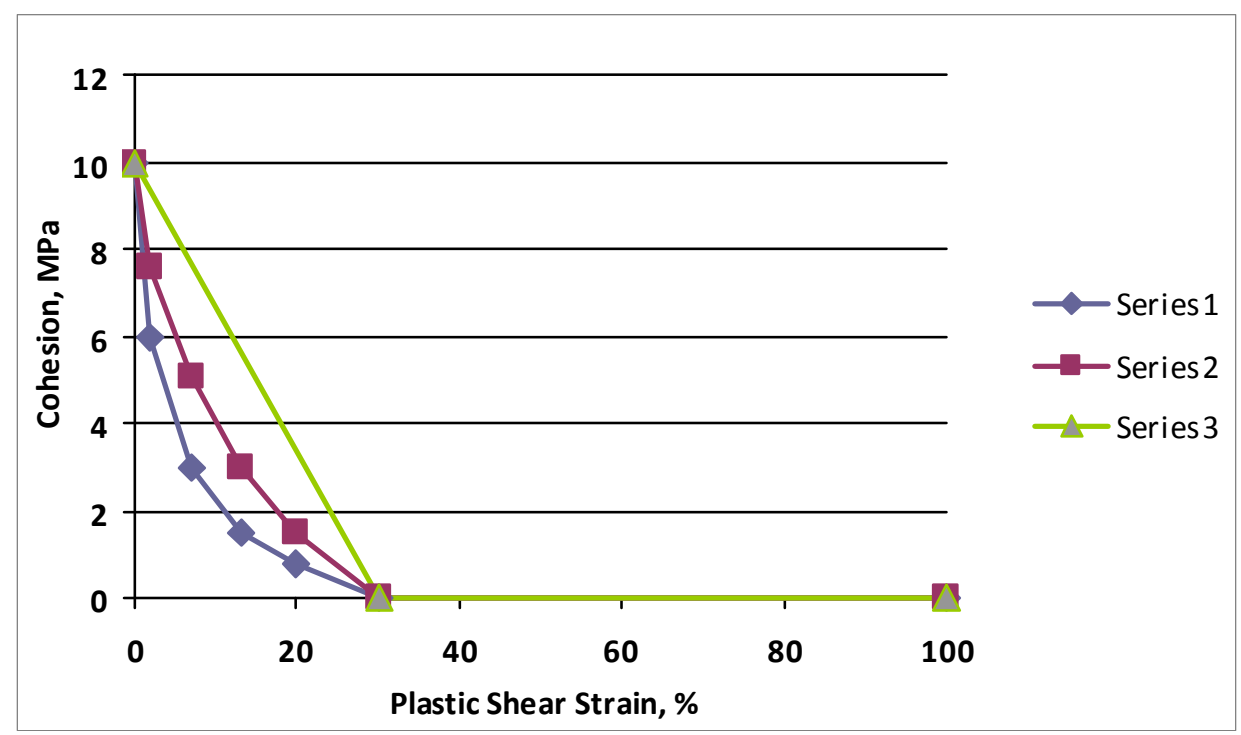

Figure 4.10 Example of different softening behavior of the rock (drop in cohesion).

Another illustration of post failure behavior of the material is given in 4.11 for three different plastic shear strain values. Failure may occur when the material reaches a certain plastic 
strain. In Figure 4.11, plots represent the shear failures that occur at different amount of plastic strain values $(10 \%, 20 \%$ and $30 \%)$.

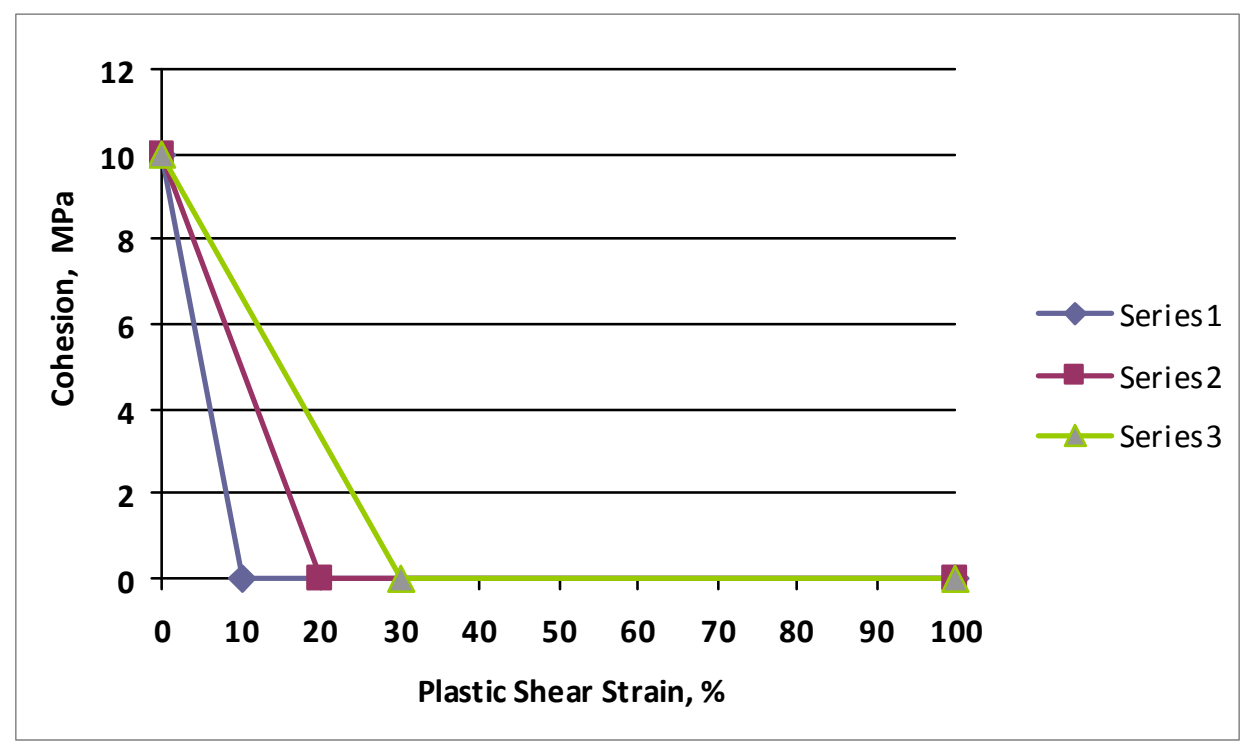

Figure 4.11 Example of softening behaviors of the rock (drop in cohesion) for different plastic shear strain values.

\subsubsection{Step and Analysis Procedure}

A basic concept in $F L A C^{3 D}$ is the division of the problem history into "steps". The step sequence provides a convenient way to capture changes in the loading and boundary conditions of the model, changes in the way parts of the model interact with each other, the removal or addition of parts, and any other changes that may occur in the model during the course of the analysis.

$F L A C^{3 D}$ can also perform automatic time stepping by using the "solve" command for mechanical static calculations. When the unbalanced force ratio reaches $1 \times 10^{-5}$, the steady-state solution is detected. However, if the model is not equilibrium and the unbalanced force never approaches zero, then the model should be executed by timesteps. The number of calculation steps to execute is controlled by the user and there is no limitation ${ }^{(25)}$. In this study, the model 
was run by using the "step" command since the unbalanced force never approached zero and the model was not in equilibrium.

\subsubsection{Element Removal}

When the shear and/or tensile failure criteria are met for a zone, all the stress components are set to zero and that zone is removed from the model. In this study, the elements are removed when plastic shear strain for a zone reaches $0.4(40 \%)$, and the plastic tensile strain reaches 0.2 $(20 \%)$.

\subsubsection{Tangent Force Calculation}

In the model, average axial and tangential forces on the cutter were calculated for a given depth of cut. During the initial runs of the model, the forces required to rotate the core were observed to deviate from tangent to the core perimeter based on the force vector plot as well as force plot. Vibration in the core during the cutting process was attributed for this behavior. In addition, the force applied on the bottom of the core was expected to be equal to the reaction forces developed on the cutter. A new algorithm was developed to calculate the resultant forces in the tangent direction to the core; however this routine increased the execution time.

After making the necessary modifications to the algorithm in the model, it was proved that the model runs accurately according to Newton's third law of motion which states that "every action has an equal and opposite reaction". In the model, the vertical forces applied on the bottom of the core were equal but in the opposite direction to the reaction forces developed on the cutter in vertical direction. Similarly, the tangential force that rotates the core was equal and in the opposite direction to the reaction force on the cutter in horizontal x-axis (Figure 4.12). 


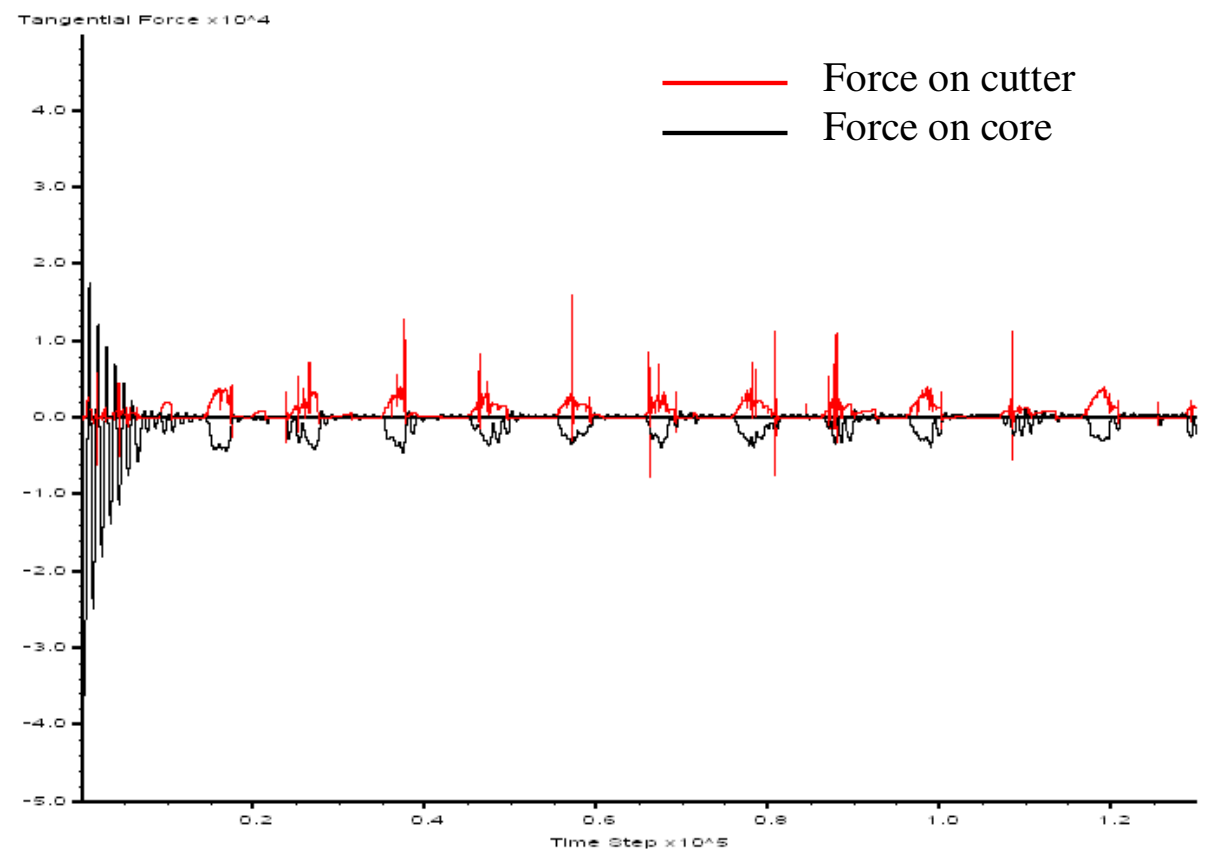

Figure 4.12 Horizontal x-forces on the cutter and core tangential force. 


\section{CHAPTER 5 \\ SENSIVITY RUNS \& \\ RESULTS AND DISCUSSIONS}

\subsection{Introduction}

Initial runs were conducted to debug the model runs and eliminate all computational errors. The next step was to calibrate the model with the experiments conducted with different confining pressures. In this study, the normal and tangential forces in the model required to achieve $1.905 \mathrm{~mm}$ depth of cut were calculated by an algorithm during the model runs. The rock cutting model after one revolution of cutter is represented in Figure 5.1. The forces calculated at each step were then exported to an excel sheet to calculate the average forces. The results were then compared with the experimental test results. Various runs were conducted with different material and post failure properties of the rock until the model calculated forces were in a fair match with the experimental results. In addition, the effects of varying several of the parameters on the resulting forces were investigated. It should be noted that it is very difficult to obtain the material properties for a specific rock without physical tests conducted in the laboratory. In addition, it is even harder to predict post failure properties of a formation to analyze the strainsoftening rock behavior, which is an important factor for the required cutting forces. The inputs of experimental data along with the input data used in the model are given in Appendix A.

In this study, numerous runs were conducted during the debugging and the calibration process for the model, and the best results are reported in the thesis. 


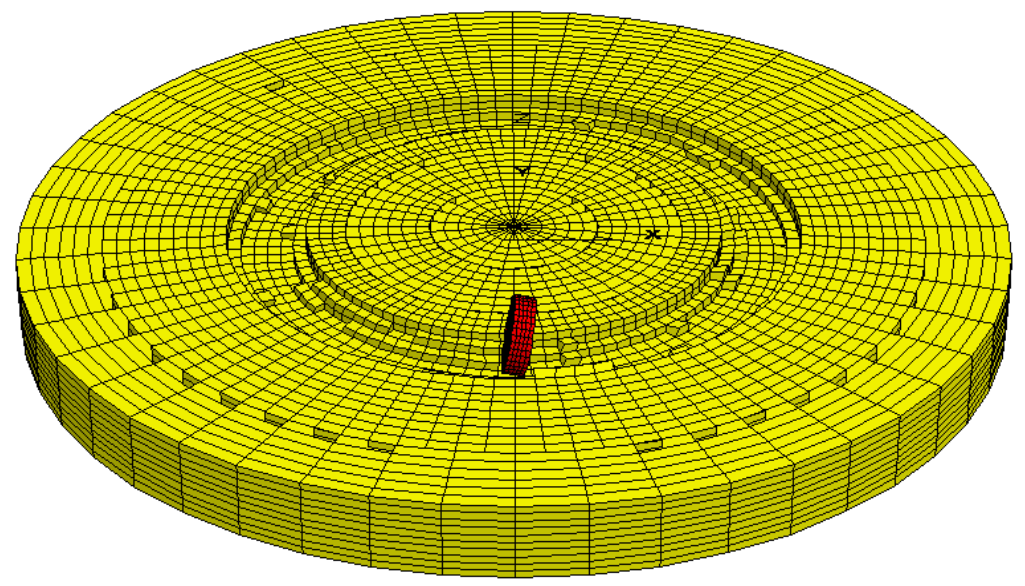

Figure 5.1 Catoosa Shale with a depth of cut of $1.905 \mathrm{~mm}(0.075 \mathrm{in})$ after one full revolution.

\subsection{Effect of Pressure}

The experiments were conducted with Catoosa Shale under different confining pressures using a cutting depth of 0.075 inch $(1.905 \mathrm{~mm})$ to study the effect of confining pressure on the axial and tangential cutting forces. 10 degrees of back rake angle was used in all tests. The cutter was set at $0.03143 \mathrm{~m}$ away from the center of the core. Table 5.1 below shows the range of pressures used in the laboratory tests and the corresponding forces recorded in metric units.

Table 5.1 Average axial and tangential forces measured in laboratory tests conducted with different confining pressures ${ }^{(2)}$.

\begin{tabular}{|c|c|c|c|}
\hline & EXPERIMENT 1 & EXPERIMENT 2 & EXPERIMENT 3 \\
\hline $\begin{array}{c}\text { Confining } \\
\text { Pressure, Pa }\end{array}$ & $2.07 \mathrm{E}+06$ & $6.89 \mathrm{E}+06$ & $2.07 \mathrm{E}+07$ \\
\hline $\begin{array}{c}\text { Average } \\
\text { Axial Force, N }\end{array}$ & 938 & 1232 & 2046 \\
\hline $\begin{array}{c}\text { Average } \\
\text { Tangential } \\
\text { Force, N }\end{array}$ & 801 & 1147 & 2139 \\
\hline $\begin{array}{c}\text { Force Ratio, } \\
\mathbf{F}_{\mathbf{T}} / \mathbf{F}_{\mathbf{A}}\end{array}$ & 0.85 & 0.93 & 1.05 \\
\hline
\end{tabular}




\subsubsection{Runs Conducted at 2.07 MPa Confining Pressure}

The first experiment examined in this study was conducted at $2.07 \mathrm{MPa}$ (300 psi) confining pressure. The runs were performed using Catoosa shale under 2.07 MPa confining pressure as reported in the experimental study ${ }^{(2)}$. Some of the material properties for Catoosa shale were obtained from available data in the literature and other properties not available in the literature were predicted using commonly accepted range of values or default values of the software for shales were used. Friction angle and cohesion were estimated from the direct shear test conducted for Catoosa shale ${ }^{(2)}$. The average friction angle calculated from the direct shear tests conducted with different fluids was 14 degrees and the average cohesion was $8 \mathrm{MPa}$. The graphs and calculations for direct shear test were given in Chapter 4. However, dilation angle and tensile strength were predicted according to the available values for shale in the literature.

The first run was performed with the parameters tabulated in Table 5.2 and the results from model calculations for axial and tangential forces are given in Table 5.3. The interface friction angle between the Catoosa Shale and the PDC cutter was calculated as 40 degrees from experimental results ${ }^{(2)}$ using Equation $5.1^{(25)}$.

$$
\psi=\tan ^{-1}\left(\frac{F_{y}}{F_{x}}\right)-\theta
$$

where $\psi$ is interfacial friction angle on cutting face, $F_{y}$ is the axial force component, $F_{x}$ is the tangential force component, $\theta$ is cutter back rake angle.

Detournay ${ }^{(25)}$ proposed that $\psi$ can be determined from the measurements of axial and tangential components of the cutting force F (Figure 5.2) according to the cutting experiments carried out. In addition, he states that interface friction angle changes under different confining stress conditions. 


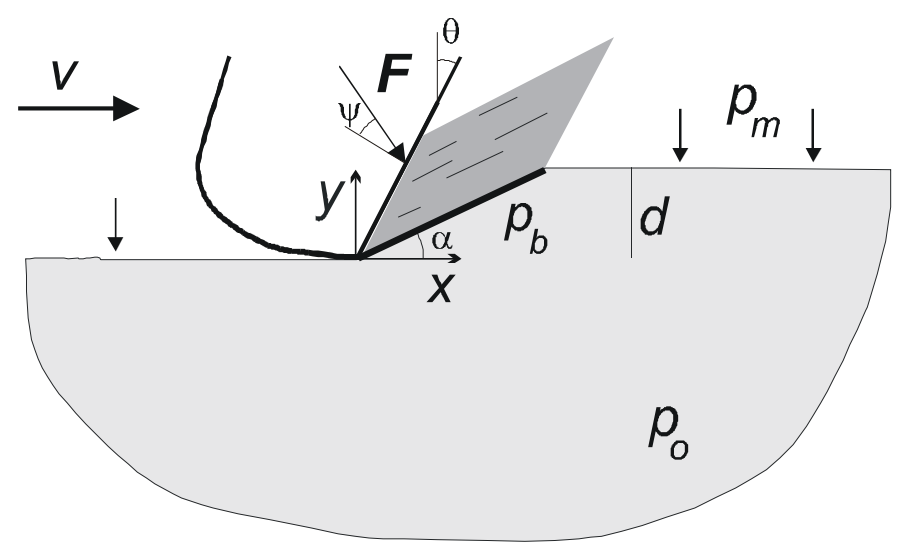

Figure 5.2 Sketch of a cutter-rock interaction under down-hole conditions ${ }^{(25)}$.

The terms shown in Figure 5.2 are defined below:

$$
\begin{aligned}
& p_{m}=\text { mud pressure (bottom-hole) }(\mathrm{Pa}) \\
& p_{o}=\text { virgin pore pressure }(\mathrm{Pa}) \\
& p_{b}=\text { pore pressure in the failed zone }(\mathrm{Pa}) \\
& v=\text { linear velocity of cutter }(\mathrm{m} / \mathrm{s}) \\
& d=\text { depth of cut }(\mathrm{m}) \\
& \theta=\text { back rake angle of cutter }(\text { degree })
\end{aligned}
$$

Table 5.2 Material properties used for the initial run.

\begin{tabular}{|c|c|c|c|c|c|c|c|}
\hline Material & $\begin{array}{c}\text { Bulk } \\
\mathrm{kg} / \mathrm{m} 3\end{array}$ & $\begin{array}{c}\text { Shear } \\
\text { Modulus, } \\
\mathrm{GPa}\end{array}$ & $\begin{array}{c}\text { Modulus, } \\
\mathrm{GPa}\end{array}$ & $\begin{array}{c}\text { Cohesion, } \\
\mathrm{MPa}\end{array}$ & $\begin{array}{c}\text { Internal Friction } \\
\text { Angle, degrees }\end{array}$ & $\begin{array}{c}\text { Dilation } \\
\text { Angle, } \\
\text { degrees }\end{array}$ & $\begin{array}{c}\text { Tensile } \\
\text { Strength, } \\
\mathrm{MPa}\end{array}$ \\
\hline PDC & 3830 & 345 & 416 & - & - & - & - \\
\hline $\begin{array}{c}\text { Catoosa } \\
\text { Shale }\end{array}$ & 2700 & 8.8 & 4.3 & 8 & 14 & 10 & 14.4 \\
\hline
\end{tabular}


The calculated axial and tangential forces are much less than the experimental results (Table 5.3). Deviations from experimental results were calculated using Equation 5.2 and very high values were obtained. Therefore, to decrease the deviations in the model calculated forces from the experimental results, more runs were performed by varied parameters. Only, one parameter was changed at a time to investigate the effect of each parameter on the cutting forces and results were again compared with experimental results to determine the net deviation. During this process, the effect of each parameter on the forces was investigated and adjustments were made for the next runs. Various runs were performed until a close match with the experimental results was obtained.

$$
\% \text { Deviation }=\frac{\text { Model } \text { PredictedValue }- \text { ExperimentalValue }}{\text { ExperimentalValue }} \times 100
$$

Table 5.3 Axial and tangential force results for initial run.

\begin{tabular}{|c|c|c|c|c|c|}
\hline & $\begin{array}{c}\text { Average } \\
\text { Axial } \\
\text { Force, } \mathrm{F}_{\mathrm{A}} \\
\mathrm{N}\end{array}$ & $\begin{array}{c}\text { Average } \\
\text { Tangential } \\
\text { Force, } \mathrm{F}_{\mathrm{T}} \\
\mathrm{N}\end{array}$ & $F_{T} / F_{A}$ & $\begin{array}{c}\text { Deviation } \\
\text { from } \\
\text { Experimental } \\
\text { Axial Force } \\
(\%)\end{array}$ & $\begin{array}{c}\text { Deviation from } \\
\text { Experimental } \\
\text { Tangential } \\
\text { Force } \\
(\%)\end{array}$ \\
\hline Run 1 & 58 & 61 & 1.05 & -93.8 & -92.4 \\
\hline
\end{tabular}

\subsubsection{Effect of Friction Angle}

Internal friction angle $(\varphi)$ for most rocks falls within the range from $15^{\circ}$ to $45^{\circ}(27)$. Average friction angle calculated from the shear tests conducted with different fluids is 14 degrees. In the model, three runs were conducted to determine the effect of friction angle on the resultant axial and tangential forces.

The input value for the variation of dilation angle and cohesion as a function of plastic shear strain are shown in Table 5.4 for Runs 1, 2 and 3. Friction angle and plastic shear strain 
relationships used in the model are given in Table 5.5 and plotted in Figure 5.3. Table 5.6 shows the variation in tensile strength as a function of plastic tensile strain employed in Runs $1,2 \& 3$.

Table 5.4 Dilation angle and cohesion as a function of plastic shear strain (Runs $1,2 \& 3$ ).

\begin{tabular}{|c|c|c|}
\hline $\begin{array}{c}\text { Plastic } \\
\text { Shear } \\
\text { Strain } \\
(\%)\end{array}$ & $\begin{array}{c}\text { Cohesion } \\
\text { (MPa) }\end{array}$ & $\begin{array}{c}\text { Dilation } \\
\text { Angle } \\
\text { (degrees) }\end{array}$ \\
\hline $\mathbf{0}$ & 8 & 10 \\
\hline $\mathbf{2}$ & 5.56 & 8 \\
\hline $\mathbf{7}$ & 3.1 & 6 \\
\hline $\mathbf{2 0}$ & 0 & 5 \\
\hline $\mathbf{1 0 0}$ & 0 & 5 \\
\hline
\end{tabular}

Table 5.5 Friction angles as a function of plastic shear strain (Runs 1, $2 \& 3$ ).

\begin{tabular}{|c|c|c|c|}
\hline $\begin{array}{c}\text { Plastic } \\
\text { Shear } \\
\text { Strain } \\
(\%)\end{array}$ & \multicolumn{3}{|c|}{$\begin{array}{c}\text { Friction Angle } \\
\text { (degrees) }\end{array}$} \\
\cline { 2 - 4 } & Run 1 & Run 2 & Run 3 \\
\hline $\mathbf{0}$ & 14 & 20 & 20 \\
\hline $\mathbf{2}$ & 13 & 18 & 18 \\
\hline $\mathbf{7}$ & 11 & 14 & 16 \\
\hline $\mathbf{2 0}$ & 10 & 10 & 16 \\
\hline $\mathbf{1 0 0}$ & 10 & 10 & 16 \\
\hline
\end{tabular}

Table 5.6 Tensile strength as a function of plastic tensile strain (Runs $1,2 \& 3$ ).

\begin{tabular}{|c|c|}
\hline $\begin{array}{c}\text { Plastic Tensile } \\
\text { Strain } \\
(\%)\end{array}$ & $\begin{array}{c}\text { Tensile } \\
\text { Strength } \\
\text { (Mpa) }\end{array}$ \\
\hline $\mathbf{0}$ & 14.4 \\
\hline $\mathbf{2}$ & 8 \\
\hline $\mathbf{7}$ & 3 \\
\hline $\mathbf{1 0}$ & 0 \\
\hline $\mathbf{1 0 0}$ & 0 \\
\hline
\end{tabular}




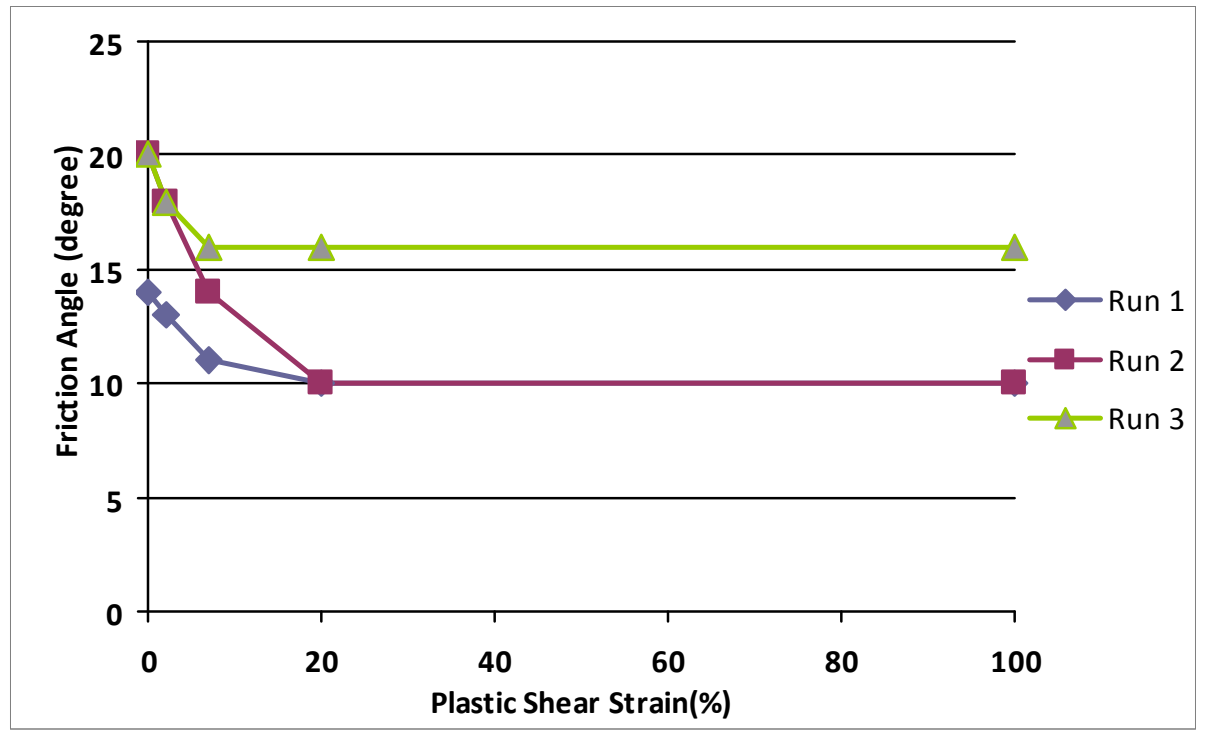

Figure 5.3 Variation of friction angle as a function of shear strain (Runs 1, 2 \& 3).

The experimental data consisted of average axial and tangential forces. The axial and tangential force results of the model were based on the arithmetic average of axial and tangential forces calculated for every time step during the model runs.

The comparison of the experimental and model predicted forces is listed in Table 5.7 together with the percent deviation of model predicted values from experimental results as well as the percent difference between two model results conducted with different parameters. The percent differences were calculated with Equation 5.3.

$$
\% \text { Difference }=\frac{\text { Finalvalue }- \text { Initialvalue }}{\text { Initialvalue }} \times 100
$$

Table 5.7 Effect of friction angle on axial and tangential forces on the cutter for Catoosa Shale.

\begin{tabular}{|c|c|c|c|c|c|c|c|}
\hline & $\begin{array}{c}\text { Average } \\
\text { Axial } \\
\text { Force, } \\
\mathrm{F}_{\mathrm{A}} \mathrm{N}\end{array}$ & $\begin{array}{c}\text { Average } \\
\text { Tangential } \\
\text { Force, } \mathrm{F}_{\mathrm{T}} \\
\mathrm{N}\end{array}$ & $F_{T} / F_{A}$ & $\begin{array}{c}\text { Difference } \\
\text { in Axial } \\
\text { Force } \\
(\%)\end{array}$ & $\begin{array}{c}\text { Difference } \\
\text { in } \\
\text { Tangential } \\
\text { Force } \\
(\%)\end{array}$ & $\begin{array}{c}\text { Deviation } \\
\text { from } \\
\text { Experimental } \\
\text { Axial Force } \\
(\%)\end{array}$ & $\begin{array}{c}\text { Deviation from } \\
\text { Experimental } \\
\text { Tangential } \\
\text { Force } \\
(\%)\end{array}$ \\
\hline Run 1 & 58 & 61 & 1.05 & - & - & -93.82 & -92.38 \\
\hline Run 2 & 59 & 62 & 1.05 & 2 & 2 & -93.71 & -92.26 \\
\hline Run 3 & 60 & 66 & 1.1 & 3 & 8 & -93.61 & -91.76 \\
\hline
\end{tabular}


With a six degree increase in friction angle for the Catoosa shale, a $2 \%$ increase was observed for the calculated axial and tangential forces. Additional increase of $1 \%$ and $6 \%$ were achieved for axial and tangential forces respectively by increasing the residual friction angle by six degrees (Run 3). This observation is consistent with formation characteristics where higher friction angles require higher forces to fail.

\subsubsection{Effect of Plastic Shear Strain at Failure Point}

Shales behave as consolidated materials and can exhibit a ductile response under different loading conditions. Some runs were performed by assigning a more ductile behavior to the shale. The plastic shear strain value at the failure point was $20 \%$ for the friction angle sensitivity runs. The run for plastic shear strain effect was conducted with the new value of $30 \%$ shear strain, and all others parameters were kept the same as in Run 3. The functional relations for cohesion, dilation and friction angles are given in Table 5.8 for Run 3.

Table 5.8 Cohesion, dilation and friction angles as a function of plastic shear strain (Run 4).

\begin{tabular}{|c|c|c|c|}
\hline $\begin{array}{c}\text { Plastic } \\
\text { Shear } \\
\text { Strain } \\
(\%)\end{array}$ & $\begin{array}{c}\text { Cohesion } \\
\text { (MPa) }\end{array}$ & $\begin{array}{c}\text { Dilation } \\
\text { Angle } \\
\text { (degrees) }\end{array}$ & $\begin{array}{c}\text { Friction } \\
\text { Angle } \\
\text { (degrees) }\end{array}$ \\
\hline $\mathbf{0}$ & 8 & 10 & 20 \\
\hline $\mathbf{2}$ & 5.56 & 8 & 19 \\
\hline $\mathbf{7}$ & 3.1 & 6 & 17 \\
\hline $\mathbf{3 0}$ & 0 & 5 & 16 \\
\hline $\mathbf{1 0 0}$ & 0 & 5 & 16 \\
\hline
\end{tabular}


The tensile strength as a function of plastic tensile strain used in the previous runs was employed for this case (Table 5.6). The results for Runs 3 and 4 conducted with $20 \%$ and $30 \%$ shear strain failure are given in Table 5.9.

Table 5.9 Effect of plastic shear strain at failure point on axial and tangential forces on the cutter for Catoosa Shale.

\begin{tabular}{|l|c|c|c|c|c|c|c|}
\hline & $\begin{array}{c}\text { Average } \\
\text { Axial } \\
\text { Force, } \\
\mathrm{F}_{\mathrm{A}} \mathrm{N}\end{array}$ & $\begin{array}{c}\text { Average } \\
\text { Tangential } \\
\text { Force, } \mathrm{F}_{\mathrm{T}} \\
\mathrm{N}\end{array}$ & $F_{T} / F_{A}$ & $\begin{array}{c}\text { Difference } \\
\text { in Axial } \\
\text { Force } \\
(\%)\end{array}$ & $\begin{array}{c}\text { Difference } \\
\text { in } \\
\text { Tangential } \\
\text { Force } \\
(\%)\end{array}$ & $\begin{array}{c}\text { Deviation } \\
\text { from } \\
\text { Experimental } \\
\text { Axial Force } \\
(\%)\end{array}$ & $\begin{array}{c}\text { Deviation } \\
\text { from } \\
\text { Experimental } \\
\text { Tangential } \\
\text { Force } \\
(\%)\end{array}$ \\
\hline Run 3 & 60 & 66 & 1.1 & - & - & -93.61 & -91.76 \\
\hline Run 4 & 85 & 99 & 1.16 & 42 & 50 & -90.94 & -87.64 \\
\hline
\end{tabular}

The increase in the value of shear strain by $50 \%$ increased the model predicted values around 50\% (Table 5.9); however, the results continued to deviate considerably from the measured laboratory values.

\subsubsection{Effect of Cohesion}

To study the effect of cohesion on the predicted forces, the cohesion value used in the earlier runs was increased. The upper range for shale cohesion given in the literature is around 38 $\mathrm{MPa}$. The average cohesion calculated from the direct shear test results (8 MPa) was used in Run 4. Two new runs were performed with different cohesion relationships while friction angle, dilation angle and tensile strength values were kept the same as in Run 4. Cohesion as a function of plastic shear strain for Runs 4, 5 and 6 are shown in Table 5.10 and plotted in Figure 5.4. 
Table 5.10 Variation in cohesion as a function of plastic shear strain (Runs 4, 5 \& 6).

\begin{tabular}{|c|c|c|c|}
\hline \multirow{2}{*}{$\begin{array}{c}\text { Plastic } \\
\text { Shear } \\
\text { Strain } \\
(\%)\end{array}$} & \multicolumn{3}{|c|}{ Cohesion (MPa) } \\
\cline { 2 - 4 } & Run 4 & Run 5 & Run 6 \\
\hline $\mathbf{0}$ & 8 & 10 & 15 \\
\hline $\mathbf{2}$ & 5.56 & 7.56 & 12.56 \\
\hline $\mathbf{7}$ & 3.1 & 5.1 & 8.1 \\
\hline $\mathbf{3 0}$ & 0 & 0 & 0 \\
\hline $\mathbf{1 0 0}$ & 0 & 0 & 0 \\
\hline
\end{tabular}

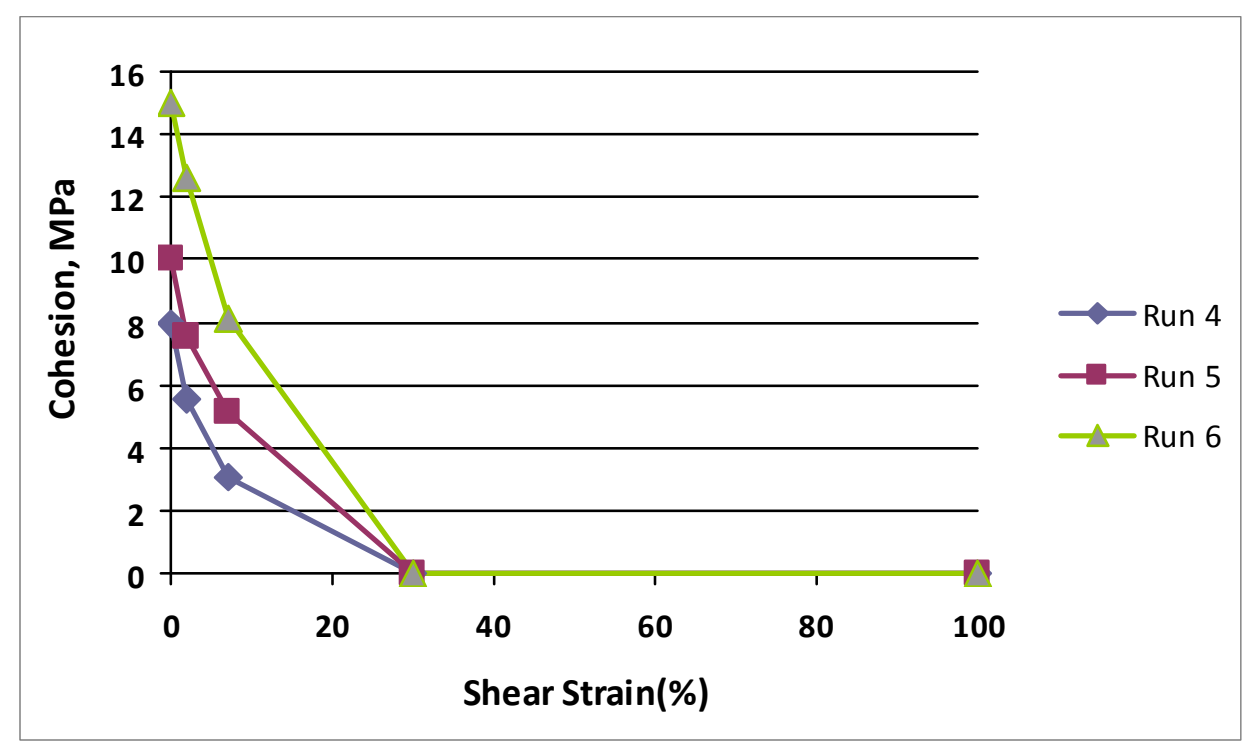

Figure 5.4 Variation in cohesion as a function of shear strain (Runs 4, $5 \& 6$ ).

Table 5.11 lists the results for axial and tangential force calculations. As a result of $20 \%$ increase in cohesion, the axial and tangential forces increased around $30 \%$ and, forces on the cutter were increased by $115 \%$ with an increase of $88 \%$ in cohesion. The calculated force changes were in proportion to the changes in cohesion. In addition, the ratio between tangential force and axial force, $F_{T} / F_{A}$ in each run did not change considerably. 
Table 5.11 Effect of cohesion on axial and tangential forces on the cutter for Catoosa Shale.

\begin{tabular}{|c|c|c|c|c|c|c|c|}
\hline & $\begin{array}{c}\text { Average } \\
\text { Axial } \\
\text { Force, } \mathrm{F}_{\mathrm{A}} \\
\mathrm{N}\end{array}$ & $\begin{array}{c}\text { Average } \\
\text { Tangential } \\
\text { Force, } \mathrm{F}_{\mathrm{T}} \\
\mathrm{N}\end{array}$ & $F_{T} / F_{A}$ & $\begin{array}{c}\text { Difference } \\
\text { in Axial } \\
\text { Force } \\
(\%)\end{array}$ & $\begin{array}{c}\text { Difference } \\
\text { in } \\
\text { Tangential } \\
\text { Force } \\
(\%)\end{array}$ & $\begin{array}{c}\text { Deviation from } \\
\text { Experimental } \\
\text { Axial Force } \\
(\%)\end{array}$ & $\begin{array}{c}\text { Deviation } \\
\text { from } \\
\text { Experimental } \\
\text { Tangential } \\
\text { Force } \\
(\%)\end{array}$ \\
\hline Run 4 & 85 & 99 & 1.16 & - & - & -90.94 & -87.64 \\
\hline Run 5 & 116 & 128 & 1.10 & 36 & 29 & -87.64 & -84.01 \\
\hline Run 6 & 186 & 207 & 1.11 & 119 & 109 & -80.18 & -74.15 \\
\hline
\end{tabular}

\subsubsection{Effect of Tangential Velocity}

Two runs (Run 7 and Run 8) were performed with rotational velocities of $4 \times 10^{-7}$ and $8 \times 10^{-7} \mathrm{~m} / \mathrm{step}$ and other properties were kept same as in Run 5 conducted with $2 \mathrm{e}-7 \mathrm{~m} / \mathrm{step}$ rotational speed.

The axial and tangential forces calculated for Runs 7 and 8 are listed together with results for Run 5 in Table 5.12. With an increase in tangential velocity, an additional increase in forces was observed. However, the force increase was attributed to the increase in the oscillations due to higher rotational velocity used in the model.

Runs presented in the following sections were conducted with a velocity of $4 \mathrm{e}-7 \mathrm{~m} / \mathrm{step}$ until a close match was reached for the desired force values. Use of a higher velocity reduced the model run times. The velocity value of $8 \mathrm{e}-7$ was not used due to larger $\%$ difference between axial and tangential forces resulted from higher increase in tangential force. When the velocity was increased to $4 \mathrm{e}-7 \mathrm{~m} / \mathrm{step}$ from $2 \mathrm{e}-7 \mathrm{~m} / \mathrm{step}$, both the axial and tangential force deviations were decreased by $3 \%$. However, when a velocity of $8 \mathrm{e}-7 \mathrm{~m} / \mathrm{step}$ was used, the tangential force deviation was decreased by $10 \%$ while the axial force deviation was decreased by $7 \%$. It was observed that when the velocity was increased over $4 \mathrm{e}-7 \mathrm{~m} / \mathrm{step}$, its effect was more pronounced in tangential force. Since the same or close amount of deviation of both model calculated forces 
from experimental results was more favorable to match both forces at the same time, the velocity of $4 \mathrm{e}-7 \mathrm{~m} / \mathrm{step}$ was used in the model runs.

Table 5.12 Effect of tangential velocity on axial and tangential forces on the cutter for Catoosa Shale.

\begin{tabular}{|c|c|c|c|c|c|c|c|}
\hline & $\begin{array}{c}\text { Average } \\
\text { Axial } \\
\text { Force, } \mathrm{F}_{\mathrm{A}} \\
\mathrm{N}\end{array}$ & $\begin{array}{c}\text { Average } \\
\text { Tangential } \\
\text { Force, } \mathrm{F}_{\mathrm{T}} \\
\mathrm{N}\end{array}$ & $F_{T} / F_{\mathrm{A}}$ & $\begin{array}{c}\text { Difference } \\
\text { in Axial } \\
\text { Force } \\
(\%)\end{array}$ & $\begin{array}{c}\text { Difference } \\
\text { in } \\
\text { Tangential } \\
\text { Force } \\
(\%)\end{array}$ & $\begin{array}{c}\text { Deviation } \\
\text { from } \\
\text { Experimental } \\
\text { Axial Force } \\
(\%)\end{array}$ & $\begin{array}{c}\text { Deviation } \\
\text { from } \\
\text { Experimental } \\
\text { Tangential } \\
\text { Force } \\
(\%)\end{array}$ \\
\hline Run 5 & 116 & 128 & 1.10 & - & - & -87.64 & -84.01 \\
\hline Run 7 & 129 & 154 & 1.19 & 11 & 20 & -86.26 & -80.77 \\
\hline Run 8 & 148 & 200 & 1.35 & 28 & 56 & -84.23 & -75.02 \\
\hline
\end{tabular}

\subsubsection{Effect of Plastic Shear Strain and Post Failure Properties Relationship}

A run was conducted with new plastic shear and tensile strain relationships using the material properties of Run 7 with a linear relationship between the variation of cohesion, friction angle, dilation angle, tensile strength and plastic strains as shown in Tables 5.13 and 5.14, respectively.

Table 5.13 Variation in friction angle, dilation angle and cohesion as a function of plastic shear strain (Run 9).

\begin{tabular}{|c|c|c|c|}
\hline $\begin{array}{c}\text { Plastic } \\
\text { Shear } \\
\text { Strain } \\
(\%)\end{array}$ & $\begin{array}{c}\text { Friction } \\
\text { Angle } \\
\text { (degrees) }\end{array}$ & $\begin{array}{c}\text { Dilation } \\
\text { Angle } \\
\text { (degrees) }\end{array}$ & $\begin{array}{c}\text { Cohesion } \\
\text { (MPa) }\end{array}$ \\
\hline $\mathbf{0}$ & 20 & 10 & 10 \\
\hline $\mathbf{3 0}$ & 16 & 5 & 0 \\
\hline $\mathbf{1 0 0}$ & 16 & 5 & 0 \\
\hline
\end{tabular}


Table 5.14 Tensile strength as a function of plastic tensile strain (Run 9).

\begin{tabular}{|c|c|}
\hline $\begin{array}{c}\text { Plastic } \\
\text { Tensile } \\
\text { Strain } \\
(\%)\end{array}$ & $\begin{array}{c}\text { Tensile } \\
\text { Strength } \\
\text { (MPa) }\end{array}$ \\
\hline $\mathbf{0}$ & 14.4 \\
\hline $\mathbf{1 0}$ & 0 \\
\hline $\mathbf{1 0 0}$ & 0 \\
\hline
\end{tabular}

In this run, the calculated forces increased by an average of $33 \%$ compared to the previous run (Run 7) as shown in Table 5.15.

Table 5.15 Effect of linear decrease in properties on axial and tangential forces on the cutter for

$$
\text { Catoosa Shale. }
$$

\begin{tabular}{|c|c|c|c|c|c|c|c|}
\hline & $\begin{array}{c}\text { Average } \\
\text { Axial } \\
\text { Force, } \\
\mathrm{F}_{\mathrm{A}} \mathrm{N}\end{array}$ & $\begin{array}{c}\text { Average } \\
\text { Tangential } \\
\text { Force, } \mathrm{F}_{\mathrm{T}} \\
\mathrm{N}\end{array}$ & $F_{T} / F_{A}$ & $\begin{array}{c}\text { Differen } \\
\text { ce } \\
\text { in Axial } \\
\text { Force } \\
(\%)\end{array}$ & $\begin{array}{c}\text { Difference } \\
\text { in } \\
\text { Tangential } \\
\text { Force } \\
(\%)\end{array}$ & $\begin{array}{c}\text { Deviation } \\
\text { from } \\
\text { Experimental } \\
\text { Axial Force } \\
(\%)\end{array}$ & $\begin{array}{c}\text { Deviation from } \\
\text { Experimental } \\
\text { Tangential } \\
\text { Force } \\
(\%)\end{array}$ \\
\hline Run 7 & 129 & 154 & 1.19 & - & - & -86.26 & -80.77 \\
\hline Run 9 & 169 & 208 & 1.23 & 31 & 35 & -81.99 & -74.02 \\
\hline
\end{tabular}

To improve predictions and increase the calculated axial and tangential forces, the ductility of shale was increased by using $40 \%$ shear strain for the failure point. Variations of properties used in Run 10 are tabulated in Table 5.16. Tensile strength values used in this run are listed in Table 5.14 under Run 9. 
Table 5.16 Friction angle, dilation angle and cohesion as a function of plastic shear strain (Run 10).

\begin{tabular}{|c|c|c|c|}
\hline $\begin{array}{c}\text { Plastic } \\
\text { Shear } \\
\text { Strain } \\
(\%)\end{array}$ & $\begin{array}{c}\text { Friction } \\
\text { Angle } \\
\text { (degrees) }\end{array}$ & $\begin{array}{c}\text { Dilation } \\
\text { Angle } \\
\text { (degrees) }\end{array}$ & $\begin{array}{c}\text { Cohesion } \\
\text { (MPa) }\end{array}$ \\
\hline $\mathbf{0}$ & 20 & 10 & 10 \\
\hline $\mathbf{4 0}$ & 16 & 5 & 0 \\
\hline $\mathbf{1 0 0}$ & 16 & 5 & 0 \\
\hline
\end{tabular}

As a result of the increase in shale ductility, the predicted axial and tangential forces increased by $37 \%$ and $47 \%$, respectively (Table 5.17).

Table 5.17 Effect of plastic shear strain at failure point on axial and tangential forces on the cutter for Catoosa Shale.

\begin{tabular}{|c|c|c|c|c|c|c|c|}
\hline & $\begin{array}{c}\text { Average } \\
\text { Axial } \\
\text { Force, } \mathrm{F}_{\mathrm{A}} \\
\mathrm{N}\end{array}$ & $\begin{array}{c}\text { Average } \\
\text { Tangential } \\
\text { Force, } \mathrm{F}_{\mathrm{T}} \\
\mathrm{N}\end{array}$ & $F_{T} / F_{A}$ & $\begin{array}{c}\text { Difference } \\
\text { in Axial } \\
\text { Force } \\
(\%)\end{array}$ & $\begin{array}{c}\text { Difference } \\
\text { in } \\
\text { Tangential } \\
\text { Force } \\
(\%)\end{array}$ & $\begin{array}{c}\text { Deviation } \\
\text { from } \\
\text { Experimental } \\
\text { Axial Force } \\
(\%)\end{array}$ & $\begin{array}{c}\text { Deviation } \\
\text { from } \\
\text { Experimental } \\
\text { Tangential } \\
\text { Force } \\
(\%)\end{array}$ \\
\hline $\begin{array}{c}\text { Run } \\
\mathbf{9}\end{array}$ & 169 & 208 & 1.23 & - & - & -86.26 & -80.77 \\
\hline $\begin{array}{c}\text { Run } \\
\mathbf{1 0}\end{array}$ & 232 & 305 & 1.32 & 37 & 47 & -81.99 & -74.02 \\
\hline
\end{tabular}

The initial cohesion property was increased by two fold (20 MPa) and an additional run was conducted (Run 11). The variations in friction and dilation angles and tensile strength for this run were kept the same as in Run 10. Results yield $84 \%$ and $75 \%$ increase in axial and tangential forces, respectively (Table 5.18). 
Table 5.18 Effect of cohesion on axial and tangential forces on the cutter for Catoosa Shale.

\begin{tabular}{|c|c|c|c|c|c|c|c|}
\hline & $\begin{array}{c}\text { Average } \\
\text { Axial } \\
\text { Force, } \mathrm{F}_{\mathrm{A}} \\
\mathrm{N}\end{array}$ & $\begin{array}{c}\text { Average } \\
\text { Tangential } \\
\text { Force, } \mathrm{F}_{\mathrm{T}} \\
\mathrm{N}\end{array}$ & $F_{T} / F_{A}$ & $\begin{array}{c}\text { Difference } \\
\text { in Axial } \\
\text { Force } \\
(\%)\end{array}$ & $\begin{array}{c}\text { Difference } \\
\text { in } \\
\text { Tangential } \\
\text { Force } \\
(\%)\end{array}$ & $\begin{array}{c}\text { Deviation } \\
\text { from } \\
\text { Experimental } \\
\text { Axial Force } \\
(\%)\end{array}$ & $\begin{array}{c}\text { Deviation from } \\
\text { Experimental } \\
\text { Tangential } \\
\text { Force } \\
(\%)\end{array}$ \\
\hline $\begin{array}{c}\text { Run } \\
\mathbf{1 0}\end{array}$ & 232 & 305 & 1.32 & - & - & -75.28 & -61.91 \\
\hline $\begin{array}{c}\text { Run } \\
\mathbf{1 1}\end{array}$ & 428 & 535 & 1.25 & 84 & 75 & -54.40 & -33.18 \\
\hline
\end{tabular}

The results indicate the importance of cohesion on the model calculated forces. The highest value for cohesion reported in the literature for shales is $38.4 \mathrm{MPa}$ and it is higher than the value used in the calculations. Both the cohesive strength and ductile behavior of the shale are very effective in increasing the modeled forces.

\subsubsection{Effect of Tensile Strength}

Once the predicted forces increased with cohesion control, another run was conducted with a lower initial value for tensile strength to investigate its effect on the cutting forces. Shale tensile strength was decreased by $50 \%$ to $7.2 \mathrm{MPa}$ since the value of $14.4 \mathrm{MPa}$ used in the previous run is close to the upper limit of tensile strength in shales (Run 12). Other properties were the same as in Run 11. As a result of reduction in tensile strength, the calculated values for axial and tangential forces were reduced by 13\% (Table 5.19). 
Table 5.19 Effect of tensile strength on axial and tangential forces on the cutter for Catoosa

Shale.

\begin{tabular}{|c|c|c|c|c|c|c|c|}
\hline & $\begin{array}{c}\text { Average } \\
\text { Axial } \\
\text { Force, } \mathrm{F}_{\mathrm{A}} \\
\mathrm{N}\end{array}$ & $\begin{array}{c}\text { Average } \\
\text { Tangential } \\
\text { Force, } \mathrm{F}_{\mathrm{T}} \\
\mathrm{N}\end{array}$ & $F_{T} / F_{A}$ & $\begin{array}{c}\text { Difference } \\
\text { in Axial } \\
\text { Force } \\
(\%)\end{array}$ & $\begin{array}{c}\text { Difference } \\
\text { in } \\
\text { Tangential } \\
\text { Force } \\
(\%)\end{array}$ & $\begin{array}{c}\text { Deviation } \\
\text { from } \\
\text { Experimental } \\
\text { Axial Force } \\
(\%)\end{array}$ & $\begin{array}{c}\text { Deviation } \\
\text { from } \\
\text { Experimental } \\
\text { Tangential } \\
\text { Force } \\
(\%)\end{array}$ \\
\hline $\begin{array}{c}\text { Run } \\
\mathbf{1 1}\end{array}$ & 428 & 535 & 1.25 & - & - & -54.40 & -33.18 \\
\hline $\begin{array}{c}\text { Run } \\
\mathbf{1 2}\end{array}$ & 372 & 467 & 1.26 & -13 & -13 & -60.37 & -41.67 \\
\hline
\end{tabular}

\subsubsection{Effect of Dilation Angle}

To understand the effect of dilation angle on calculated forces, a run was conducted with the same formation properties as Run 11 and the dilation angle was increased by $50 \%$ to 15 degrees from 10 degrees.

The net effect of dilation angle increase to 15 degrees was to lower the model calculated forces (Table 5.20). This reduction was more significant for the tangential force.

Table 5.20 Effect of dilation angle on axial and tangential forces on the cutter for Catoosa Shale.

\begin{tabular}{|c|c|c|c|c|c|c|c|}
\hline & $\begin{array}{c}\text { Average } \\
\text { Axial } \\
\text { Force, } \mathrm{F}_{\mathrm{A}} \\
\mathrm{N}\end{array}$ & $\begin{array}{c}\text { Average } \\
\text { Tangential } \\
\text { Force, } \mathrm{F}_{\mathrm{T}} \\
\mathrm{N}\end{array}$ & $F_{T} / F_{A}$ & $\begin{array}{c}\text { Difference } \\
\text { in Axial } \\
\text { Force } \\
(\%)\end{array}$ & $\begin{array}{c}\text { Difference } \\
\text { in } \\
\text { Tangential } \\
\text { Force } \\
(\%)\end{array}$ & $\begin{array}{c}\text { Deviation } \\
\text { from } \\
\text { Experimental } \\
\text { Axial Force } \\
(\%)\end{array}$ & $\begin{array}{c}\text { Deviation from } \\
\text { Experimental } \\
\text { Tangential } \\
\text { Force } \\
(\%)\end{array}$ \\
\hline $\begin{array}{c}\text { Run } \\
\mathbf{1 1}\end{array}$ & 428 & 535 & 1.25 & - & - & -54.40 & -33.18 \\
\hline $\begin{array}{c}\text { Run } \\
\mathbf{1 3}\end{array}$ & 382 & 427 & 1.12 & -11 & -20 & -59.30 & -46.67 \\
\hline
\end{tabular}

Since a change in cohesion results in the large changes in both axial and tangential forces, cohesion was increased from $20 \mathrm{MPa}$ (Run 11) to $30 \mathrm{MPa}$ (Run 13) to increase the accuracy of the model calculations. This modification in cohesion is inline with the properties of shales used 
in the literature. As a result of the increase in cohesion, the predicted axial and tangential forces increased by $31 \%$ and $25 \%$, respectively (Table 5.21 ).

Table 5.21 Effect of cohesion on axial and tangential forces on the cutter for Catoosa Shale.

\begin{tabular}{|c|c|c|c|c|c|c|c|}
\hline & $\begin{array}{c}\text { Average } \\
\text { Axial } \\
\text { Force, } \mathrm{F}_{\mathrm{A}} \\
\mathrm{N}\end{array}$ & $\begin{array}{c}\text { Average } \\
\text { Tangential } \\
\text { Force, } \mathrm{F}_{\mathrm{T}} \\
\mathrm{N}\end{array}$ & $F_{T} / F_{A}$ & $\begin{array}{c}\text { Difference } \\
\text { in Axial } \\
\text { Force } \\
(\%)\end{array}$ & $\begin{array}{c}\text { Difference } \\
\text { in } \\
\text { Tangential } \\
\text { Force } \\
(\%)\end{array}$ & $\begin{array}{c}\text { Deviation } \\
\text { from } \\
\text { Experimental } \\
\text { Axial Force } \\
(\%)\end{array}$ & $\begin{array}{c}\text { Deviation from } \\
\text { Experimental } \\
\text { Tangential } \\
\text { Force } \\
(\%)\end{array}$ \\
\hline $\begin{array}{c}\text { Run } \\
\mathbf{1 1}\end{array}$ & 428 & 535 & 1.25 & - & - & -54.40 & -33.18 \\
\hline $\begin{array}{c}\text { Run } \\
\mathbf{1 4}\end{array}$ & 562 & 671 & 1.19 & 31 & 25 & -40.12 & -16.20 \\
\hline
\end{tabular}

The dilation angle given in the literature for most rocks is between 0-15 degrees. Dilation angle has a reverse effect when its value was increased to 15 degrees. In order to improve the model predictions with dilation angle, new runs were conducted with the lower dilation angle values of five and zero degrees (Table 5.22).

Table 5.22 Dilation angle as a function of plastic shear strain (Runs $15 \& 16$ ).

\begin{tabular}{|c|c|c|}
\hline \multirow{2}{*}{$\begin{array}{c}\text { Plastic } \\
\text { Shear } \\
\text { Strain } \\
(\%)\end{array}$} & \multicolumn{2}{|c|}{$\begin{array}{c}\text { Dilation Angle } \\
\text { (degrees) }\end{array}$} \\
\cline { 2 - 3 } & Run 15 & Run 16 \\
\hline 0 & 5 & 0 \\
\hline 40 & 3 & 0 \\
\hline 100 & 3 & 0 \\
\hline
\end{tabular}

Net effect of dilation angle change was to increase tangential force more than the axial force and to create a difference in the magnitude of calculated forces (Table 5.23). 
Table 5.23 Effect of dilation angle on axial and tangential forces on the cutter for Catoosa Shale.

\begin{tabular}{|c|c|c|c|c|c|c|c|}
\hline & $\begin{array}{c}\text { Average } \\
\text { Axial } \\
\text { Force, } \mathrm{F}_{\mathrm{A}} \\
\mathrm{N}\end{array}$ & $\begin{array}{c}\text { Average } \\
\text { Tangential } \\
\text { Force, } \mathrm{F}_{\mathrm{T}} \\
\mathrm{N}\end{array}$ & $F_{T} / F_{A}$ & $\begin{array}{c}\text { Difference } \\
\text { in Axial } \\
\text { Force } \\
(\%)\end{array}$ & $\begin{array}{c}\text { Difference } \\
\text { in } \\
\text { Tangential } \\
\text { Force } \\
(\%)\end{array}$ & $\begin{array}{c}\text { Deviation } \\
\text { from } \\
\text { Experimental } \\
\text { Axial Force } \\
(\%)\end{array}$ & $\begin{array}{c}\text { Deviation from } \\
\text { Experimental } \\
\text { Tangential } \\
\text { Force } \\
(\%)\end{array}$ \\
\hline $\begin{array}{c}\text { Run } \\
\mathbf{1 4}\end{array}$ & 562 & 671 & 1.19 & - & - & -40.12 & -16.20 \\
\hline $\begin{array}{c}\text { Run } \\
\mathbf{1 5}\end{array}$ & 656 & 846 & 1.29 & 17 & 26 & -30.11 & 5.66 \\
\hline $\begin{array}{c}\text { Run } \\
\mathbf{1 6}\end{array}$ & 623 & 857 & 1.38 & 11 & 28 & -33.62 & 7.03 \\
\hline
\end{tabular}

\subsubsection{Effect of Plastic Tensile Strain at Failure Point}

A new run (Run 17) was conducted with increased failure point value for plastic tensile strain. To improve the results for the model calculations and reduce the deviation in forces, dilation angle value was increased to 10 degrees. The new value of plastic tensile strain at the failure point was twice (20\%) the value used in Run 14. The results for axial and tangential forces were increased by $18 \%$ and $16 \%$, respectively (Table 5.24). To increase the calculated forces further, a follow up run (Run 18) was conducted with a higher friction angle (Table 5.25). Under the conditions of increased plastic tensile strain value for rock failure and friction angle, a much better result was obtained. The increase in friction angle increased the value of axial force with a closer match to the experimental result; however, a higher deviation from the reported lab value was observed for the tangential force (Table 5.26). 
Table 5.24 Effect of tensile strain at failure point on axial and tangential forces on the cutter for Catoosa Shale.

\begin{tabular}{|c|c|c|c|c|c|c|c|}
\hline & $\begin{array}{c}\text { Average } \\
\text { Axial } \\
\text { Force, } \mathrm{F}_{\mathrm{A}} \\
\mathrm{N}\end{array}$ & $\begin{array}{c}\text { Average } \\
\text { Tangential } \\
\text { Force, } \mathrm{F}_{\mathrm{T}} \\
\mathrm{N}\end{array}$ & $F_{T} / F_{A}$ & $\begin{array}{c}\text { Difference } \\
\text { in Axial } \\
\text { Force } \\
(\%)\end{array}$ & $\begin{array}{c}\text { Difference } \\
\text { in } \\
\text { Tangential } \\
\text { Force } \\
(\%)\end{array}$ & $\begin{array}{c}\text { Deviation } \\
\text { from } \\
\text { Experimental } \\
\text { Axial Force } \\
(\%)\end{array}$ & $\begin{array}{c}\text { Deviation } \\
\text { from } \\
\text { Experimental } \\
\text { Tangential } \\
\text { Force } \\
(\%)\end{array}$ \\
\hline $\begin{array}{c}\text { Run } \\
\mathbf{1 4}\end{array}$ & 562 & 671 & 1.19 & - & - & -40.12 & -16.20 \\
\hline $\begin{array}{c}\text { Run } \\
\mathbf{1 7}\end{array}$ & 664 & 781 & 1.18 & 18 & 16 & -29.25 & -2.46 \\
\hline
\end{tabular}

Table 5.25 Friction angle relationships as a function of plastic shear strain (Runs $17 \& 18$ ).

\begin{tabular}{|c|c|c|}
\hline $\begin{array}{c}\text { Plastic } \\
\text { Shear } \\
\text { Strain } \\
(\%)\end{array}$ & \multicolumn{2}{|c|}{$\begin{array}{c}\text { Friction Angle } \\
\text { (degrees) }\end{array}$} \\
\cline { 2 - 3 } & Run 17 & Run 18 \\
\hline $\mathbf{0}$ & 20 & 25 \\
\hline $\mathbf{4 0}$ & 16 & 23 \\
\hline $\mathbf{1 0 0}$ & 16 & 23 \\
\hline
\end{tabular}

Table 5.26 Effect of friction angle on axial and tangential forces on the cutter for Catoosa Shale.

\begin{tabular}{|c|c|c|c|c|c|c|c|}
\hline & $\begin{array}{c}\text { Average } \\
\text { Axial } \\
\text { Force, } \mathrm{F}_{\mathrm{A}} \\
\mathrm{N}\end{array}$ & $\begin{array}{c}\text { Average } \\
\text { Tangential } \\
\text { Force, } \mathrm{F}_{\mathrm{T}} \\
\mathrm{N}\end{array}$ & $F_{T} / F_{A}$ & $\begin{array}{c}\text { Difference } \\
\text { in Axial } \\
\text { Force } \\
(\%)\end{array}$ & $\begin{array}{c}\text { Difference } \\
\text { in } \\
\text { Tangential } \\
\text { Force } \\
(\%)\end{array}$ & $\begin{array}{c}\text { Deviation from } \\
\text { Experimental } \\
\text { Axial Force } \\
(\%)\end{array}$ & $\begin{array}{c}\text { Deviation } \\
\text { from } \\
\text { Experimental } \\
\text { Tangential } \\
\text { Force } \\
(\%)\end{array}$ \\
\hline $\begin{array}{c}\text { Run } \\
\mathbf{1 7}\end{array}$ & 664 & 781 & 1.18 & - & - & -29.25 & -2.46 \\
\hline $\begin{array}{c}\text { Run } \\
\mathbf{1 8}\end{array}$ & 882 & 1120 & 1.27 & 33 & 43 & -6.03 & 39.88 \\
\hline
\end{tabular}

\subsubsection{Effect of Residual Dilation Angle}

A new run was conducted with different residual dilation angle values while keeping the other parameters the same as in Run 18. The variation in dilation angle as a function of plastic shear strain is given in Table 5.27 and plotted in Figure 5.5. 
Table 5.27 Dilation angle relationship as a function of plastic shear strain (Runs $18 \& 19$ ).

\begin{tabular}{|c|c|c|}
\hline \multirow{2}{*}{$\begin{array}{c}\text { Plastic } \\
\text { Shear } \\
\text { Strain } \\
(\%)\end{array}$} & \multicolumn{2}{|c|}{$\begin{array}{c}\text { Dilation Angle } \\
\text { (degrees) }\end{array}$} \\
\cline { 2 - 3 } & Run 18 & Run 19 \\
\hline $\mathbf{0}$ & 10 & 10 \\
\hline $\mathbf{4 0}$ & 5 & 3 \\
\hline $\mathbf{1 0 0}$ & 5 & 3 \\
\hline
\end{tabular}

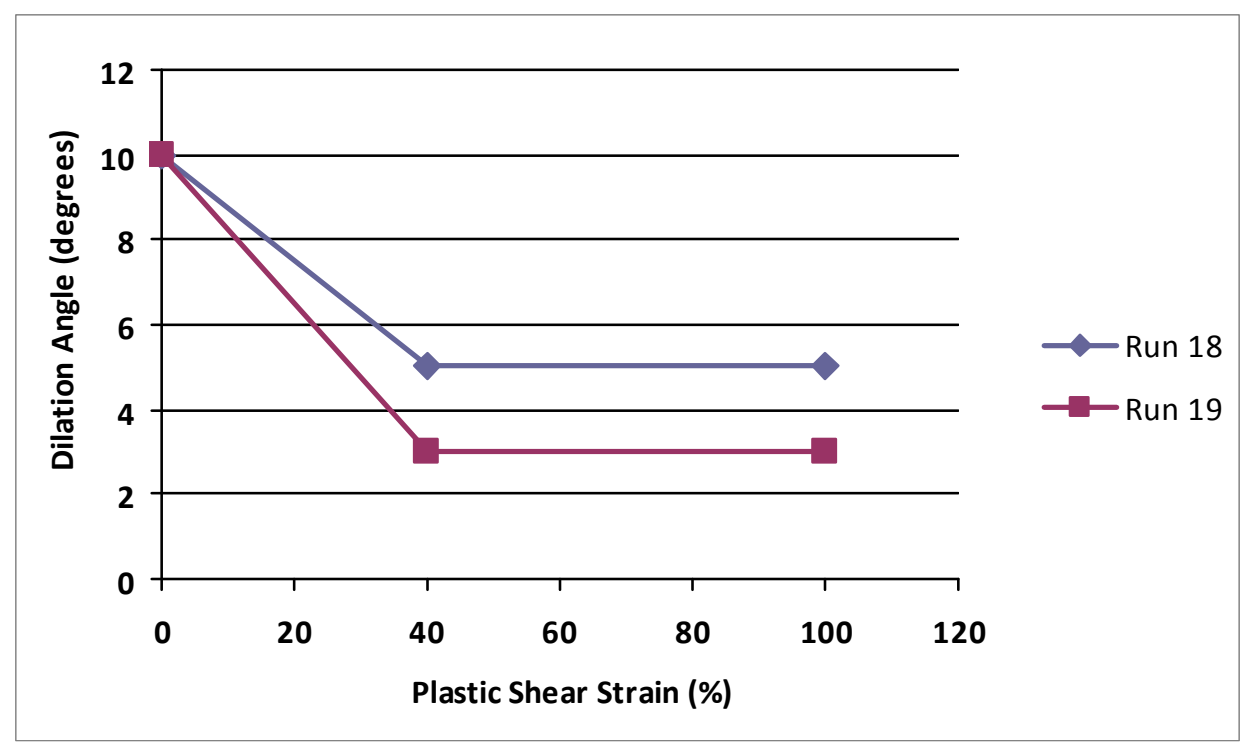

Figure 5.5 Variation in dilation angle as a function of shear strain (Runs 18 \& 19).

When the residual dilation angle was decreased to three degrees (Run 19), a decrease was observed in the calculated force values compared to the run conducted with five degrees of residual dilation angle value (Run 18). This result was consistent with other dilation angle sensitivity runs. 
Table 5.28 Effect of residual dilation angle on axial and tangential forces on the cutter for

\section{Catoosa Shale.}

\begin{tabular}{|c|c|c|c|c|c|c|c|}
\hline & $\begin{array}{c}\text { Average } \\
\text { Axial } \\
\text { Force, } \\
\mathrm{F}_{\mathrm{A}} \mathrm{N}\end{array}$ & $\begin{array}{c}\text { Average } \\
\text { Tangential } \\
\text { Force, } \mathrm{F}_{\mathrm{T}} \\
\mathrm{N}\end{array}$ & $F_{T} / F_{A}$ & $\begin{array}{c}\text { Difference } \\
\text { in Axial } \\
\text { Force } \\
(\%)\end{array}$ & $\begin{array}{c}\text { Difference } \\
\text { in } \\
\text { Tangential } \\
\text { Force } \\
(\%)\end{array}$ & $\begin{array}{c}\text { Deviation } \\
\text { from } \\
\text { Experimental } \\
\text { Axial Force } \\
(\%)\end{array}$ & $\begin{array}{c}\text { Deviation } \\
\text { from } \\
\text { Experimental } \\
\text { Tangential } \\
\text { Force } \\
(\%)\end{array}$ \\
\hline $\begin{array}{c}\text { Run } \\
\mathbf{1 8}\end{array}$ & 882 & 1120 & 1.27 & - & - & -6.03 & 39.88 \\
\hline $\begin{array}{c}\text { Run } \\
\mathbf{1 9}\end{array}$ & 847 & 1070 & 1.26 & -4 & -4 & -9.76 & 33.64 \\
\hline
\end{tabular}

Additional runs were conducted with four different dilation angles given in Table 5.29 and all other parameters were kept the same as in Run 17. The results indicated an improved match between calculated and experimental axial and tangential forces. The dilation angle appeared to be one of the important parameters to control the forces generated during the cutting process and a better match was obtained with five degrees of dilation angle where the absolute value of deviation was the same for both axial and tangential forces (Table 5.30).

Table 5.29 Dilation angle as a function of plastic shear strain (Runs 20, 21, 22 \& 23).

\begin{tabular}{|c|c|c|c|c|}
\hline $\begin{array}{c}\text { Plastic } \\
\text { Shear } \\
\text { Strain } \\
(\%)\end{array}$ & \multicolumn{4}{|c|}{$\begin{array}{c}\text { Dilation Angle } \\
\text { (degrees) }\end{array}$} \\
\cline { 2 - 5 } & Run 20 & Run 21 & Run 22 & Run 23 \\
\hline $\mathbf{0}$ & 3 & 5 & 6 & 10 \\
\hline $\mathbf{4 0}$ & 0 & 0 & 0 & 0 \\
\hline $\mathbf{1 0 0}$ & 0 & 0 & 0 & 0 \\
\hline
\end{tabular}


Table 5.30 Effect of dilation angle on axial and tangential forces on the cutter for Catoosa Shale.

\begin{tabular}{|c|c|c|c|c|c|c|c|}
\hline & $\begin{array}{c}\text { Average } \\
\text { Axial } \\
\text { Force, } \\
F_{\mathrm{A}} \mathrm{N}\end{array}$ & $\begin{array}{c}\text { Average } \\
\text { Tangential } \\
\text { Force, } \mathrm{F}_{\mathrm{T}}\end{array}$ & $F_{T} / F_{A}$ & $\begin{array}{c}\text { Difference } \\
\text { in Axial } \\
\text { Force } \\
(\%)\end{array}$ & $\begin{array}{c}\text { Difference } \\
\text { in } \\
\text { Tangential } \\
\text { Force } \\
(\%)\end{array}$ & $\begin{array}{c}\text { Deviation } \\
\text { from } \\
\text { Experimental } \\
\text { Axial Force } \\
(\%)\end{array}$ & $\begin{array}{c}\text { Deviation } \\
\text { from } \\
\text { Experimental } \\
\text { Tangential } \\
\text { Force } \\
(\%)\end{array}$ \\
\hline $\begin{array}{c}\text { Run } \\
\mathbf{1 7}\end{array}$ & 664 & 781 & 1.17 & - & - & -29.25 & -2.46 \\
\hline $\begin{array}{c}\text { Run } \\
\mathbf{2 0}\end{array}$ & 702 & 907 & 1.29 & 6 & 16 & -25.21 & 13.28 \\
\hline $\begin{array}{c}\text { Run } \\
\mathbf{2 1}\end{array}$ & 769 & 941 & 1.22 & 16 & 20 & -18.07 & 17.53 \\
\hline $\begin{array}{c}\text { Run } \\
\mathbf{2 2}\end{array}$ & 736 & 939 & 1.28 & 11 & 20 & -21.58 & 17.28 \\
\hline $\begin{array}{c}\text { Run } \\
\mathbf{2 3}\end{array}$ & 738 & 884 & 1.20 & 11 & 13 & 21.37 & 10.41 \\
\hline
\end{tabular}

The results of dilation angle sensitivity runs indicated that between zero and five degrees, the forces increase proportionally with the increase in dilation angle. However, between six and 15 degrees, dilation angle has a reverse effect on forces causing them to decrease as the angle increases.

\subsubsection{Effect of Residual Friction Angle}

Runs were conducted with different friction angle residual values while keeping the cohesion value at $30 \mathrm{Mpa}$, friction angle at 20 degrees and using a dilation angle of five degrees. Friction angle variation as a function of plastic shear strain for all three runs are shown in Table 5.31 and plotted in Figure 5.6. 
Table 5.31 Friction angle relationship as a function of plastic shear strain (Runs 21, $24 \& 25$ ).

\begin{tabular}{|c|c|c|c|}
\hline \multirow{2}{*}{$\begin{array}{c}\text { Plastic } \\
\text { Shear } \\
\text { Strain } \\
(\%)\end{array}$} & \multicolumn{3}{|c|}{$\begin{array}{c}\text { Friction Angle } \\
\text { (degrees) }\end{array}$} \\
\cline { 2 - 4 } & Run 24 & Run 21 & Run 25 \\
\hline $\mathbf{0}$ & 20 & 20 & 20 \\
\hline $\mathbf{4 0}$ & 8 & 16 & 18 \\
\hline $\mathbf{1 0 0}$ & 8 & 16 & 18 \\
\hline
\end{tabular}

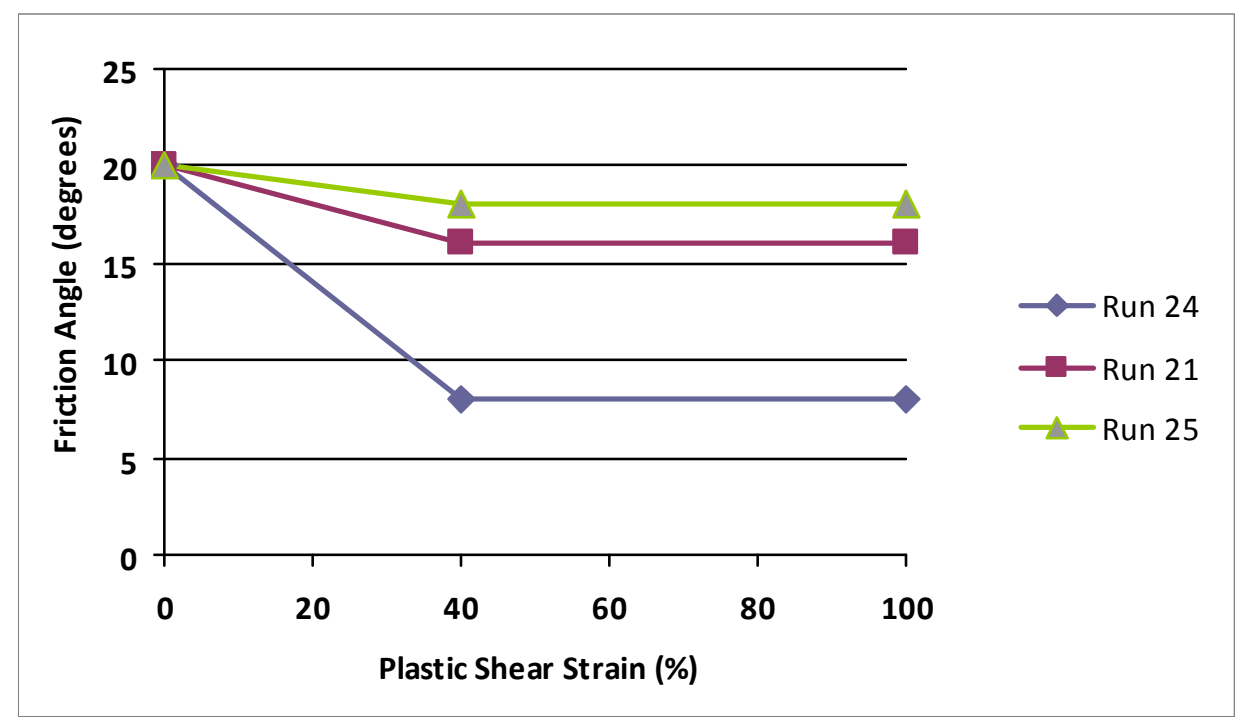

Figure 5.6 Variation in friction angle as a function of shear strain (Runs 21, 24 \& 25).

When residual friction angle was decreased to eight degrees, a decrease in both calculated forces was observed whereas when the residual friction angle was increased to 18 degrees, only tangential force was increased (Table 5.32). As a result of changes made in residual friction angle, the results were not improved. 
Table 5.32 Effect of residual friction angle on axial and tangential forces on the cutter for

Catoosa Shale.

\begin{tabular}{|c|c|c|c|c|c|c|c|}
\hline & $\begin{array}{c}\text { Average } \\
\text { Axial } \\
\text { Force, } F_{A} \\
N\end{array}$ & $\begin{array}{c}\text { Average } \\
\text { Tangential } \\
\text { Force, } F_{\mathrm{T}} \\
\mathrm{N}\end{array}$ & $F_{T} / F_{A}$ & $\begin{array}{c}\text { Difference } \\
\text { in Axial } \\
\text { Force } \\
(\%)\end{array}$ & $\begin{array}{c}\text { Difference } \\
\text { in } \\
\text { Tangential } \\
\text { Force } \\
(\%)\end{array}$ & $\begin{array}{c}\text { Deviation from } \\
\text { Experimental } \\
\text { Axial Force } \\
(\%)\end{array}$ & $\begin{array}{c}\text { Deviation from } \\
\text { Experimental } \\
\text { Tangential } \\
\text { Force } \\
(\%)\end{array}$ \\
\hline $\begin{array}{c}\text { Run } \\
\mathbf{2 1}\end{array}$ & 769 & 941 & 1.22 & - & - & -18.07 & 17.53 \\
\hline $\begin{array}{c}\text { Run } \\
\text { 24 }\end{array}$ & 671 & 842 & 1.25 & -13 & -11 & -28.51 & 5.16 \\
\hline $\begin{array}{c}\text { Run } \\
\text { 25 }\end{array}$ & 761 & 986 & 1.30 & -1 & +5 & -18.92 & 23.15 \\
\hline
\end{tabular}

\subsubsection{Effect of Residual Cohesion}

Cohesion value was assigned as zero at the point where the rock completely failed in the previous runs and for Run 25; residual cohesion was assigned as $5 \mathrm{MPa}$. Cohesion and plastic shear strain relationship used in Run 25 is given in Table 5.33. Other parameters are the same as in Run 20.

Table 5.33 Residual cohesion relationship as a function of plastic shear strain (Runs $21 \& 26$ ).

\begin{tabular}{|c|c|c|}
\hline \multirow{2}{*}{$\begin{array}{c}\text { Plastic } \\
\text { Shear } \\
\text { Strain } \\
(\%)\end{array}$} & \multicolumn{2}{|c|}{$\begin{array}{c}\text { Cohesion } \\
\text { (MPa) }\end{array}$} \\
\cline { 2 - 3 } & Run 21 & Run 26 \\
\hline $\mathbf{0}$ & 30 & 30 \\
\hline $\mathbf{4 0}$ & 0 & 5 \\
\hline $\mathbf{1 0 0}$ & 0 & 5 \\
\hline
\end{tabular}

In Run 26, the change in axial force is negligible whereas the error for tangential force was increased by approximately $10 \%$ (Table 5.34). 
Table 5.34 Effect of residual cohesion on axial and tangential forces on the cutter for Catoosa

Shale.

\begin{tabular}{|c|c|c|c|c|c|c|c|}
\hline & $\begin{array}{l}\text { Averag } \\
\text { e Axial } \\
\text { Force, } \\
F_{A} N\end{array}$ & $\begin{array}{c}\text { Average } \\
\text { Tangential } \\
\text { Force, } \mathrm{F}_{\mathrm{T}} \\
\mathrm{N}\end{array}$ & $F_{T} / F_{A}$ & $\begin{array}{c}\text { Difference } \\
\text { in Axial } \\
\text { Force } \\
(\%)\end{array}$ & $\begin{array}{l}\text { Difference } \\
\text { in } \\
\text { Tangential } \\
\text { Force } \\
(\%)\end{array}$ & $\begin{array}{l}\text { Deviation } \\
\text { from } \\
\text { Experimental } \\
\text { Axial Force } \\
(\%)\end{array}$ & $\begin{array}{c}\text { Deviation } \\
\text { from } \\
\text { Experimental } \\
\text { Tangential } \\
\text { Force } \\
(\%) \\
\end{array}$ \\
\hline $\begin{array}{c}\text { Run } \\
21\end{array}$ & 769 & 941 & 1.22 & - & - & -18.07 & 17.53 \\
\hline $\begin{array}{c}\text { Run } \\
26\end{array}$ & 767 & 1020 & 1.33 & -0.3 & +8.4 & -18.28 & 27.39 \\
\hline
\end{tabular}

Run 27 was conducted by increasing the plastic tensile strain at the point of failure to $30 \%$ (Table 5.35) while keeping the shear strain at $40 \%$ and the material properties the same as in Run 21. Increasing the tensile strain at the point of failure was expected to increase the forces, and provide a better match with the experimental results. However, its impact on the results was minimal; it decreased the axial force by $3 \%$ and increased the tangential force by $2 \%$ (Table 5.36).

Table 5.35 Tensile strength as a function of plastic tensile strain (Run 27).

\begin{tabular}{|c|c|}
\hline $\begin{array}{c}\text { Plastic } \\
\text { Tensile Strain } \\
(\%)\end{array}$ & $\begin{array}{c}\text { Tensile } \\
\text { Strength } \\
\text { (MPa) }\end{array}$ \\
\hline $\mathbf{0}$ & 14.4 \\
\hline $\mathbf{3 0}$ & 0 \\
\hline $\mathbf{1 0 0}$ & 0 \\
\hline
\end{tabular}


Table 5.36 Effect of tensile strain at failure point on axial and tangential forces on the cutter for

Catoosa Shale.

\begin{tabular}{|c|c|c|c|c|c|c|c|}
\hline & $\begin{array}{c}\text { Average } \\
\text { Axial } \\
\text { Force, } \mathrm{F}_{\mathrm{A}} \\
\mathrm{N}\end{array}$ & $\begin{array}{c}\text { Average } \\
\text { Tangential } \\
\text { Force, } \mathrm{F}_{\mathrm{T}} \\
\mathrm{N}\end{array}$ & $F_{T} / F_{A}$ & $\begin{array}{c}\text { Difference } \\
\text { in Axial } \\
\text { Force } \\
(\%)\end{array}$ & $\begin{array}{c}\text { Difference } \\
\text { in } \\
\text { Tangential } \\
\text { Force } \\
(\%)\end{array}$ & $\begin{array}{c}\text { Deviation from } \\
\text { Experimental } \\
\text { Axial Force } \\
(\%)\end{array}$ & $\begin{array}{c}\text { Deviation from } \\
\text { Experimental } \\
\text { Tangential } \\
\text { Force } \\
(\%)\end{array}$ \\
\hline $\begin{array}{c}\text { Run } \\
\mathbf{2 1}\end{array}$ & 769 & 941 & 1.22 & - & - & -18.07 & 17.53 \\
\hline $\begin{array}{c}\text { Run } \\
\mathbf{2 7}\end{array}$ & 747 & 957 & 1.28 & -3 & +2 & -20.41 & 19.52 \\
\hline
\end{tabular}

Based on the runs conducted with the model, the effects of each parameter are summarized in Table 5.37. The changes in friction angle, cohesion and shear strain value at the point of shale failure have more pronounced effect on calculated forces.

Table 5.37 Effect of property changes on axial and tangential forces.

\begin{tabular}{|c|c|c|c|}
\hline $\begin{array}{c}\text { Model } \\
\text { Parameters }\end{array}$ & $\begin{array}{l}\text { Change in } \\
\text { Property }\end{array}$ & $\begin{array}{l}\text { Change in } \\
\text { Axial Force }\end{array}$ & $\begin{array}{c}\text { Change in } \\
\text { Tangential Force }\end{array}$ \\
\hline Friction Angle & $\uparrow$ & $\uparrow$ & $\uparrow$ \\
\hline $\begin{array}{c}\text { Residual Friction } \\
\text { Angle }\end{array}$ & $\uparrow$ & $\uparrow$ & $\uparrow$ \\
\hline Cohesion & $\uparrow$ & $\uparrow$ & $\uparrow$ \\
\hline Residual Cohesion & $\uparrow$ & $\downarrow$ & $\uparrow$ \\
\hline Dilation Angle & $\begin{array}{l}\uparrow \\
\uparrow\end{array}$ & $\begin{array}{l}\uparrow \\
\downarrow\end{array}$ & $\begin{array}{l}\uparrow \\
\downarrow\end{array}$ \\
\hline $\begin{array}{l}\text { Residual Dilation } \\
\text { Angle }\end{array}$ & $\begin{array}{l}\uparrow \\
\uparrow\end{array}$ & $\begin{array}{l}\uparrow \\
\downarrow\end{array}$ & $\begin{array}{l}\uparrow \\
\downarrow\end{array}$ \\
\hline Tensile Strength & $\uparrow$ & $\uparrow$ & $\uparrow$ \\
\hline Velocity & $\uparrow$ & $\uparrow$ & $\uparrow$ \\
\hline Tensile Strain & $\begin{array}{l}\uparrow \\
\uparrow\end{array}$ & $\begin{array}{l}\uparrow \\
\leftrightarrow\end{array}$ & $\begin{array}{l}\uparrow \\
\leftrightarrow\end{array}$ \\
\hline Shear Strain & $\uparrow$ & $\uparrow$ & $\uparrow$ \\
\hline
\end{tabular}




\subsubsection{Additional Runs Conducted with 2.07 MPa Confining Pressure}

Additional runs were designed with the model to improve the calculated forces and reduce the deviations from the experimental results (Table 5.38).

Table 5.38 Material properties and the results for additional runs conducted with $2.07 \mathrm{MPa}$ confining pressure.

\begin{tabular}{|c|c|c|c|c|c|c|c|c|c|c|c|c|c|c|c|}
\hline$\underset{\sim}{\stackrel{\infty}{Z}}$ & 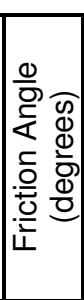 & 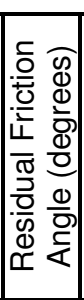 & 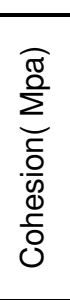 & 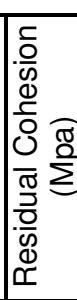 & 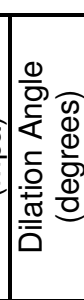 & 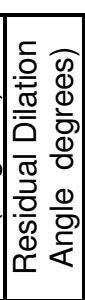 & 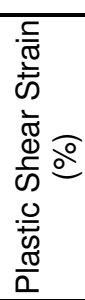 & 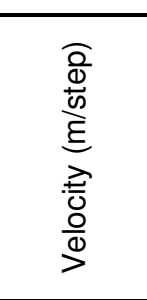 & 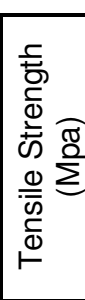 & 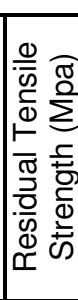 & 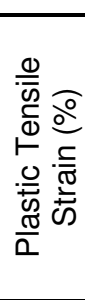 & $\begin{array}{l}z \\
0 \\
0 \\
0 \\
\frac{0}{4} \\
. \frac{\pi}{x} \\
\frac{x}{4}\end{array}$ & 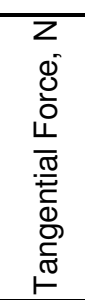 & 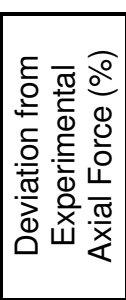 & 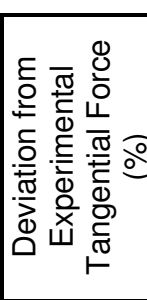 \\
\hline 28 & 20 & 16 & 30 & 0 & 5 & 0 & 40 & DOE-07 & 14.4 & 0 & 20 & 678 & 853 & -27.76 & 6.53 \\
\hline 29 & 20 & 16 & 35 & 0 & 5 & 0 & 40 & & 14. & ( & 2 & 761 & 977 & 18.92 & 2.02 \\
\hline 30 & 20 & 16 & 35 & 0 & 15 & 13 & 4 & $00 \mathrm{E}-0$ & 14.4 & & 2 & 549 & 603 & 41.51 & 24.69 \\
\hline 31 & 25 & 20 & 30 & 0 & 10 & 3 & 40 & 00E-07 & 14.4 & & 2 & 820 & 983 & -12.63 & 22.77 \\
\hline 32 & 25 & 20 & 30 & 0 & 10 & 0 & 40 & 00E-07 & 14.4 & 0 & 20 & 764 & 932 & -18.60 & 16.40 \\
\hline 33 & 30 & 20 & 30 & 0 & 10 & 0 & 40 & 0E-07 & 14.4 & 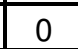 & 2 & 906 & 1140 & -3.47 & 42.38 \\
\hline 34 & 30 & 24 & 30 & 0 & 10 & 0 & 40 & E-07 & 14.4 & ( & 20 & 945 & 1200 & 0.68 & 49.87 \\
\hline 35 & 30 & 24 & 30 & 0 & 15 & 0 & 40 & 0 E-07 & 14.4 & 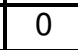 & 20 & 923 & 1130 & -1.66 & 41.13 \\
\hline 36 & 30 & 24 & 30 & 0 & 15 & 5 & & & 14 & 0 & 2 & 861 & 1020 & -8.27 & 27.39 \\
\hline 37 & 20 & 16 & 38 & 0 & 15 & 13 & 40 & OE-07 & 14.4 & T & 20 & 640 & 764 & -31.81 & -4.58 \\
\hline 38 & 25 & 16 & 35 & c & 15 & 13 & 40 & E-07 & 14 & & 20 & 662 & 762 & -29.47 & -4.83 \\
\hline 39 & 25 & 18 & 35 & 0 & 15 & 13 & 40 & & 14.4 & 0 & 2 & 706 & 727 & -24.78 & -9.20 \\
\hline 40 & 25 & 19 & 35 & 0 & 15 & 13 & 40 & E-07 & 14.4 & 0 & 20 & 765 & 844 & -18.49 & 5.41 \\
\hline & 25 & 20 & 35 & 0 & 15 & 13 & 40 & $4.00 \mathrm{E}-07$ & 14.4 & & 20 & 772 & 883 & -17.75 & 10.28 \\
\hline
\end{tabular}

Initially, the velocity parameter was decreased to $2 \times 10^{-7} \mathrm{~m} / \mathrm{step}$ due to higher increase observed in tangential force compared to the axial force with the velocity of $4 \times 10^{-7} \mathrm{~m} / \mathrm{step}$ used in the previous runs. Therefore, a velocity value of $2 \times 10^{-7} \mathrm{~m} / \mathrm{step}$ was used to eliminate discrepancy in results. Approximately 10\% of decrease was observed in both forces (Run 28). When cohesion was increased to $35 \mathrm{MPa}$ in order to decrease the deviation from experimental axial force, an average error of $20 \%$ was observed (Run 29). To better match the results between the experimental data and the model predicted forces; other parameters such as dilation angle and 
friction angle were adjusted. When the 15 degrees dilation angle was used (Run 30), forces decreased and this increased the deviation from experimental forces. Therefore, the dilation angle was decreased to 10 degree and friction angle was increased to 25 degrees (Run 31). An increase in forces was achieved; however, the tangential force was $22 \%$ higher than the target value. When the residual dilation angle was decreased to zero degree, a $16 \%$ deviation was observed for tangential force while the deviation for axial force was 18\% (Run 32).

Additional runs were conducted to decrease the deviation between calculated and measured forces. Friction angle was increased to 30 degrees resulting in an exact match for the axial force. However, a very high increase was observed in the tangential force (Runs 33 and 34). To decrease tangential load, the dilation angle was increased to 15 degree (Run 35). When the residual dilation angle was zero, the changes in results were not significant; however, when a five degrees was used for the residual dilation angle, tangential force deviation was decreased to $27 \%$ (Runs 35 and 36). With a friction angle of 30 degrees, the tangential force deviation seemed to be high. Therefore friction angle was reduced to 20 degrees and the forces were controlled with cohesion, its value was increased to its possible highest value, $38 \mathrm{MPa}$ (Run 37). Velocity was assigned as $4 \times 10^{-7} \mathrm{~m} / \mathrm{step}$ to save run time since no significant decrease in the deviations of both forces was observed in the results obtained with $2 \times 10^{-7} \mathrm{~m} / \mathrm{step}$ velocity. Dilation angle was increased to prevent an excessive increase in forces since lower dilation angle (between zero and five degrees) was known to increase tangential force more than axial force. As a result, a considerable amount of decrease was observed in both forces in this run (Run 37). Tangential force error was around 5\% but, axial force was deviated by $31 \%$ from the experimental result. Thus, friction angle and cohesion were changed in Run 38 since they are the two effective controls in favor of axial force. In Run 38, the deviation for axial force was reduced to $29 \%$. 
Since tangential force was very close to the experimental value, only axial force was to be adjusted. To achieve that, the residual friction angle was increased resulting in a moderate increase in forces (Runs 39, 40 and 41). When 19 degree was used for the friction angle, the deviation of $18 \%$ for axial and $5 \%$ for tangential force was achieved.

\subsubsection{Runs Conducted at 6.89 MPa Confining Pressure}

The results from the runs conducted with 300 psi confining pressure indicated that the smallest overall deviations in force calculations were obtained with parameters used in Run 40. The same properties were used initially for simulating Experiment $2^{(2)}$ under 1000 psi confining pressure. All the runs conducted are listed in Table 5.39 below.

Table 5.39 Runs conducted with 6.89 MPa confining pressure.

\begin{tabular}{|c|c|c|c|c|c|c|c|c|c|c|c|c|c|c|c|c|}
\hline 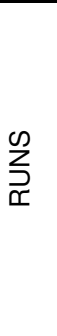 & 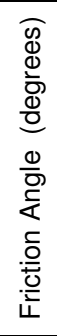 & 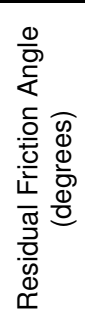 & 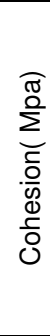 & 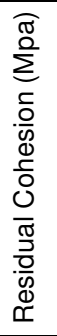 & 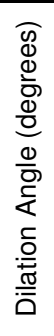 & 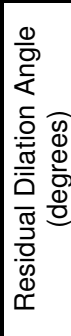 & 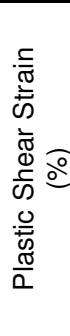 & 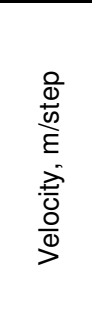 & 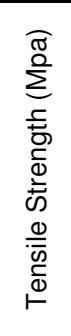 & 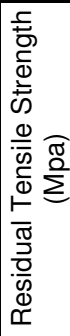 & 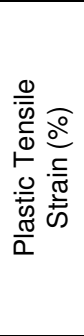 & 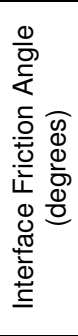 & $\begin{array}{l}z \\
0 \\
0 \\
0 \\
\frac{0}{4} \\
\frac{0}{.0} \\
\frac{\pi}{x}\end{array}$ & 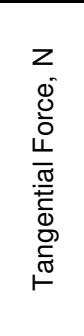 & 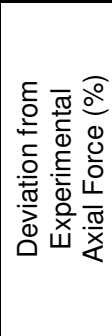 & 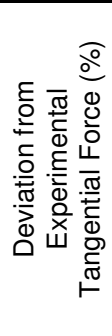 \\
\hline 42 & 25 & 19 & 35 & 0 & 15 & 13 & 40 & $4 \mathrm{E}-07$ & 14.4 & 0 & 20 & 36 & 814 & 923 & -33.94 & -19.57 \\
\hline 43 & 25 & 19 & 35 & 0 & 15 & 13 & 40 & $4 \mathrm{E}-07$ & 14.4 & 0 & 20 & 40 & 781 & 896 & -36.62 & -21.93 \\
\hline 44 & 25 & 20 & 35 & 0 & 15 & 13 & 40 & $4 \mathrm{E}-07$ & 14.4 & 0 & 20 & 36 & 876 & 1020 & -28.91 & -11.12 \\
\hline 45 & 25 & 20 & 35 & 0 & 15 & 13 & 40 & $4 \mathrm{E}-07$ & 14.4 & 0 & 20 & 40 & 772 & 885 & -37.3 & -22.9 \\
\hline 46 & 25 & 19 & 35 & 0 & 5 & 0 & 40 & $4 \mathrm{E}-07$ & 14.4 & 0 & 20 & 36 & 1010 & 1330 & -18.03 & 15.89 \\
\hline 47 & 25 & 19 & 35 & 0 & 5 & 0 & 40 & $4 \mathrm{E}-07$ & 14.4 & 0 & 20 & 40 & 962 & 1290 & -21.93 & 12.40 \\
\hline 48 & 25 & 19 & 35 & 0 & 5 & 0 & 40 & $4 \mathrm{E}-07$ & 14.4 & 0 & 20 & 20 & 917 & 1340 & -25.58 & 16.76 \\
\hline
\end{tabular}

The interface friction angle between Catoosa Shale and PDC cutter was calculated as 36 degrees for 1000 psi confining pressure using Equation 5.1. As a result of Run 42, the average forces predicted by the model were less than the experiments. Therefore, a 40 degree interface 
friction angle was used in the next run (Run 43) to investigate its effect on forces. Approximately $3 \%$ increase was observed in both axial and tangential forces. Since the deviation from experimental result was over $30 \%$ for the axial force, the residual friction angle was increased (Runs 44 and 45). The calculated results for forces were improved by around 10\%. To decrease the deviation from the experimental results, another run (Run 46) was conducted with the same parameters as in Run 42, except for the dilation angle. The dilation angle was decreased to five degrees resulting in increases for both axial and tangential forces. Other runs were conducted with the same parameters but with 20 degrees and 40 degrees interface friction angles (Runs 47 and 48). A good match with experimental results was obtained in Run 47.

\subsubsection{Runs Conducted at 20.7 MPa Confining Pressure}

In this section, runs conducted with 3000 psi confining pressure are presented. The interface friction angle between the Catoosa Shale and PDC cutter was calculated as 34 degrees

for 3000 psi confining pressure using Equation 5.1. All the runs conducted are listed in Table 5.40 . 
Table 5.40 Runs conducted with 3000 psi confining pressure.

\begin{tabular}{|c|c|c|c|c|c|c|c|c|c|c|c|c|c|c|c|c|}
\hline 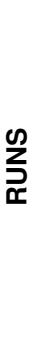 & 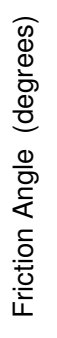 & 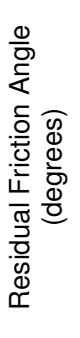 & 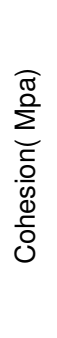 & 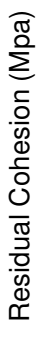 & 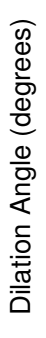 & 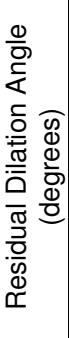 & 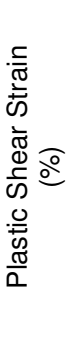 & $\begin{array}{l}\frac{0}{0} \\
\frac{0}{0} \\
E \\
\frac{D}{0} \\
\frac{0}{0} \\
>\end{array}$ & 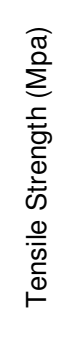 & 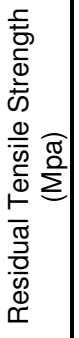 & 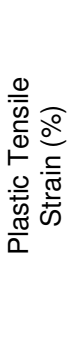 & 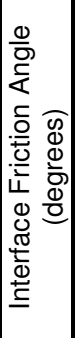 & 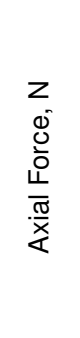 & 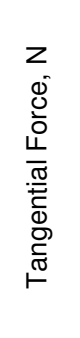 & 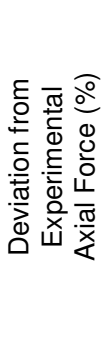 & 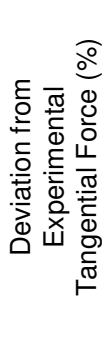 \\
\hline 49 & 25 & 19 & 35 & 0 & 5 & 0 & 40 & 4E-07 & 14.4 & 0 & 20 & 40 & 1190 & 1560 & -41.84 & -27.09 \\
\hline 50 & 25 & 19 & 35 & 0 & 5 & 0 & 40 & $4 \mathrm{E}-07$ & 14.4 & 0 & 20 & 34 & 1340 & 1660 & -34.5 & -22.4 \\
\hline 51 & 25 & 20 & 35 & 0 & 5 & 0 & 40 & $4 \mathrm{E}-07$ & 14.4 & 0 & 20 & 34 & 1340 & 1680 & -34.5 & -21.5 \\
\hline 52 & 30 & 24 & 35 & 0 & 15 & 13 & 40 & $4 \mathrm{E}-07$ & 14.4 & 0 & 20 & 34 & 1200 & 1460 & -41.35 & -31.76 \\
\hline 53 & 30 & 24 & 35 & 0 & 15 & 13 & 45 & 4E-07 & 14.4 & 0 & 25 & 34 & 1190 & 1550 & -41.84 & -27.56 \\
\hline 54 & 30 & 24 & 35 & 0 & 5 & 0 & 40 & 4E-07 & 14.4 & 0 & 20 & 34 & 1440 & 2130 & -29.63 & -0.45 \\
\hline 55 & 30 & 25 & 35 & 0 & 5 & 0 & 40 & 4E-07 & 14.4 & 0 & 20 & 34 & 1480 & 2120 & -27.67 & -0.92 \\
\hline 56 & 30 & 27 & 35 & 0 & 5 & 0 & 40 & 4E-07 & 14.4 & 0 & 20 & 34 & 1560 & 2250 & -23.76 & 5.16 \\
\hline 57 & 30 & 28 & 35 & 0 & 5 & 0 & 40 & 4E-07 & 14.4 & 0 & 20 & 34 & 1480 & 2260 & -27.67 & 5.63 \\
\hline 58 & 30 & 28 & 35 & 0 & 5 & 0 & 40 & 4E-07 & 14.4 & 0 & 20 & 40 & 1530 & 2360 & -25.23 & 10.30 \\
\hline 59 & 30 & 24 & 35 & 0 & 5 & 0 & 45 & 4E-07 & 14.4 & 0 & 25 & 34 & 1670 & 2230 & -18.38 & 4.23 \\
\hline 60 & 30 & 27 & 35 & 0 & 5 & 0 & 45 & $4 \mathrm{E}-07$ & 14.4 & 0 & 25 & 34 & 1650 & 2370 & -19.36 & 10.77 \\
\hline 61 & 30 & 24 & 36 & 0 & 5 & 0 & 40 & $4 \mathrm{E}-07$ & 14.4 & 0 & 20 & 34 & 1600 & 2190 & -21.81 & 2.34 \\
\hline 62 & 30 & 25 & 36 & 0 & 5 & 0 & 40 & 4E-07 & 14.4 & 0 & 20 & 34 & 1460 & 2090 & -28.65 & -2.32 \\
\hline
\end{tabular}

The initial run (Run 49) at 20.7 Mpa (3000 psi) was conducted with the shale properties used in Run 47 conducted at $6.89 \mathrm{MPa}$ (1000 psi) confining pressure since Run 47 had a good match with Experiment $2^{(2)}$. However, when the confining pressure was 3000 psi, the model predicted forces did not match with the forces measured in the experiment. The calculated deviation was around $42 \%$ for the axial force. Next, Run 50 was conducted with the calculated interface friction angle value of 34 degrees for 3000 psi and model calculated forces were improved by 5\%. When the residual friction angle was increased to 20 degrees, no significant improvement was observed in the calculated forces (Run 51). To improve the results of force calculations in the model, a run (Run 52) was conducted with higher friction and dilation angles. The deviations from experimental results were $40 \%$ and $30 \%$ for axial and tangential loads, 
respectively. To increase forces, shale ductility was increased (Run 53) and the deviation for the tangential force was improved by $4 \%$. In Run 54, the dilation angle was decreased to five degrees and the tangential force was closely matched, but the axial force value was still lower than the experimental measurement. More runs were conducted to increase the axial force and to have a better match. Previously, the friction angle was observed as a good control for the axial force. Only the residual value of the friction angle was increased since the friction angle assigned in the model was already high (Runs 55, 56 and 57). When the residual friction angle was 25 degrees, the axial force was increased by $2 \%$ and when it was 27 degrees both forces were increased by $4 \%$. However, when it was increased to 28 degrees, a drop in the axial force was observed. The best result was obtained when the friction angle dropped from 30 to 27 degrees yielding 23\% and 5\% error for axial and tangential forces, respectively. Interface friction angle was increased to 40 degrees similar to runs with 300 psi to determine its impact on the results (Run 58). No significant change was observed in the results. In the next run, the ductility of the shale was increased and the plastic shear and tensile strain for the failure point were increased to $45 \%$ and $25 \%$, respectively (Run 59) and other parameters were kept same as in Run 54. In Run 59, the calculated deviations were $18 \%$ and $4 \%$ for axial and tangential loads. Since increasing ductility resulted in an improvement, another run (Run 60) was conducted with same shear and tensile strain values using the same parameters as in Run 56. The calculated forces increased by $5 \%$, but the results were poorer than the results of Run 59. Run 61 was conducted by increasing the cohesion to $36 \mathrm{MPa}$ and decreasing the plastic shear and tensile strain at the failure point to $40 \%$ and $20 \%$, respectively, while keeping the other parameters the same as in Run 59. Tangential force deviation was around $2 \%$ and axial force deviation was $21 \%$. Run 62 
was conducted with 25 degrees of residual friction angle, however, no improvement was observed in the results.

\subsubsection{Runs with the Same Set of Properties for Different Confining Pressures}

In the previous sections, the best matches with experimental results were obtained for different confining pressures. The best result for 300 psi was obtained using a friction angle of 25 degrees, a cohesion of $35 \mathrm{MPa}$ and a dilation angle of 15 degrees (Run 40). The model results yielded a higher deviation from experimental results when the same material properties were used with 1000 psi confining pressure. However, when the dilation angle was decreased to five degrees, a better match was obtained with $18 \%$ and $15 \%$ errors for axial and tangential forces, respectively (Run 46). At 3000 psi pressure, when the friction angle and its residual value were increased to 30 and 27 degrees, respectively, $23 \%$ and 5\% errors were obtained for axial and tangential forces, respectively (Run 56). When cohesion was increased to 36 degrees, $21 \%$ error was calculated for axial force while $2 \%$ error was obtained for tangential force (Run 61).

Rocks behave differently under pressure. Although they may be brittle under low stress conditions, they can show ductility under high confining stress. Ductility in rock may occur with sufficient high confining pressure. As a result, model runs were conducted with the same set of properties for all three confining pressures and the ductility of the rock was decreased as the pressure reduced from 3000 psi to 300 psi. The goal was to use the same set of properties to simulate the experiments conducted at three different pressures with Catoosa shale. The runs conducted for this purpose are tabulated in Table 5.41.

Initial properties were selected from the run that yielded the best match with the experimental results for 3000 psi confining pressure. Since the interface friction angle was 34 
degrees in Run 63, next run (Run 64) was conducted with an angle of 40 degrees. The change in interface friction angle resulted in $2 \%$ decrease in results of forces. When shear strain at the failure point was increased to $45 \%$, the deviation for axial and tangential forces were $23 \%$ and $8 \%$, respectively.

Runs were conducted with same properties for 1000 psi confining pressure with both 36 and 40 degrees interface friction angles. The least errors in the results for axial and tangential forces were observed when the shale failed completely at $30 \%$ shear strain. The same formation properties were used for the next run with 40 degrees interface friction angle. An average of $22 \%$ deviation from experimental results was obtained for axial and tangential forces.

Additionally, four runs were conducted with 300 psi confining pressure where shale had $20 \%, 22 \%, 23 \%$ and $25 \%$ plastic shear strain values at the point of failure. The least deviation in the calculated forces was obtained with $22 \%$ shear strain. The results of the model deviated by $25 \%$ and $22 \%$ from the experimental results for axial and tangential forces, respectively, at the end of one revolution of the cutter. The results from force calculations with the model at three confining pressures are tabulated in Table 5.41 and the results from the model were compared with the experimental results as shown in Table 5.42 and plotted in Figure 5.7. 
Table 5.41 Runs conducted with 300 psi, 1000 psi and 3000 psi confining pressure.

\begin{tabular}{|c|c|c|c|c|c|c|c|c|c|c|c|c|c|c|c|c|c|c|c|c|c|c|c|c|c|}
\hline \multirow[b]{3}{*}{ 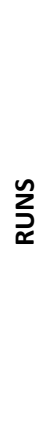 } & \multirow{2}{*}{\multicolumn{13}{|c|}{ Parameters }} & \multicolumn{12}{|c|}{ RESULTS } \\
\hline & & & & & & & & & & & & & & \multicolumn{4}{|c|}{ Quarter cut } & \multicolumn{4}{|c|}{ Half Cut } & \multicolumn{4}{|c|}{ Full Cut (1 revolution) } \\
\hline & 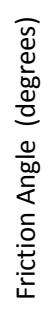 & 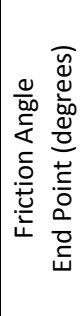 & 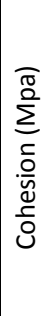 & 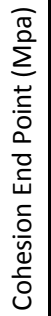 & $\begin{array}{l}\bar{y} \\
\frac{d}{d} \\
\frac{0}{0} \\
\frac{0}{0} \\
\frac{0}{00} \\
\frac{0}{4} \\
\frac{0}{0} \\
\frac{0}{0} \\
\frac{\pi}{0}\end{array}$ & 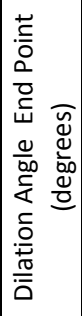 & 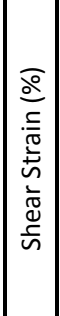 & 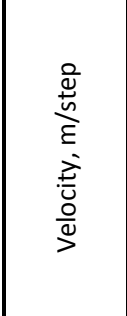 & 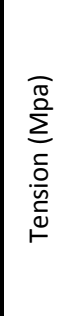 & 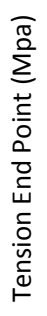 & 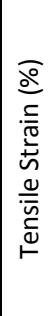 & 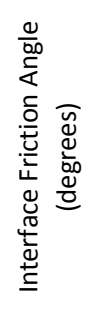 & 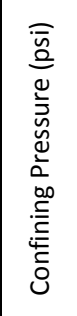 & 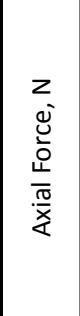 & 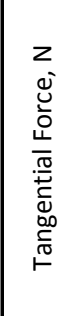 & 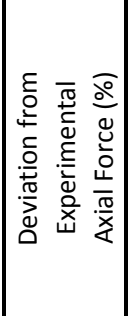 & 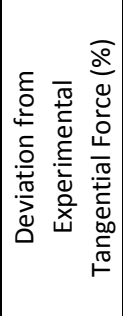 & $\begin{array}{l}z \\
0 \\
0 \\
0 \\
\frac{0}{4} \\
\frac{\pi}{x} \\
\frac{\pi}{x}\end{array}$ & 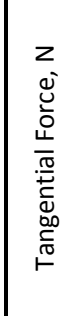 & 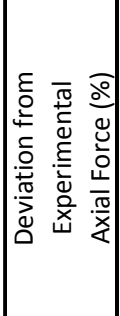 & 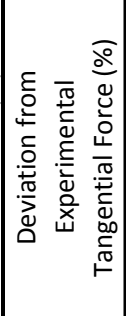 & 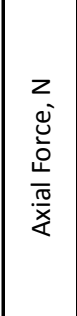 & 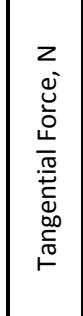 & 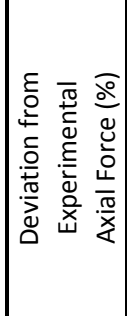 & 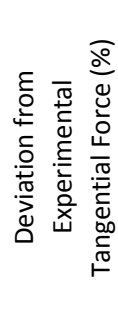 \\
\hline 63 & 30 & 24 & 36 & 0 & 5 & 0 & 40 & 4.00E-07 & 14.4 & 0 & 20 & 34 & 3000 & 1600 & 2190 & -21.80 & 2.34 & 1520 & 2200 & -25.71 & 2.80 & 1490 & 2190 & -27.17 & 2.34 \\
\hline 64 & 30 & 24 & 36 & 0 & 5 & 0 & 40 & 4.00E-07 & 14.4 & 0 & 20 & 40 & 3000 & 1620 & 2170 & -20.82 & 1.40 & 1520 & 2170 & -25.71 & 1.40 & 1450 & 2120 & -29.13 & -0.93 \\
\hline 65 & 30 & 24 & 36 & 0 & 5 & 0 & 45 & $4.00 \mathrm{E}-07$ & 14.4 & 0 & 20 & 34 & 3000 & 1540 & 2300 & -24.73 & 7.48 & 1470 & 2370 & -28.15 & 10.75 & 1420 & 2350 & -30.60 & 9.81 \\
\hline 66 & 30 & 24 & 36 & 0 & 5 & 0 & 45 & $4.00 \mathrm{E}-07$ & 14.4 & 0 & 20 & 40 & 3000 & 1720 & 2320 & -15.93 & 8.41 & 1640 & 2370 & -19.84 & 10.75 & 1570 & 2310 & -23.26 & 7.94 \\
\hline 67 & 30 & 24 & 36 & 0 & 5 & 0 & 33 & $4.00 \mathrm{E}-07$ & 14.4 & 0 & 20 & 36 & 1000 & 1040 & 1460 & -15.60 & 27.22 & 996 & 1490 & -19.17 & 29.83 & 958 & 1470 & -22.25 & 28.09 \\
\hline 68 & 30 & 24 & 36 & 0 & 5 & 0 & 32 & $4.00 \mathrm{E}-07$ & 14.4 & 0 & 20 & 40 & 1000 & 988 & 1430 & -19.82 & 24.60 & 962 & 1450 & -21.93 & 26.35 & 946 & 1450 & -23.22 & 26.35 \\
\hline 69 & 30 & 24 & 36 & 0 & 5 & 0 & 30 & $4.00 \mathrm{E}-07$ & 14.4 & 0 & 20 & 36 & 1000 & 1030 & 1380 & -16.41 & 20.25 & 919 & 1340 & -25.42 & 16.76 & 883 & 1330 & -28.34 & 15.89 \\
\hline 70 & 30 & 24 & 36 & 0 & 5 & 0 & 30 & $4.00 \mathrm{E}-07$ & 14.4 & 0 & 20 & 40 & 1000 & 951 & 1330 & -22.82 & 15.89 & 915 & 1360 & -25.74 & 18.50 & 901 & 1360 & -26.88 & 18.50 \\
\hline 71 & 30 & 24 & 36 & 0 & 5 & 0 & 25 & $4.00 \mathrm{E}-07$ & 14.4 & 0 & 20 & 40 & 300 & 856 & 1110 & -8.80 & 38.63 & 978 & 1240 & 4.20 & 54.87 & 932 & 1220 & -0.70 & 52.37 \\
\hline 72 & 30 & 24 & 36 & 0 & 5 & 0 & 23 & $4.00 \mathrm{E}-07$ & 14.4 & 0 & 20 & 40 & 300 & 663 & 898 & -29.36 & 12.15 & 712 & 1050 & -24.14 & 31.14 & 774 & 1110 & -17.53 & 38.63 \\
\hline 73 & 30 & 24 & 36 & 0 & 5 & 0 & 22 & $4.00 \mathrm{E}-07$ & 14.4 & 0 & 20 & 40 & 300 & 640 & 865 & -31.81 & 8.03 & 643 & 869 & -31.49 & 8.53 & 701 & 983 & -25.31 & 22.77 \\
\hline
\end{tabular}


Table 5.42 Comparison of model results with experimental results at the end of one revolution.

\begin{tabular}{|c|c|c|c|c|c|c|}
\hline \multirow{2}{*}{ RESULTS } & \multicolumn{5}{|c|}{ Confining Pressure } \\
\cline { 2 - 7 } & \multicolumn{2}{|c|}{$\mathbf{3 0 0}$ PSI } & \multicolumn{2}{c|}{$\mathbf{1 0 0 0}$ PSI } & \multicolumn{2}{c|}{3000 PSI } \\
\cline { 2 - 7 } & $\begin{array}{c}\text { Axial } \\
\text { Force, N }\end{array}$ & $\begin{array}{c}\text { Tangential } \\
\text { Force, N }\end{array}$ & $\begin{array}{c}\text { Axial } \\
\text { Force, N }\end{array}$ & $\begin{array}{c}\text { Tangential } \\
\text { Force, N }\end{array}$ & $\begin{array}{c}\text { Axial } \\
\text { Force, N }\end{array}$ & $\begin{array}{c}\text { Tangential } \\
\text { Force, N }\end{array}$ \\
\hline Experiment & 938 & 800 & 1232 & 1148 & 2046 & 2140 \\
\hline Model & 701 & 983 & 901 & 1360 & 1570 & 2310 \\
\hline
\end{tabular}

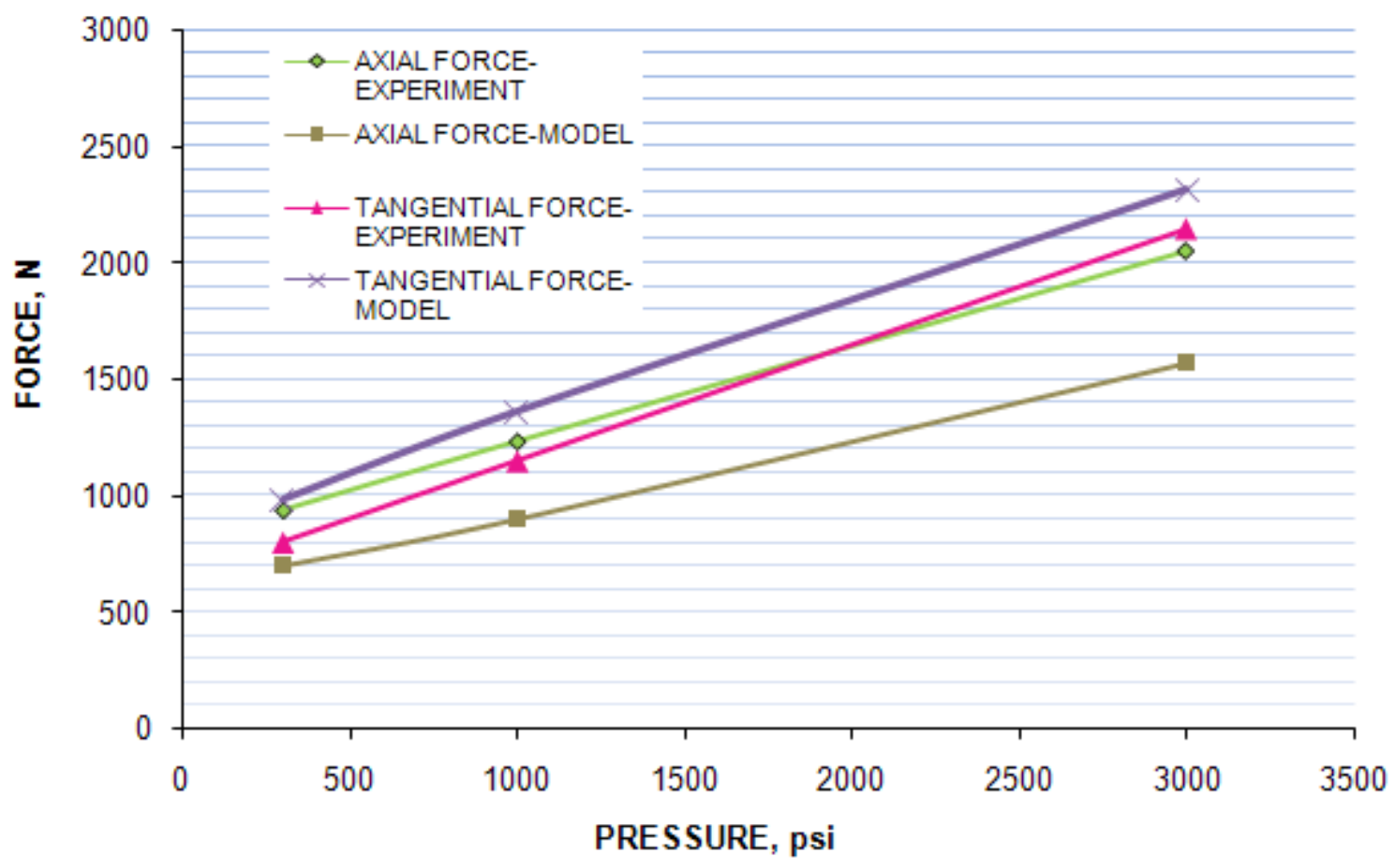

Figure 5.7 Comparison of axial and tangential forces from experimental results and model predictions. 


\section{CHAPTER 6}

\section{CONCLUSIONS AND RECOMMENDATIONS}

\section{CONCLUSIONS}

A parametric study was conducted to determine the formation material and post-failure properties that control the cutting forces of a single PDC cutter required for the cutting process in shales. Runs were conducted with the finite difference $F L A C^{3 D}$ model, jointly developed by Petroleum and Natural Gas Engineering and Mining Engineering at WVU.

In this study, the effects of the formation properties and operational parameters on cutting forces were investigated and the model was calibrated with the results from experiments conducted with Catoosa Shale under three different confining pressures. A good agreement was obtained between numerical and experimental test results. The model can be used with different confining pressures by obtaining the ductility value for the rock by interpolation to the new confining pressure.

In this study, the effect of cohesion, friction angle, dilation angle and tensile strength properties of Catoosa shale on the cutting forces were investigated. The results indicated that friction angle and cohesion are the two most important parameters that control cutting forces. Tensile strength has a limited effect on the results of forces. Dilation angle increases the forces when its value is between zero and five degrees, yet shows a reverse effect between six to ten degrees.

When the ductility of the rock increased, the forces increased considerably. Higher rotational velocities of the core resulted in increased forces due to mechanical oscillations in the model. 
The change in the magnitude of the axial and tangential forces with the change in a formation parameter depends on several factors including other material properties and pressure. The same amount of change in a parameter may not result in the same rate of change in forces when the other parameters are different. Therefore the exact outcome of a parameter change is difficult to predict.

Average axial and tangential cutting forces calculated by the numerical model were close to the forces measured in the experiments with deviations ranging between $0.93 \%$ and $29.1 \%$ depending on the confining pressures. The deviations are attributed to the shortcomings of the model which are explained below:

* The most noticeable difference was the confining pressure treatment in the model since this pressure was not maintained for the lower level of grids when the elements were removed. The limitations of the model to apply confining pressure only to the surface grids may cause a lower axial force during the cutting process.

* In this study, the rock failure was modeled with strain-softening Mohr-Coulomb model. Only one plastic failure model was used for shale and other plasticity models were not considered in this study.

* Chip sticking and balling effects of cuttings are not considered due to the model feature to remove elements from the core as they fail. However, in the experiment, there was no mud circulation and the chips were not removed as the drilling continued which may affect the resultant forces.

Uniform properties were assigned to the core in the model, however the core used in the experiment may contain non-homogeneous properties. 


\section{RECOMMENDATIONS}

Based on the results of this research, following recommendations can be made.

- In this study, rock behavior was represented by a strain softening Mohr-Coulomb plasticity model and the cutter was modeled with an elastic model. Mohr-Coulomb is the most common model for the rocks; however, $F L A C^{3 D}$ has other plasticity models such as Drucker-Prager, Cam-clay, Hoek-Brown, double yield, and bilinear strainhardening/softening ubiquitous-joint plasticity model to represent plastic failure of rock. Those models may be investigated to determine their accuracy in predicting rock failures.

- The model accurately simulates the rock properties (elastic modulus, Poisson's Ratio, cohesion, friction angle, dilation angle) and failure processes at different pressures, but it does not take into account the effects of temperature. At high temperatures, the rock may behave differently.

- Mud pressures exerted on the core in the laboratory tests were simulated in the model without specifying the type of fluid. The mechanical model should be coupled with a fluid model to determine the effect of fluid-rock interaction.

- In this study, the model evaluated local failure using static mechanical analysis. Dynamic analysis augmented with non-local gradient models can also be studied. However, those models are still phenomenological and require the calibration of a length scale parameter, and the solution of an additional partial differential equation beyond the standard balance laws of linear and angular momentum. Also, dynamic analysis is often very complicated and requires a considerable amount of insight to interpret correctly. 


\section{REFERENCES}

1) Zijsling, D. H. "Single cutter testing - A key for PDC bit development" SPE 16529, Proceedings of Offshore Europe 87, Aberdeen, Scotland, 1987.

2) Smith, J. R.: "Diagnosis of Poor PDC Bit Performance in Deep Shales", PhD Thesis, Louisiana State University, 1998.

3) Synthetic-diamond Drill Bit Development (2003). National Driller. Retrieved from http://www.nationaldriller.com/Articles/Feature_Article/fe7dd117b7197010VgnVCM100000f93 $2 \mathrm{a} 8 \mathrm{c} 0$.

4) Swenson, D. V., Wesenberg, D. L., and Jones, A. K.: "Analytical and Experimental Investigations of Rock Cutting Using Polycrystalline Diamond Compact Drag Cutters", SPE 10150, Proceedings of the $56^{\text {th }}$ Annual Fall Technical Conference and Exhibition of the SPE of AIME, San Antonio, TX, 1981.

5) Key, S. W., Beisinger, Z. E., and Krieg, R. D.: "HONDO II, A Finite Element Computer Program for the Large Deformation Dynamic Response of Axisymmetric Solids", Sandia National Laboratories, SAND78-0422, Albuquerque, NM Oct. 1978.

6) Zeuch D. H. and Finger J.T.: "Rock Breakage Mechanisms with A PDC Cutter", Sandia National Laboratories, SPE 14219, Proceedings of the $60^{\text {th }}$ Annual Technical Conference and Exhibition of the SPE, Las Vegas, NV, 1985.

7) Clayton, R., Chen S., and Lefort, G.: "New Bit Design, Cutter Technology Extend PDC Applications to Hard Rock Drilling”, SPE 91840, Technical Conference and Exhibition of the SPE, Amsterdam, the Netherlands, 2005. 
8) Wang, J.K. and Lehnhoff, T.F.: "Bit Penetration into Rock- A Finite Element Study", International Journal of Rock Mechanics and Mining Sciences and Geomechanics Abstracts, Vol. 13, pp 11-16, Pergamon Press, 1976.

9) Huang H. I. and Iversen R. E.: "The Positive Effects of Side Rake in Oilfield Bits Using Polycrystalline Diamond Compact Cutters", SPE 10152, Proceedings of the $56^{\text {th }}$ Annual Fall Technical Conference and Exhibition of SPE of AIME, San Antonio, TX, 1981.

10) Cerkovnik, J.: "Design, Application and Future of Polycrystalline Diamond Compact Cutters in the Rocky Mountains", SPE 10893, Proceedings of the Rocky Mountain Regional Meeting of the SPE, Billings, MT, 1982.

11) Cheatham, Jr. J.B. and Daniels, W.H.: "A Study of Factors Influencing the Drillability of Shales: Single-Cutter Experiments with STRATAPAX Drill Blanks", Journal of Energy Resources Technology, Vol 101, pp 189-195, 1979.

12) Glowka, D. A. and Stone, C. M.: "Thermal Response of Polycrystalline Diamond Compact Cutters under Simulated Downhole Conditions", SPE 11947, Proceedings of Annual Technical Conference and Exhibition of the SPE, San Francisco, CA, 1983.

13) Glowka, D. A. and Stone, C. M.: "Effects of Thermal and Mechanical Loading on PDC Bit Life", SPE 13257, Proceedings of Annual Technical Conference and Exhibition of the SPE, Houston, TX, 1986.

14) Glowka, D.A.: "Use of Single-Cutter Data in the Analysis of PDC Bit Design: Part 1Development of a PDC Cutting Force Model", SPE 15619, JPT (Aug. 1989) 797.

15) Glowka, D.A.: "Use of Single-Cutter Data in the Analysis of PDC Bit Designs: Part 2Development and Use of the PDCWEAR Computer Code", SPE 19309, JPT (Aug.1989) 850-59. 
16) Han, G., Bruno, M., and Lao, K.: "Percussion Drilling in Oil Industry: Review and Rock Failure Modelling”, Terralog Technologies USA, In, AADE-05-NTCE-59, 2005.

17) Kaitkay, P.V.: "Modeling of Rock Cutting Using Distinct Element Methods", Master's Thesis, Kansas State University, 2002.

18) Shewalla, M.: "Evaluation of Shear Strength Parameters of Shale and Siltstone Using Single Point Cutter Tests", Master's Thesis, Louisiana State University, 2007.

19) Bourgoyne, A.T., Jr., Millheim, K.K., Chenevert, M.E., and Young, F.S., Jr. "Applied Drilling Engineering”, Society of Petroleum Engineers, Richardson, TX, 1986.

20) Rolling Cutter Drill Bits. (1994). Retrieved from http://www.patentstorm.us/patents/5372210/description.html.

21) Small Disc Cutter, and Drill Bits, Cutterheads, and Tunnel Boring Machines Employing Such Rolling Disc Cutters. (2000). Retrieved from http://www.patentstorm.us/patents/6131676/description.html.

22) Itasca. 2002. FLAC3D - Fast Lagrangian Analysis of Continua in 3 Dimensions - User's Guide. Itasca Consulting Group, Minneapolis, MN.

23) Wood, D.M. "Soil Behavior and Critical State Soil Mechanics", Cambridge University Press, 1990.

24) Cao, P., Liu B., Yin K., and Zhang Z.: "Optimization design and residual thermal stress analysis of PDC functionally graded materials" Journal of Zhejiang University - Science A, Vol 7, Number 8, pp 1318-1323, 2006.

25) Detournay, E., Tan C.P.: "Dependence of Drilling Specific Energy on Bottom-Hole Pressure in Shales", SPE/ISRM 78221, the SPE/ISRM Rock Mechanics Conference, Irving, TX, 2002. 
APPENDICES 


\section{APPENDIX A}

In this section, parameters for cutter back rake angle, cutter offset, depth of cut, rotational speed, confining pressures and fluid specifications used in the model are listed with the experimental data in Table A.1. Properties of the cutter (PDC) and the core (Catoosa shale) used in the model are compared with the reported experimental data in Table A.2 and Table A.3, respectively. All parameters used in the model are in metric units.

Table A.1 Comparison of test parameters used in the experiments and the model.

\begin{tabular}{|c|c|c|c|c|c|c|}
\hline $\begin{array}{c}\text { Test } \\
\text { Parameters }\end{array}$ & $\begin{array}{c}\text { Back } \\
\text { Rake } \\
\text { Angle, } \\
\text { degrees }\end{array}$ & $\begin{array}{c}\text { Cutter } \\
\text { Offset, } \\
\mathbf{m}\end{array}$ & $\begin{array}{c}\text { Depth of Cut, } \\
\mathbf{m} / \text { revolution }\end{array}$ & $\begin{array}{c}\text { Rotary } \\
\text { Speed }\end{array}$ & $\begin{array}{c}\text { Confining } \\
\text { Pressure Range, } \\
\text { Pa }\end{array}$ & $\begin{array}{c}\text { Fluid } \\
\text { Type }\end{array}$ \\
\hline Experiment & 10 & -0.03143 & $1.905 \mathrm{E}-03$ & $\begin{array}{c}273 \\
\mathrm{rpm}\end{array}$ & $\begin{array}{c}2.07 \mathrm{E}+06- \\
2.07 \mathrm{E}+07\end{array}$ & water \\
\hline Model & 10 & -0.03143 & $1.905 \mathrm{E}-03$ & $\begin{array}{c}4 \mathrm{e}-7 \\
\mathrm{~m} / \mathrm{time} \\
\text { step }\end{array}$ & $\begin{array}{c}2.07 \mathrm{E}+06- \\
2.07 \mathrm{E}+07\end{array}$ & no fluid \\
\hline
\end{tabular}

Table A.2 PDC cutter properties used in the experiments and the model.

\begin{tabular}{|c|c|c|c|c|c|}
\hline $\begin{array}{c}\text { Cutter (PDC) } \\
\text { Properties }\end{array}$ & $\begin{array}{c}\text { Diameter, } \\
\mathbf{m}\end{array}$ & $\begin{array}{c}\text { Thickness, } \\
\mathbf{m}\end{array}$ & $\begin{array}{c}\text { Density, } \\
\mathbf{k g} / \mathbf{m 3}\end{array}$ & $\begin{array}{c}\text { Bulk } \\
\text { Modulus, } \\
\mathbf{P a}\end{array}$ & $\begin{array}{c}\text { Shear } \\
\text { Modulus, } \\
\mathbf{P a}\end{array}$ \\
\hline Experiment & 0.009398 & 0.0075 & not given & not given & not given \\
\hline Model & 0.009398 & 0.0075 & 3830 & $3.45 \mathrm{E}+11$ & $4.16 \mathrm{E}+11$ \\
\hline
\end{tabular}


Table A.3 Core properties used in the experiments and the model.

\begin{tabular}{|c|c|c|c|c|c|c|c|c|c|c|c|c|}
\hline $\begin{array}{c}\text { Core } \\
\text { Properties }\end{array}$ & Formation & $\begin{array}{c}\text { Diameter, } \\
\mathbf{m}\end{array}$ & $\begin{array}{l}\text { Length, } \\
\text { m }\end{array}$ & $\begin{array}{c}\text { Density, } \\
\mathrm{kg} / \mathrm{m} 3\end{array}$ & $\begin{array}{c}\text { Porosity, } \\
\%\end{array}$ & $\begin{array}{l}\text { Unconfined } \\
\text { Compressive } \\
\text { Strength, } \mathrm{Pa}\end{array}$ & $\begin{array}{c}\text { Bulk } \\
\text { Modulus, } \\
\text { Pa }\end{array}$ & $\begin{array}{c}\text { Shear } \\
\text { Modulus, } \\
\mathrm{Pa}\end{array}$ & $\begin{array}{l}\text { Friction } \\
\text { Angle, } \\
\text { degrees }\end{array}$ & $\begin{array}{c}\text { Cohesion, } \\
\text { Pa }\end{array}$ & $\begin{array}{l}\text { Dilation } \\
\text { Angle, } \\
\text { degrees }\end{array}$ & $\begin{array}{c}\text { Tensile } \\
\text { Strength, } \\
\mathrm{Pa}\end{array}$ \\
\hline Experiment & $\begin{array}{c}\text { Catoosa } \\
\text { Shale }\end{array}$ & 0.0889 & unknown & 2390 & 12 & not given & not given & not given & 14 & 8 & not given & not given \\
\hline Model & $\begin{array}{c}\text { Catoosa } \\
\text { Shale }\end{array}$ & 0.12572 & 0.01 & 2390 & $\begin{array}{c}\text { not } \\
\text { assigned }\end{array}$ & $3.50 \mathrm{E}+07$ & $8.81 \mathrm{E}+09$ & $4.30 \mathrm{E}+09$ & 30 & 36 & 5 & $1.44 \mathrm{E}+07$ \\
\hline
\end{tabular}




\begin{abstract}
APPENDIX B
In this section, the axial and tangential cutting forces calculated in the model were plotted for different confining pressures. In Figures B.1 and B.2, the results for the runs conducted with 2.07 Mpa (300 psi) confining pressure were plotted. In Figures B.3 and B.4, the results for axial and tangential forces were plotted for the runs with 6.89 MPa (1000 psi) confining pressure. In Figures B.5 and B.6, the results for the runs with 20.7 MPa (3000 psi) confining pressure were plotted. The results showed that as the confining pressure increases, both the axial and tangential forces increase. As seen in the figures, higher peak values were observed on the plots as the pressure increased from 300 to 3000 psi.
\end{abstract}

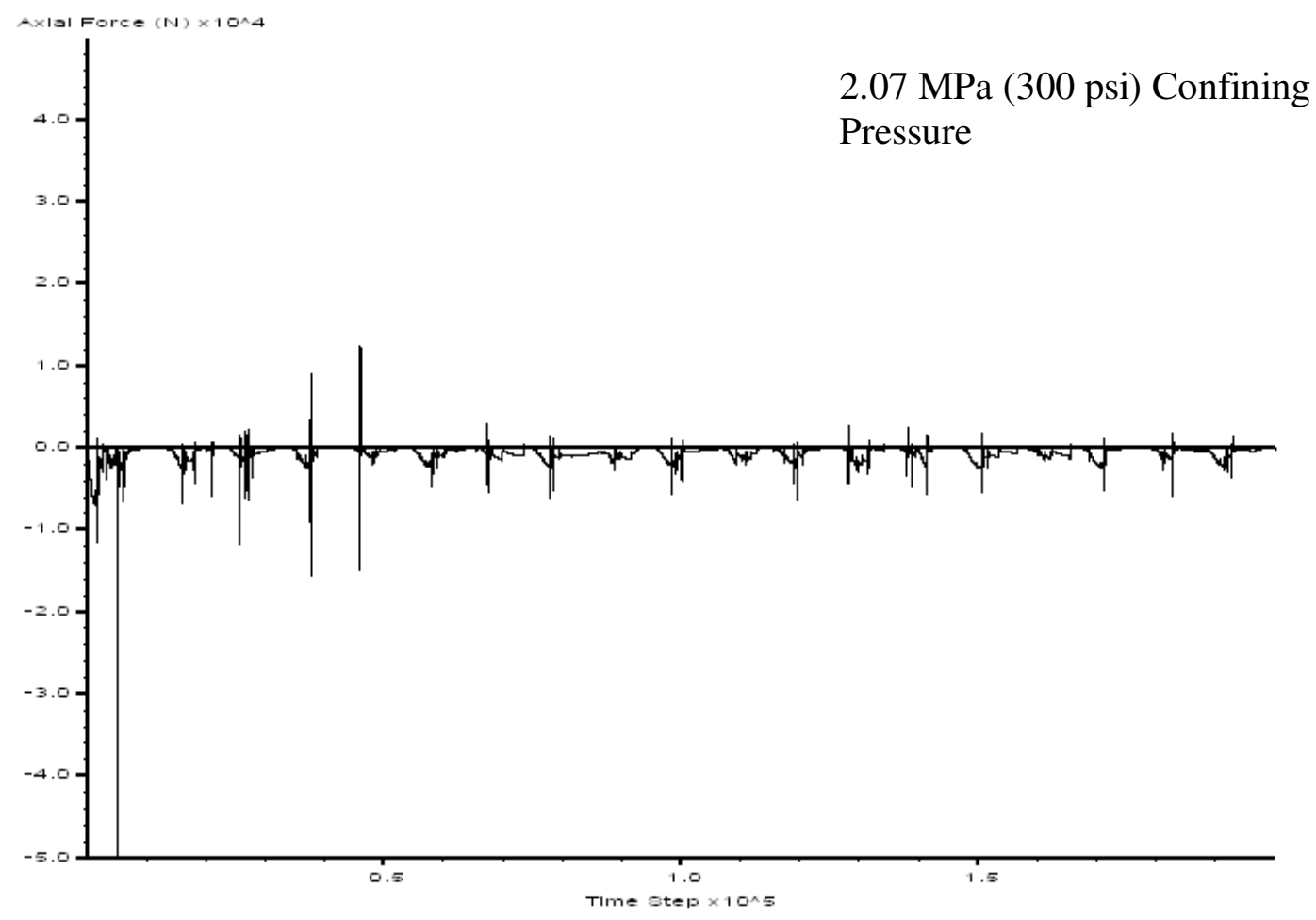

Figure B.1 Axial force versus time step for the model run conducted under 300 psi confining pressure. 


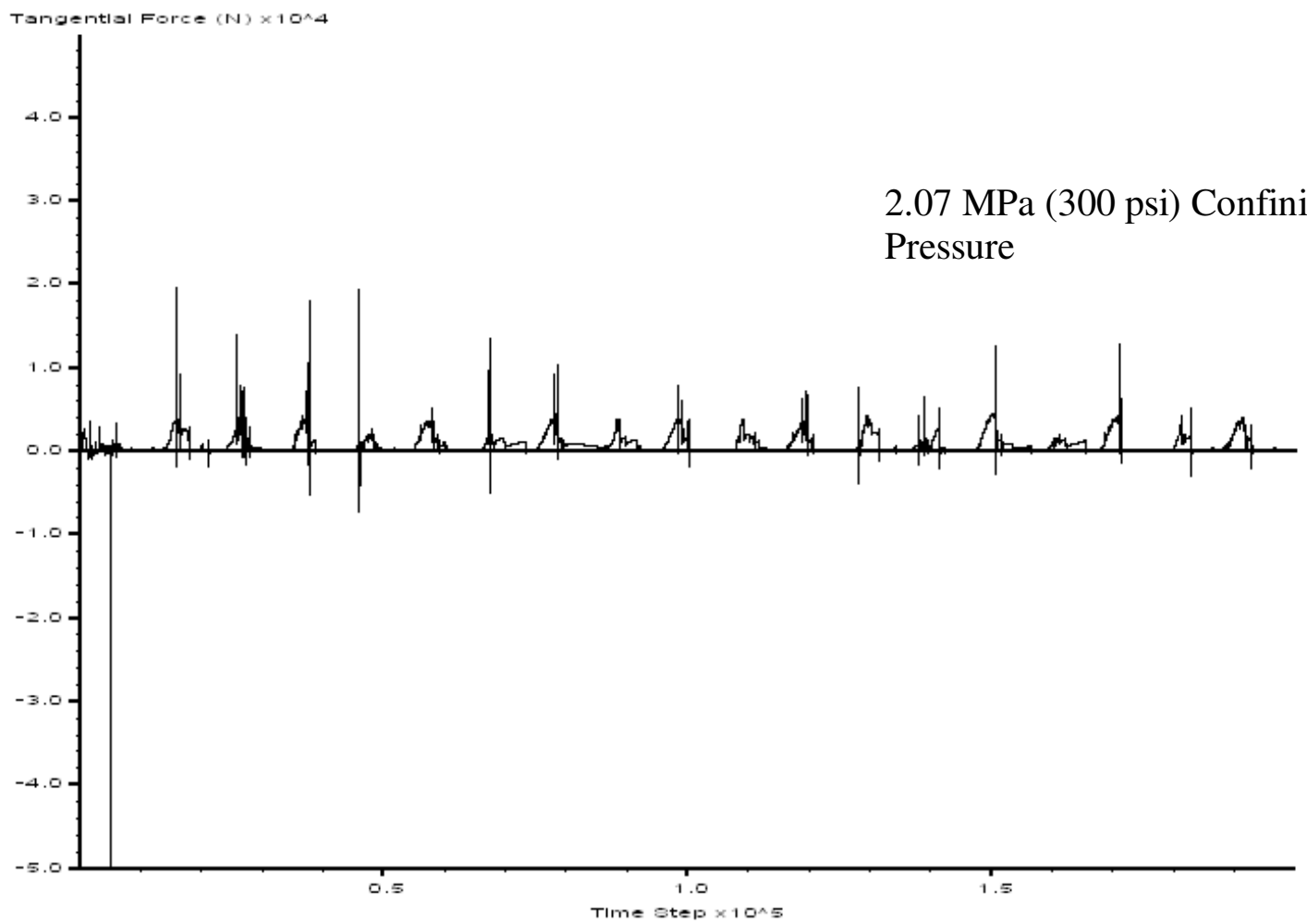

Figure B.2 Tangential force versus time step for the model run conducted under 300 psi confining pressure. 


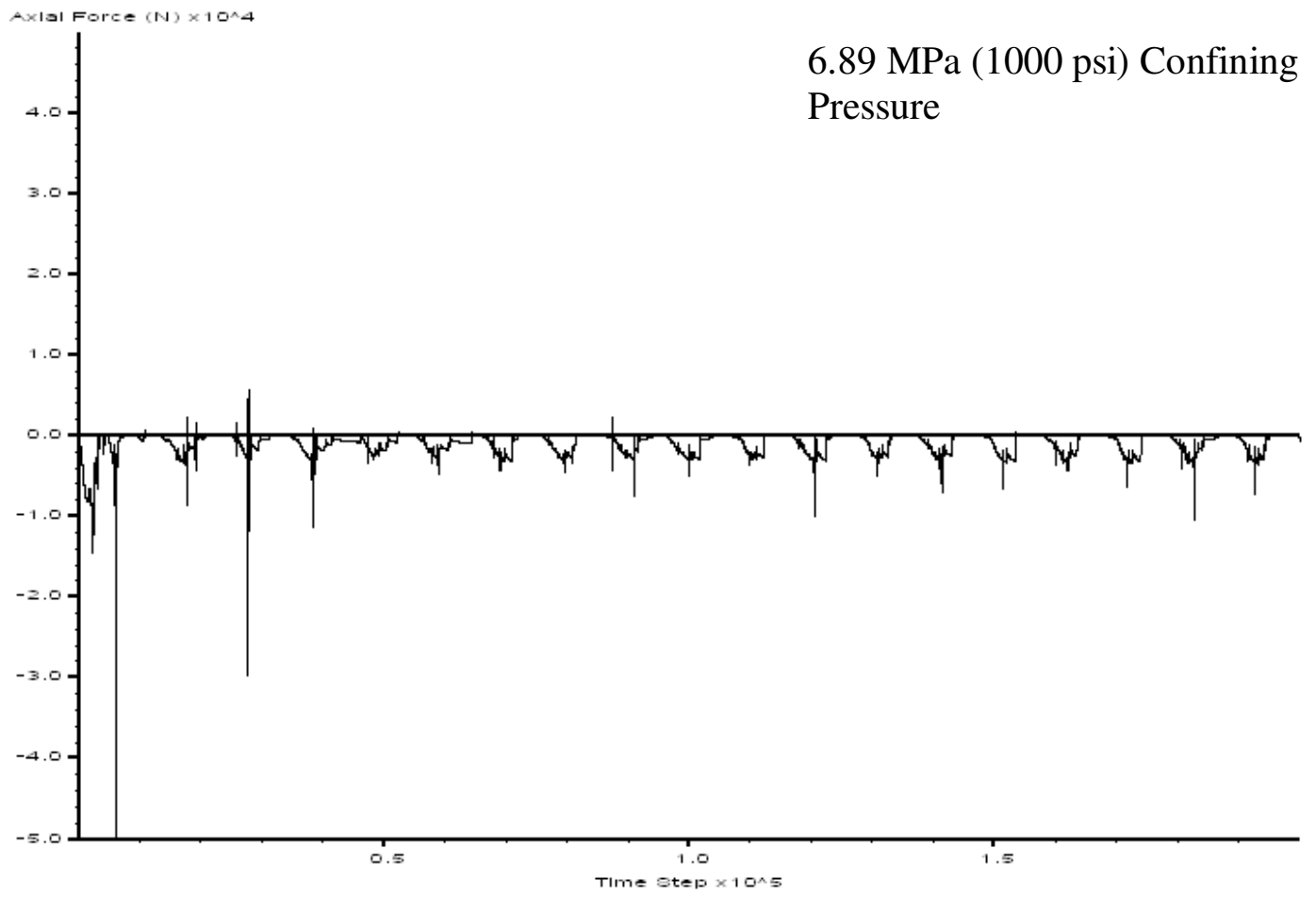

Figure B.3 Axial force versus time step for the model run conducted under 1000 psi confining pressure.

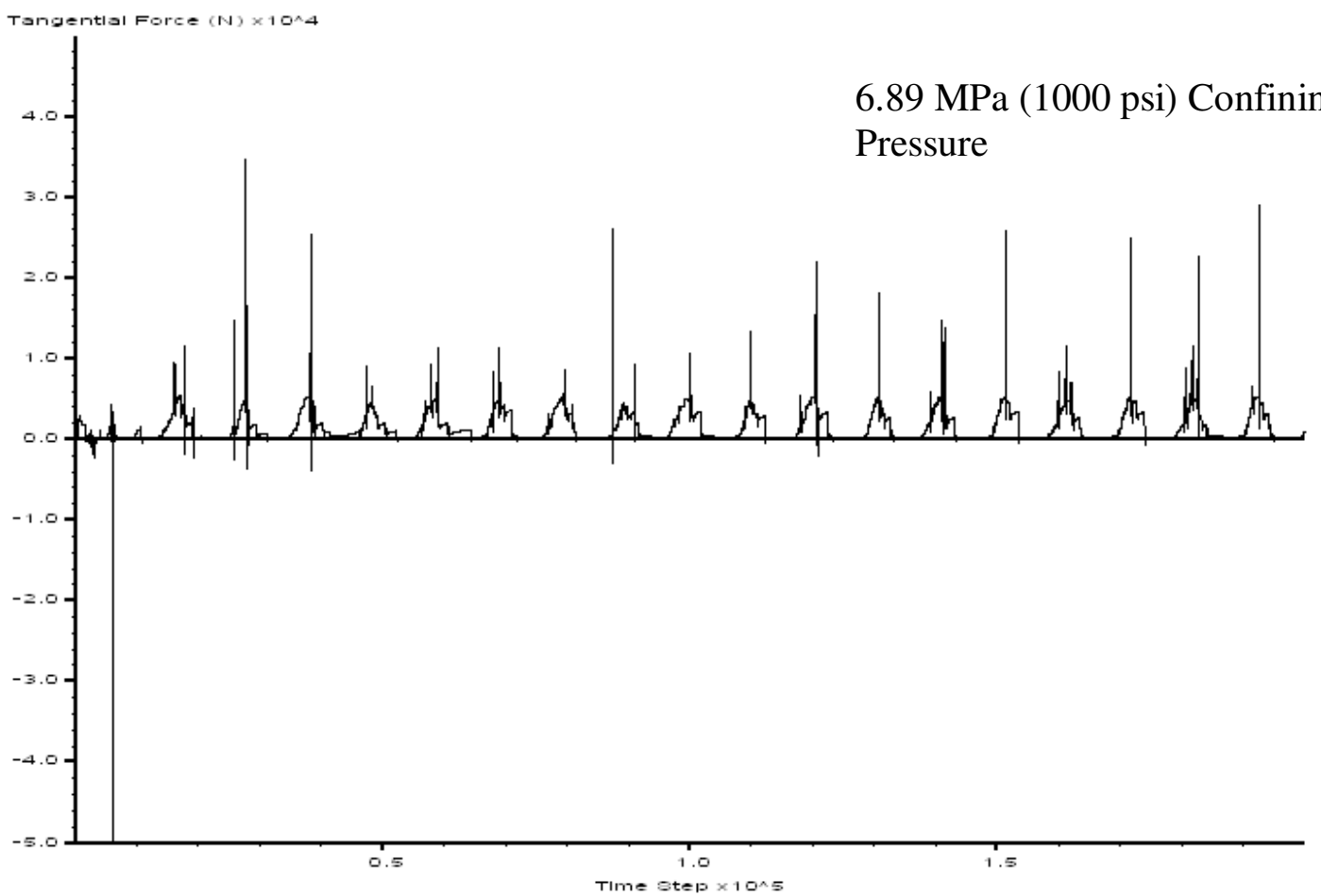

Figure B.4 Tangential force versus time step for the model run conducted under $1000 \mathrm{psi}$ confining pressure. 


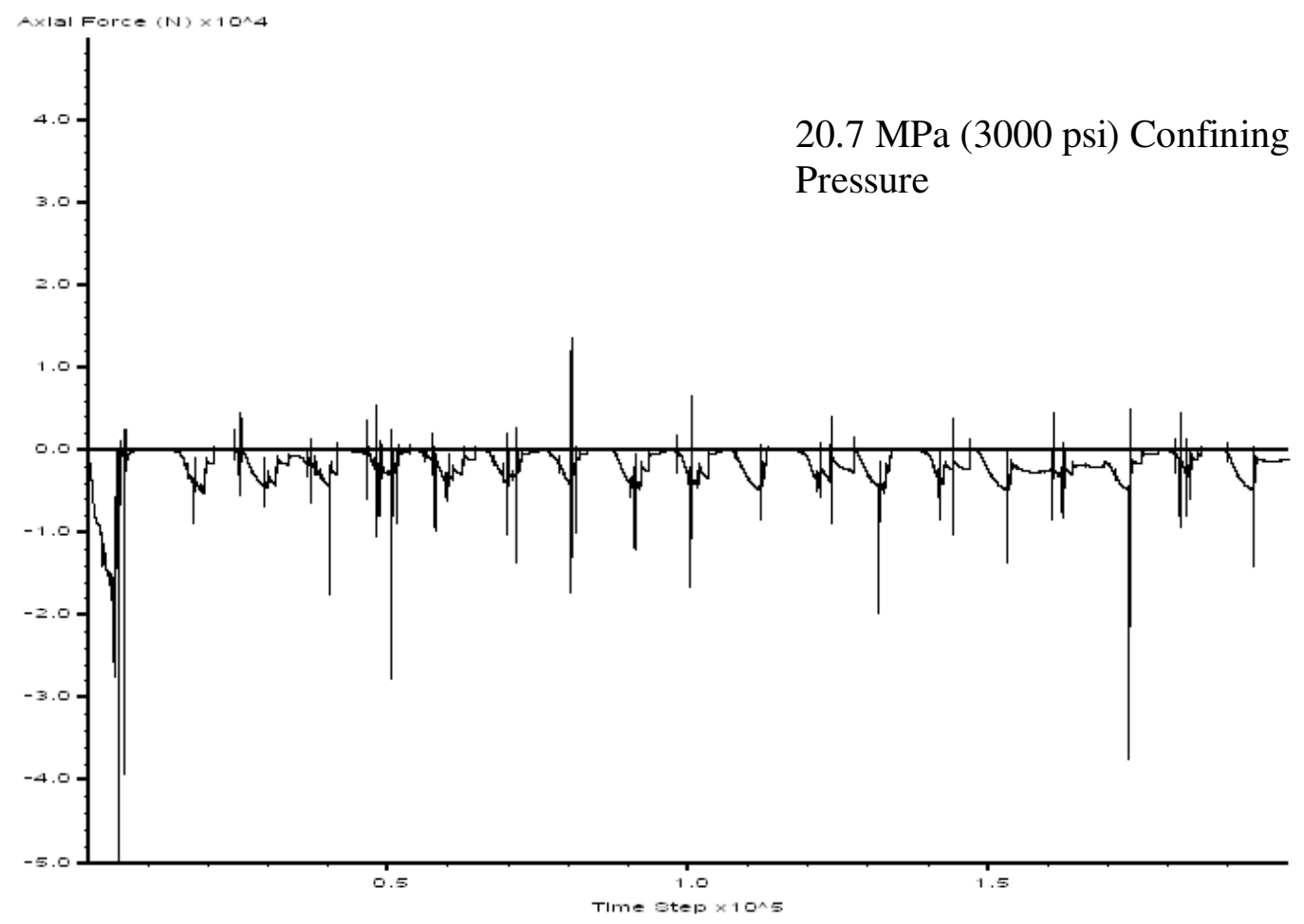

Figure B.5 Axial force versus time step for the model run conducted under 3000 psi confining pressure.

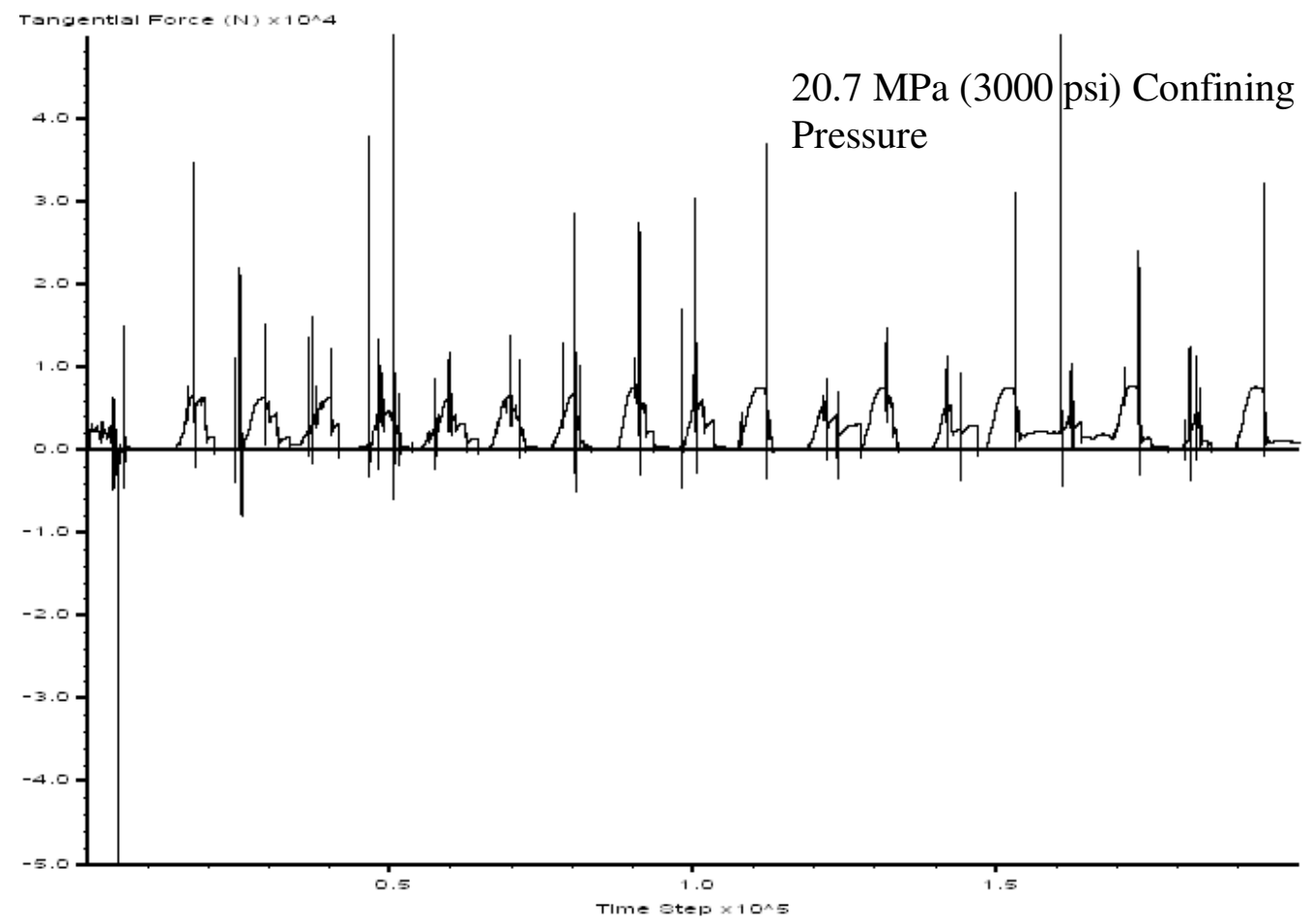

Figure B.6 Tangential force versus time step for the model run conducted under 3000 psi confining pressure. 